\title{
Basic Principles of Emulsion Templating and Its Use as an Emerging Manufacturing Method of Tissue Engineering Scaffolds
}

\section{OPEN ACCESS}

Edited by:

Lorenzo Moroni,

Maastricht University, Netherlands

Reviewed by:

Jules Harings,

Maastricht University, Netherlands

Patricia Diaz-Rodriguez,

University of La Laguna, Spain

*Correspondence:

Frederik Claeyssens f.claeyssens@sheffield.ac.uk

Specialty section:

This article was submitted to

Biomaterials,

a section of the journal Frontiers in Bioengineering and

Biotechnology

Received: 21 April 2020

Accepted: 08 July 2020

Published: 12 August 2020

Citation:

Aldemir Dikici B and Claeyssens F (2020) Basic Principles of Emulsion

Templating and Its Use as an Emerging Manufacturing Method of Tissue Engineering Scaffolds. Front. Bioeng. Biotechnol. 8:875. doi: 10.3389/fbioe.2020.00875
Betül Aldemir Dikici'1,2 and Frederik Claeyssens ${ }^{1,2 *}$

${ }^{1}$ Department of Materials Science and Engineering, Kroto Research Institute, The University of Sheffield, Sheffield, United Kingdom, ${ }^{2}$ Department of Materials Science and Engineering, INSIGNEO Institute for In Silico Medicine,

The University of Sheffield, Sheffield, United Kingdom

Tissue engineering (TE) aims to regenerate critical size defects, which cannot heal naturally, by using highly porous matrices called TE scaffolds made of biocompatible and biodegradable materials. There are various manufacturing techniques commonly used to fabricate TE scaffolds. However, in most cases, they do not provide materials with a highly interconnected pore design. Thus, emulsion templating is a promising and convenient route for the fabrication of matrices with up to 99\% porosity and high interconnectivity. These matrices have been used for various application areas for decades. Although this polymer structuring technique is older than TE itself, the use of polymerised internal phase emulsions (PolyHIPES) in TE is relatively new compared to other scaffold manufacturing techniques. It is likely because it requires a multidisciplinary background including materials science, chemistry and TE although producing emulsion templated scaffolds is practically simple. To date, a number of excellent reviews on emulsion templating have been published by the pioneers in this field in order to explain the chemistry behind this technique and potential areas of use of the emulsion templated structures. This particular review focusses on the key points of how emulsion templated scaffolds can be fabricated for different TE applications. Accordingly, we first explain the basics of emulsion templating and characteristics of PolyHIPE scaffolds. Then, we discuss the role of each ingredient in the emulsion and the impact of the compositional changes and process conditions on the characteristics of PolyHIPEs. Afterward, current fabrication methods of biocompatible PolyHIPE scaffolds and polymerisation routes are detailed, and the functionalisation strategies that can be used to improve the biological activity of PolyHIPE scaffolds are discussed. Finally, the applications of PolyHIPEs on soft and hard TE as well as in vitro models and drug delivery in the literature are summarised.

Keywords: emulsion templating, tissue engineering, biomaterials, scaffold, PolyHIPE, porosity, interconnectivity, tunability

\section{INTRODUCTION}

Tissue and organ failure is one of the most frequent, inevitable major public health problems due to congenital health issues, traumas, diseases, and the increasing average age of the population (Langer and Vacanti, 1993; Dzobo et al., 2018). Tissue Engineering (TE) aims to devise solutions to restore or to improve the functions of injured/diseased parts of the host tissue which cannot 
heal naturally. TE utilises porous matrices that are called scaffolds to fill the defect site (Figure 1A). Scaffolds serve as a guide for tissue regeneration as a three-dimensional substrate for cell attachment, proliferation, infiltration, and they also provide temporary mechanical support. There are five essential requirements that an ideal scaffold should have (O'Brien, 2011; Bose et al., 2012); (i) biocompatibility, not causing any adverse effect at any level, from cellular activity to molecular signalling, on cells/tissues when they are in contact (Williams, 2008; Bose et al., 2012), (ii) biodegradability, degrading over time in vivo to create a space for newly forming tissues, (iii) having appropriate surface chemistry to allow cellular attachment, proliferation and differentiation, (iv) having similar mechanical properties with the native tissue not to fail tissue formation due to excessive deformation (Hollister, 2005; Bose et al., 2012), and (v) the morphology is the key feature that affects both biological and mechanical efficiency of the scaffolds. Scaffolds are needed to have a porous architecture with high interconnectivity to enable cell infiltration, nutrient flow, and integration of the material within the host tissue (Figure 1B).

To date, various scaffold manufacturing techniques such as gas foaming (Salerno et al., 2009; Bak et al., 2014), porogen leaching (Reignier and Huneault, 2006; Bak et al., 2014), electrospinning (Aldemir Dikici et al., 2019a; Mangir et al., 2019a; Dikici et al., 2020b,c), and additive manufacturing (AM) (Elomaa et al., 2011; Aldemir Dikici et al., 2017) have been widely used to introduce porosity into TE scaffolds. Recently, emulsion templating has gained particular attention as a scaffold fabrication technique due to its three main advantages; providing (i) high porosity[(up to 99\%) (Richez et al., 2005)], (ii) high interconnectivity (Figure 1C), and (iii) high tunability. While high porosity and interconnectivity enable cell migration, vascularisation, and providing space for newly forming tissues (O'Brien, 2011; Loh and Choong, 2013), high tunability of physical, chemical and mechanical properties of emulsion templated matrices enables fabrication of precisely engineered scaffolds to meet the requirements of specific TE applications.

The technique is based on two basic steps; the preparation of emulsion composed of at least two immiscible liquids where one phase (internal phase, dispersed phase) dispersed in the other phase (continuous phase, external phase) and solidification of the continuous phase of the emulsion. In this process, droplets of dispersed phase behave like templates, and they are removed following solidification to obtain porous matrices (Figure 2). These biphasic emulsion systems can be either water-in-oil (w/o) or oil-in-water $(\mathrm{o} / \mathrm{w})$ depending on the positioning of the lipophilic (non-polar, fat-loving, oil) and hydrophilic (polar, water-loving, water) phases.

Although emulsion templating has been mentioned as a relatively new scaffold manufacturing route in recent publications, the birth of the term of emulsion templating in the literature is older than TE itself (Figure 3); it dates back to the late 1950s (Guenther, 1959) where it was defined in a patent. Many other patents -including one by National Aeronautics and Space Administration (NASA)- followed up the development of emulsion templated polymers for different applications such as oil absorbents (Fletcher and Marsh, 1977) and 3D shaped porous objects with smooth surfaces (Guenther, 1971). Over the years, emulsion templated matrices have been used in various other areas such as; catalyst supports (Zhang Y. et al., 2016), separation columns (Yang et al., 2010), heavy metal removal (Mert et al., 2012), solid-phase synthesis (Small and Sherrington, 1989), and substrates for electrodes (Brown and Sotiropoulos, 2001).

Studies on the use of emulsion templating for the manufacturing of 3D substrates for cell culture applications is relatively new; it dates back to the early 1990s (Lee et al., 1992a,b; Schrimpf and Friedl, 1993; Akay et al., 2000). That is most likely why the number of TE-related studies is not more than $6 \%$ of the total reported number emulsion templating publications. Emulsion templating also has the lowest number of reports on TE applications when compared with other well-known scaffold manufacturing techniques (Figure 4A). However, there has been an increasing trend in the number of publications on emulsion templating in the last years, and almost $40 \%$ of emulsion templating in TE papers have been published in the last 3 years (Figure 4B).

Development of the emulsion templated scaffolds requires a multidisciplinary approach that combines knowledge and experience from chemistry, materials science, and TE. To date, there has been a number of significant reviews from the pioneers in the field of emulsion templating in the literature (Cameron, 2005; Silverstein and Cameron, 2010; Pulko and Krajnc, 2012; Silverstein, 2014a,b; Zhang et al., 2019). These reviews comprehensively cover the chemistry and material science behind this technique and briefly summarise all of the potential usage areas of emulsion templating. Accordingly, in this review, we aimed to approach emulsions templating as solely a TE scaffold fabrication technique. We summarised the basics of emulsion templating by reviewing the literature and determined a road map for the researchers that would like to explore this advantageous technique in their TE applications and reported the current state of the art of emulsion templating in TE as a retrospective.

\section{POLYMERISED HIGH INTERNAL PHASE EMULSIONS: TERMINOLOGY}

One of the most favourable features of emulsion templated scaffolds is the tunability of their porosity by simply increasing the internal phase volume. In the literature, emulsions that have at least $74.048 \%$ internal phase volume are defined as High Internal Phase Emulsions (HIPEs). The value of $0.74048(\pi / \sqrt{ } 18)$ is the densest possible monodispersed sphere packing density, according to Kepler Conjecture (Hales, 2005). Also, according to Oswald's phase volume theory, this value corresponds to monodispersed, undistorted, hexagonal-packed droplets (Princen, 1979). Beyond this value, emulsions have been assumed to tend to break unless the emulsion is heterodisperse, because the heterodispersity will enable smaller droplets to fill the intersects of the bigger droplets, and this results in higher internal phase volume for the emulsion. Lissant (1966) reported that it is possible to prepare relatively mono-disperse emulsions with internal phase beyond $74.048 \%$ by the right choice of 

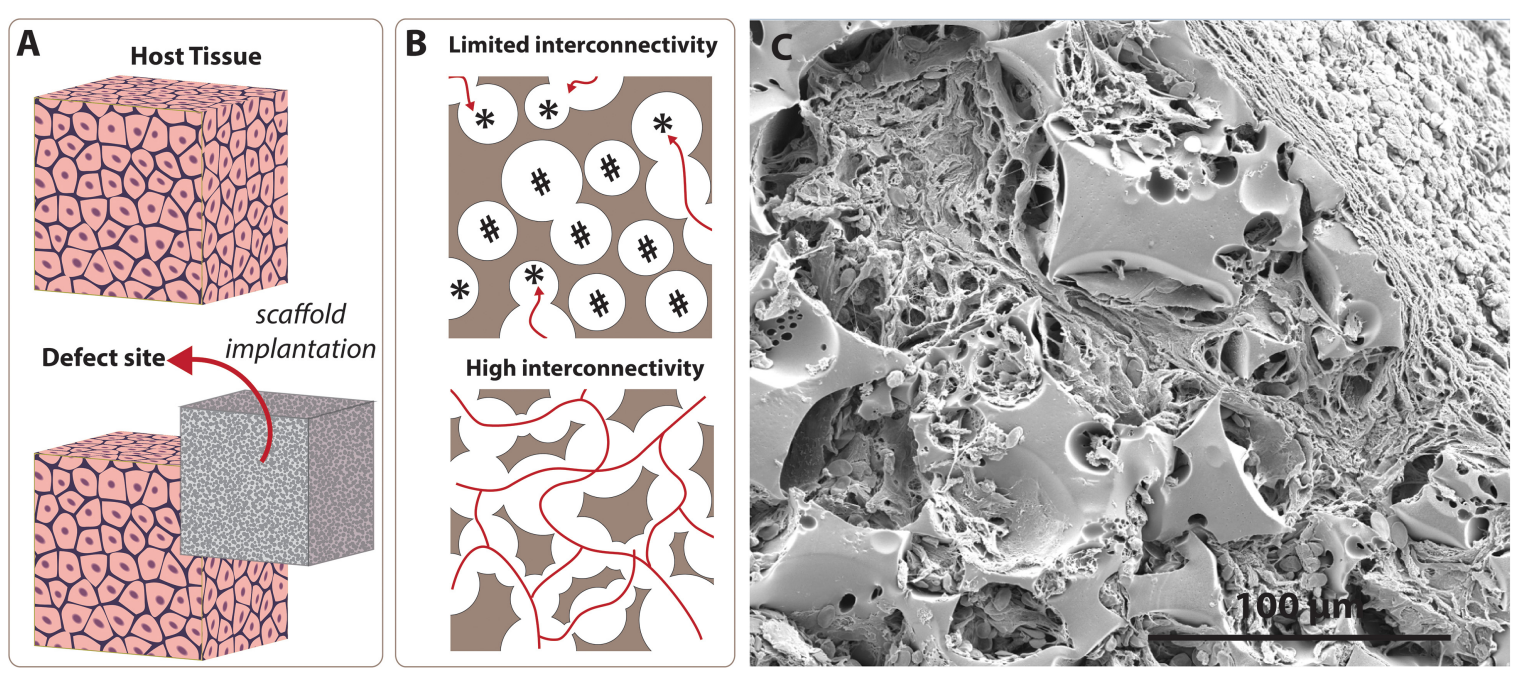

FIGURE 1 | Significance of the interconnectivity on scaffold design. (A) Scaffolds are 3D substrates that are implanted to the defect site to guide tissue regeneration. (B) Low interconnectivity limits cell infiltration due to blind (labelled with *) and inaccessible (labelled with \#) pores, while higher interconnectivity provides enhanced permeability and cell penetration. (C) Scanning electron microscope image of the emulsion templated scaffold (polycaprolactone PolyHIPE) that shows tissue infiltration through the interconnected pores of the scaffold.

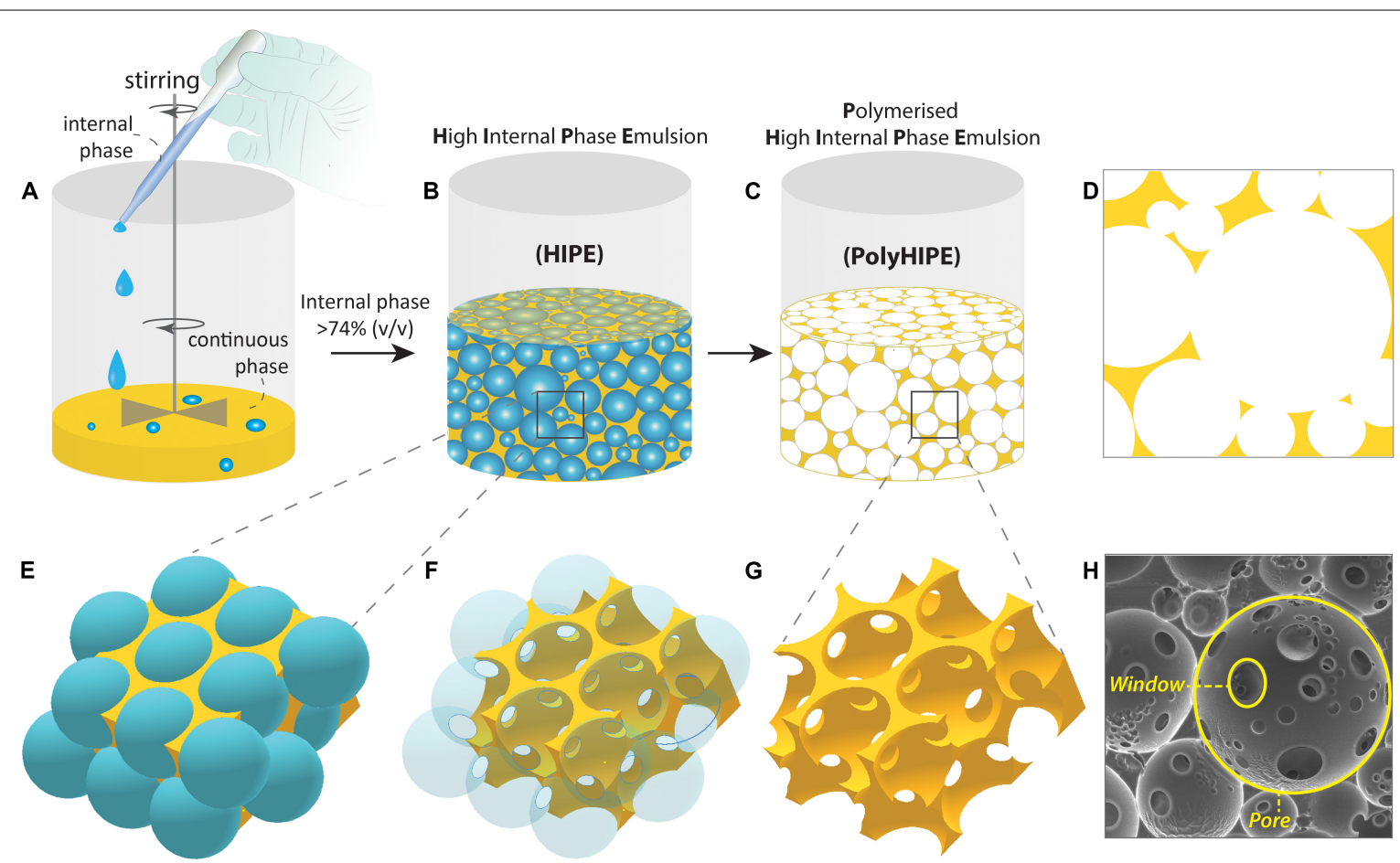

FIGURE 2 | Fabrication steps of the Polymerised High Internal Phase Emulsion (PolyHIPE). (A,B) The gradual addition of the internal phase into the continuous phase while the system is mixed, (C) polymerisation of the high internal phase emulsion (HIPE), (D) 2D projection of PolyHIPE, (E-G) the formation of the pores and windows, and $\mathbf{( H )}$ scanning electron microscope image of the PolyHIPE.

surfactant and demonstrated that monodispersed water droplets deformed into polyhedrons as the touching points become flattened (Figure 5).

This situation applies in monodispersed spheres, and already in 1907 Spencer Pickering questioned the validity of this value for liquid spheres as liquid droplets in emulsion are in reality not uniform but are polydisperse (Pickering, 1907). Additionally, in emulsions, liquid droplets are not actually in contact; there is a thin wall separating the droplets from each other. That's why, even the maximum packing density for mono-disperse, 


\section{$1950 \mathrm{~s}$}

Development of the emulsion templating technique a

1966

The term "HIPE" was described ${ }^{\text {b }}$

1980 s

Emerging of the field of tissue engineering ${ }^{c}$

$\quad \mathbf{1 9 8 2}$

The term "PolyHIPE" was described ${ }^{\mathrm{d}}$

1992

The use of PolyHIPEs in vitro cell culture ${ }^{e}$

1993

The term "tissue engineering" was described ${ }^{f}$

1997

Development of fully o/w PolyHIPE $g$

1999

Foams made by photopolymerisation of emulsions reported ${ }^{\mathrm{h}}$

2001

An attempt to make a biodegradable tissue engineering scaffold ${ }^{i}$

\section{7}

Development of a biodegradable, synthetic-polymer-based PolyHIPE ${ }^{j}$

2010

Launch of the commercial non-biodegradable PolyHIPE substrate (Alvetex $\left.{ }^{\circledast}\right)^{k}$

2011

Development of biodegradable and injectable HIPEs '

2013

Additive manufacturing has been combined with emulsion templating $\mathrm{m}$

2014

Development of PolyHIPEs solidified using solvent evaporation ${ }^{n}$

2019

Development of PolyHIPEs fully made of photocurable polycaprolactone ${ }^{\circ}$

2019

PolyHIPE scaffolds were tested in vivo first time ${ }^{p}$

\begin{tabular}{l|l}
$\begin{array}{l}\text { Developments in emulsion } \\
\text { templating technique }\end{array}$ & $\begin{array}{l}\text { Developments in tissue engineering applications of } \\
\text { emulsion template substrates }\end{array}$
\end{tabular}

FIGURE 3 | Historical landmarks in emulsion templating in terms of material development and its use in tissue engineering applications [a. (Guenther, 1959), b. (Lissant, 1966), c. (Vacanti, 2006; Meyer, 2009), d. (Barby and Haq, 1985), e. (Lee et al., 1992a,b), f. (Langer and Vacanti, 1993), g. (Kitagawa, 2001), h. (Thunhorst et al., 2003), i. (Busby et al., 2001), j. (Christenson et al., 2007), k. (Padbury, 2019), I. (Moglia et al., 2011), m. (Johnson et al., 2013; Sušec et al., 2013), n. (Hu et al., 2014a), o. (Aldemir Dikici et al., 2019b), p. (Aldemir Dikici et al., 2019a)]. 


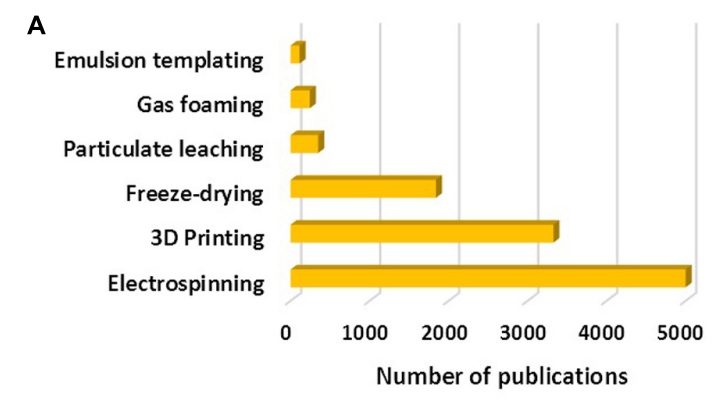

B

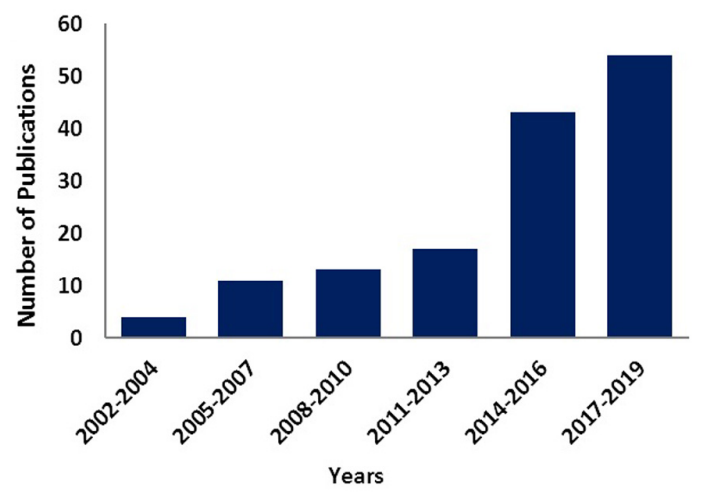

FIGURE 4 | (A) The number of publications between 1900 and 2019 (Data obtained on 22 Nov 2019) for various scaffold fabrication methods. Data generated using -the name of the manufacturing route- and "tissue engineering" as a search term. (B) The number of papers published on emulsion templating in TE in the given years. Data generated using "emulsion templating" and "tissue engineering" as search terms. Web of Science was used as a search platform, and keywords were searched in all the fields.

non-deformed liquid droplets would be less than the maximum packing density of the solid spheres $(<74.048 \%)$. Indeed, the requirement for a revised definition of HIPEs has also been highlighted recently by other researchers (Menner et al., 2006; Manley et al., 2009; Aldemir Dikici et al., 2019b). However, herein, we use the commonly recognised definition of HIPEs.

Although emulsion polymerisation has previously been described in the literature (Bartl and Von Bonin, 1962; Bartl and von Bonin, 1963), the term "Polymerised High Internal Phase Emulsion (PolyHIPE)" appeared in the literature in 1982 to define porous structures formed following solidification of the HIPEs (Barby and Haq, 1985). Emulsion templated matrices with various internal phase volumes; PolyHIPEs [ 74-99\% (Robinson et al., 2014)], Polymerised Medium Internal Phase Emulsions (PolyMIPEs) (30-74\%) and Polymerised Low Internal Phase Emulsions (PolyLIPEs) [ $<30 \%$ (Zhang et al., 2019)] have been reported in the literature. However, in this review, we mainly focus on PolyHIPEs unless otherwise stated.

In terminology, it is important to comprehend the difference between HIPEs and PolyHIPEs. HIPEs can be further processed until the gelation point to change their droplet size and viscosity, but PolyHIPEs are the solid matrices that are made of solely the continuous phase, and they are obtained by the polymerisation of HIPEs. The cavities formed after removal of the internal phase being defined as "pores," "cells," or "voids." The throats connect the adjacent pores to each other are defined as "interconnects" or "windows" (Figure 2). The formation of these interconnects has been reported to be due to the rupture of the thin polymer films between neighbouring pores during the polymerisation (Cameron et al., 1996). Depending on the presence and absence of interconnects, PolyHIPEs are categorised as "open cellular" and "closed cellular," respectively.

\section{CHARACTERISTICS OF HIPES AND PolyHIPEs}

Emulsion templating combines two main research areas that are emulsion science and porous polymer fabrication. Emulsions have been widely used for various industries, such as food, petroleum, paint, pharmaceutical, and cosmetic, for centuries (Grace, 1992; Fox et al., 2012). Also, porous polymer matrices/polymer foams have been fabricated by following a great variety of other routes (Jin et al., 2019). Thus, the characteristics of emulsions such as droplet size and viscosities (Goodarzi and Zendehboudi, 2019) and the characteristics of polymer foams such as morphological, mechanical features (Ceglia et al., 2012; Jin et al., 2019) are well-reported in the literature, and these characteristics are also mostly valid for HIPEs and PolyHIPEs, respectively. However, in this section, it is crucial to summarise these characteristics briefly to introduce the parameters that can
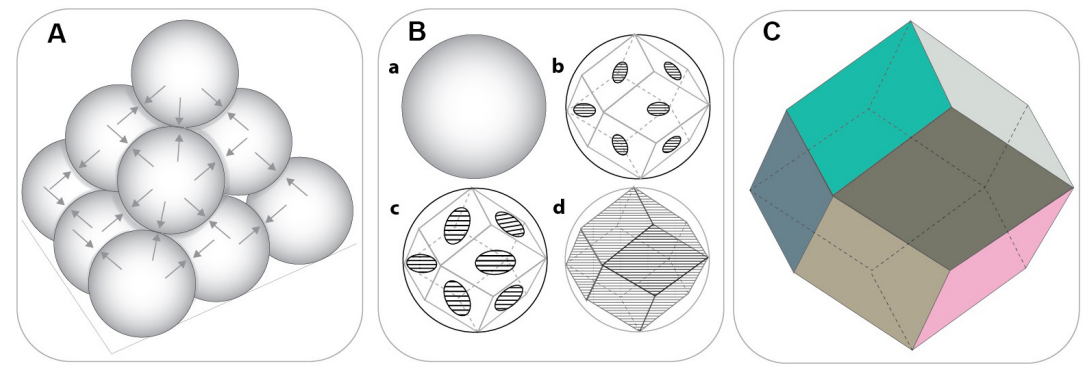

FIGURE 5 | (A) Closest packing density of the solid spheres (non-deformed) (74.048\%) where each sphere touches twelve other spheres. (B) The transition from sphere to rhomboidal dodecahedron $(\mathrm{RDH})$ by the gradual flattening of the touching points. (C) The geometry of the basic RDH. [Adapted images were recreated using Ref. Lissant (1966) as a guide]. 
be controlled and precisely engineered for specific applications by simply changing their composition and process conditions which are detailed in section "Development of the Emulsion Templated Scaffolds."

\section{Morphological Characteristics}

Internal phase volume is the main factor determining the porosity of emulsion templated scaffolds. However, the volume of the internal phase does not always correspond to the porosity of PolyHIPE scaffolds. In our recent study, the porosity of polycaprolactone (PCL) PolyHIPEs prepared using $82 \%$ internal phase volume was measured around $70 \%$. This is likely because of $15-20 \%$ shrinkage of these scaffolds in each dimension during crosslinking and drying (Aldemir Dikici et al., 2019b). This is corroborated by other studies, for example, Chen et al. (2018) also reported a lesser extent of porosity than the internal phase volume of poly(styrene-co-2-ethylhexylacrylate) PolyHIPEs due to the same reason. They also reported that the extent of the shrinkage depends on the fractions of the 2-ethyl hexyl acrylate (EHA) and styrene in the composition of the PolyHIPE.

Thus, the porosities of the PolyHIPEs can be calculated using Eq. 1 (Ovadia and Silverstein, 2016; Barbara et al., 2017; Aldemir Dikici et al., 2019b), where $\rho_{\text {PolyHIPE }}$ is the PolyHIPE density and $\rho_{\text {wall }}$ is the density of PolyHIPE wall. The measured density of the bulk polymer is used for the density of the wall.

$$
\% \text { Porosity }=\left(1-\frac{\rho_{\text {PolyHIPE }}}{\rho_{\text {wall }}}\right) \times 100
$$

It has been reported that emulsion templated scaffolds may shrink in a dry state depending on their chemical compositions (Pierre et al., 2006; Murphy et al., 2017). On the contrary, they may swell in various solvents to a certain extent. For example, PEG diacrylate (PEGDA) PolyHIPEs has been reported to have swelling ratio up to $700 \%$ as a whole scaffold (material and pores), and $60 \%$ as a scaffold material (not accounting pores) (Murphy et al., 2017) in PBS and this swelling process may cause expansion of the pores (Ovadia and Silverstein, 2016). Thus, pore sizes and the porosities of those may be different at their wet and dry conditions. However, for TE scaffolds, we assume that the pore size and porosity in the wet state (in a physiologically relevant aqueous solution) is more relevant as the scaffolds are introduced into a fluid-rich environment in the body.

Higher volume of the internal phase causes a reduction in the pore size as tighter packing of the droplets is needed (Sušec et al., 2015). Typically, the average pore size and window size ranges of PolyHIPEs are 1-150 $\mu \mathrm{m}$ and $0.2-50 \mu \mathrm{m}$, respectively (Barbetta et al., 2005b; Robinson et al., 2014). Mercury porosimetry and nitrogen adsorption methods are effective tools to characterise the structural and physical features of PolyHIPEs (Barbetta and Cameron, 2004). Another commonly used method is measuring the pore and window sizes using scanning electron microscopy (SEM) images of the cross-section of the PolyHIPEs. However, when the scaffolds are sectioned, pores are not ideally bisected; they are sectioned from a random distance $(h)$ from the centre (Figure 6). Thus, as we can only measure the radius of the circular section at a distance of $\mathrm{h}$ from the centre of the pore $(r)$ rather

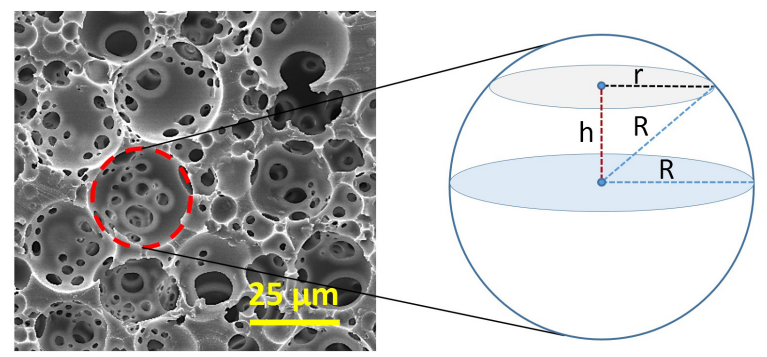

FIGURE 6 | Derivation of the statistical correction factor that is applied for adjusting the underestimation of the exact diameter of the pore size. $R$, an actual radius of the pore and $r$, the radius of the circular section at a distance of $\mathrm{h}$ from the centre of the pore.

than the exact pore radius $(R)$, a statistical correction factor should be applied to the measured average pore size (Barbetta and Cameron, 2004). The relationship between $R, r$, and $h$ can be expressed using Eq. 2.

$$
R^{2}=h^{2}+r^{2}
$$

The value of $h$ can be between 0 to $R$, depending on the position of the sectioning. By replacing an average value for $h ; R / 2$, in Eq. $2, R / r$ can be found $2 / \sqrt{ } 3$ as a correction factor that is applied to the measured diameter for adjusting the underestimation of the exact diameter.

The degree of interconnectivity of PolyHIPEs is calculated by dividing the average window size to average pore size $(d / D)$ (Carnachan et al., 2006; Aldemir Dikici et al., 2019b) however, as this number does not give any indication about the number of windows, an alternative definition of the degree of openness, which is suggested to be calculated by dividing open surface area of the pore to total surface area of the pore (Eq. 3) (Pulko and Krajnc, 2012; Owen et al., 2016).

$$
\text { Degree of openness }=\frac{\begin{array}{l}
\text { Open surface area of the pore } \\
\text { (area of the windows })
\end{array}}{\text { Total surface area of the pore }}
$$

\section{Physical Characteristics}

PolyHIPEs are defined as low-density polymeric foams with typical densities of around $0.1 \mathrm{~g} / \mathrm{cm}^{3}$ (Silverstein et al., 2011). This value can be lowered with higher porosity and a higher degree of openness, and it has a direct effect on the mechanical properties of the matrices (Kravchenko et al., 2018). PolyHIPEs are also characterised with the low surface area due to the openness on the cavities. While increasing internal phase volume reduces the surface area dramatically (Cameron, 2005), the addition of porogenic solvents can increase the surface area up to $690 \mathrm{~m}^{2} / \mathrm{g}$. PolyHIPEs with significantly higher surface area (up to $2,000 \mathrm{~m}^{2} / \mathrm{g}$ ) can be obtained using the hyper-crosslinking approach (Pulko et al., 2010; Mezhoud et al., 2018).

\section{Rheological Characteristics}

HIPEs are viscous emulsions, and they have a mayonnaise-like consistency with yellowish-white colour due to the difference in 
light refraction between the oil and water phases. They exhibit shear-thinning behaviour (Sears et al., 2016; Bhagavathi Kandy et al., 2018; Aldemir Dikici et al., 2020). The viscosity of HIPEs depends on the viscosities of the internal and continuous phases, droplet size, and the internal phase volume (Ford and Furmidge, 1967; Das et al., 1992; Borwankar and Case, 1997; Welch et al., 2006; Ilia Anisa and Nour, 2010).

\section{Mechanical Characteristics}

The mechanical features of PolyHIPEs can be tailored to a large extent by tuning their composition (Caldwell et al., 2012; Owen et al., 2016) and morphology (Karageorgiou and Kaplan, 2005; Huš and Krajnc, 2014; Owen et al., 2015, 2016; Aldemir Dikici et al., 2019b; Kovačič et al., 2019). Although high porosity is desired for better cell infiltration in TE scaffolds, there is an indirect relationship between porosity and mechanical properties of porous foams (Karageorgiou and Kaplan, 2005; Owen et al., 2015, 2016). Similarly, the higher degree of interconnectivity results in a larger open area within the walls, and it leads to lower structural integrity (Barbetta and Cameron, 2004; Aldemir Dikici et al., 2019b).

The Young's modulus of the porous foams has been shown to increase by increasing pore size and relative density (Jiang et al., 2007; Lin-Gibson et al., 2007; Huš and Krajnc, 2014; Aldemir Dikici et al., 2019b; Kovačič et al., 2019). Also, the impact of strut thickness, shape, and other morphological parameters on the mechanical properties of porous materials has been shown using theoretical models and experimental studies (Li et al., 2006; Gholami et al., 2017).

\section{DEVELOPMENT OF THE EMULSION TEMPLATED SCAFFOLDS}

Emulsion templated scaffolds are fabricated by following a multistep route before they are used in TE applications (Figure 7); (i) development of the emulsions by optimisation of their composition and emulsification conditions, (ii) structuring the emulsions, (iii) applying the appropriate solidification method, and (iv) post-processing which include improving the functionality of the scaffolds, purification, and sterilisation.

\section{Preparation of HIPEs}

There are at least three essential ingredients that need to be used to make HIPEs; (i) a continuous phase (polymer phase), (ii) an internal phase, and (iii) a stabiliser [although there is a limited number of studies on the development of stabiliser-free HIPEs (Oh et al., 2015)]. In addition to these core elements of the HIPEs, additional ingredients may be required to be added into the inner or/and into the continuous phase of the emulsion.

\section{Formulation of the Continuous Phase}

The selection of the monomeric or oligomeric pre-polymer for the continuous phase of the PolyHIPEs is the fundamental basis to formulating emulsion templated structures with pre-determined properties and will be discussed in section "Monomers/Macromers." The pre-polymer is typically formulated with a number of additives (i.e., solvent, stabiliser and initiator) to form the continuous phase, which will be discussed in this section.

\section{Diluting Solvents}

Pre-polymers used in the emulsification process may be in solid-state or in liquid phase with high viscosity. During the mixing of the two immiscible phases, although the high viscosity of the continuous phase increases the kinetic stability of the emulsion, it needs to be low enough to enable efficient mixing of the two phases (Kuhlmann, 2000; Christenson et al., 2007). In order to reduce the viscosity of the polymer phase, either the temperature of the system can be increased (Figure 7), or polymers can be diluted with the solvents that are called diluting or porogenic solvents as they are removed after polymerisation. After removal, these matrices shrink up to $50 \%$ (Busby et al., 2002). Also, the addition of diluting solvents may provide additional nanoscale porosity on the walls of the PolyHIPEs (Silverstein et al., 2005).

Diluent type (Aldemir Dikici et al., 2019b) and volume (Christenson et al., 2007; Aldemir Dikici et al., 2019b) plays a critical role in the characteristics of HIPEs and PolyHIPEs. While water and phosphate buffer saline (PBS) are commonly used to dilute the continuous phase of the $\mathrm{o} / \mathrm{w}$ emulsions (Oh et al., 2015), more apolar solvents (with less solubility in water) such as; toluene (Busby et al., 2001; Christenson et al., 2007; Changotade et al., 2015; Aldemir Dikici et al., 2019b), chloroform (Aldemir Dikici et al., 2019b), tetrahydrofuran (THF) (David and Silverstein, 2009), dichloromethane (DCM), and dichloroethane (DCE) (Johnson et al., 2015) are used as diluents in w/o emulsions.

Recently, we have shown the impact of absence/presence, volume and the type of diluting solvents on the stability of PCL HIPEs and the morphology of PCL PolyHIPEs (Aldemir Dikici et al., 2019b). Increasing the volume of the diluent enhances the limit of the maximum internal phase volume that can be incorporated into the emulsion. However, a further increase in the solvent volume from a certain point reduces stability HIPE (Aldemir Dikici et al., 2019b). Thus, there is a narrow range that a stable emulsion can be formed. The viscosity should be low enough to enable mixing of the two phases, but high enough to form a stable emulsion.

\section{Internal Phase (Dispersed Phase)}

While the internal phase of w/o emulsions is most dominantly composed of water, in reversed emulsions $(\mathrm{o} / \mathrm{w})$, more apolar liquids, often toluene (Barbetta et al., 2005a,b; Krajnc et al., 2005) form the internal phase. Selection of the internal phase composition and the volume is another factor that has an impact on the properties of HIPEs and PolyHIPEs. Krajnc et al. (2005) tested toluene, chlorobenzene, DCM, and chloroform as the internal phases for acrylic acid PolyHIPEs $(\mathrm{o} / \mathrm{w})$, and reported that only the emulsions prepared with toluene resulted in as a stable emulsion.

There are some salts such as sodium sulphate $\left(\mathrm{Na}_{2} \mathrm{SO}_{4}\right)$, calcium chloride $\left(\mathrm{CaCl}_{2}\right)$, sodium chloride $(\mathrm{NaCl})$ (Pons et al., 2007), and potassium iodide (KI) that are included in the internal 


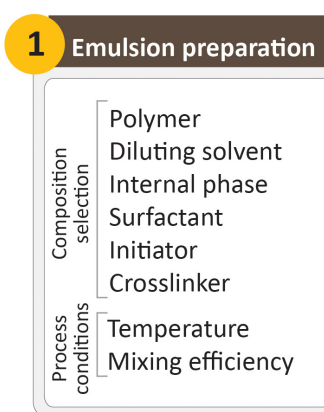

\begin{tabular}{|l|l|}
\hline 2 & Fabrication route \\
\hline Casting \\
Stereolithography \\
Emulsion printing \\
Injecting \\
Electrospinning \\
Porous particle \\
manufacturing
\end{tabular}

\section{Emulsion solidification}

Free-radical polymerisation

-Thermal polymerisation

-Photo-initiated polymerisation

-Redox-initiated polymerisation

Step-growth polymerisation

Ring-opening polymerisation

Solvent evaporation

Crosslinking

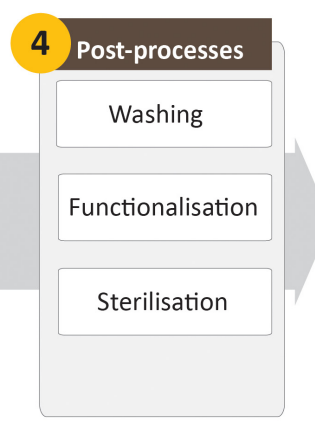

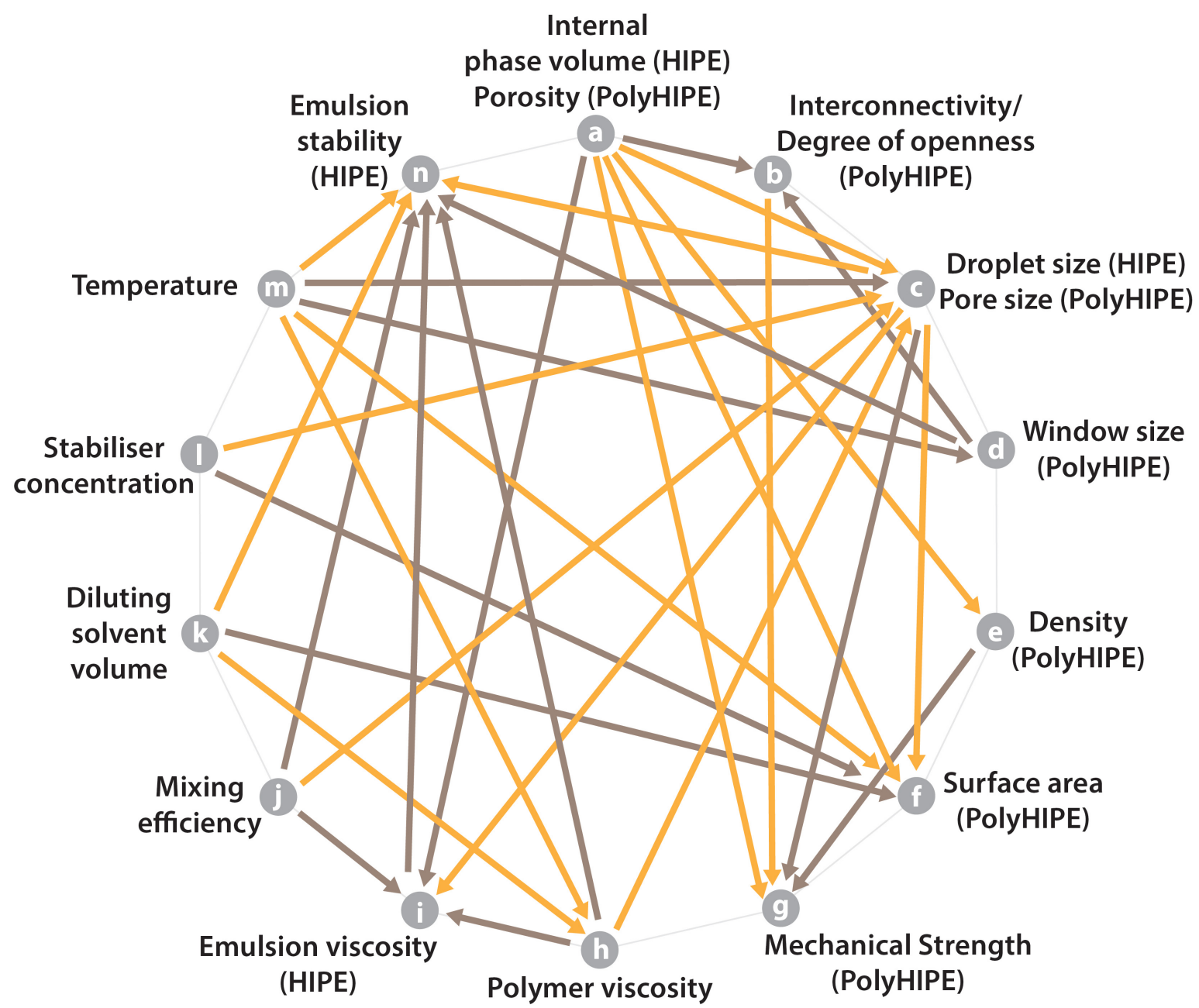

FIGURE 7 | (Top) Steps of manufacturing of the emulsion templated substrates, (Bottom) commonly seen relations of the characteristics of HIPEs and PolyHIPEs and some of the process conditions (orange arrows indicate one-way reciprocal proportionality, brown arrows indicate one-way direct proportionality. For example, an increase in the porosity of PolyHIPEs (or internal phase volume of HIPEs - characteristic of HIPEs and PolyHIPEs corresponds to each other) reduces the density of PolyHIPEs and increases the emulsion viscosity. References for the relations; (a-i) (Pal and Rhodes, 1985; Cameron and Sherrington, 1996; Farah et al., 2005), (a-g) (Karageorgiou and Kaplan, 2005; Owen et al., 2015, 2016), (a-e) (Kravchenko et al., 2018), (a-c) (Sušec et al., 2015; Kravchenko et al., 2018), (a-b) (Barbetta et al., 2005b; Owen et al., 2016), (a-f) (Cameron, 2005), (b-g) (Barbetta and Cameron, 2004; Owen et al., 2016; Aldemir Dikici et al., 2019b), (c-i) (Zhou et al., 2019), (c-g) (Lin-Gibson et al., 2007; Huš and Krajnc, 2014; Aldemir Dikici et al., 2019b; Kovačič et al., 2019), (c-f) (Cameron, 2005), (c-n) (Lim et al., 2015), (d-b) (Pulko and Krajnc, 2012), (d-n) (Cameron, 2005), (e-g) (Kravchenko et al., 2018), (h-c) (Aldemir Dikici et al., 2019b), (h-n) (Aldemir Dikici et al., 2019b), (h-i) (Barnes, 1994), (i-n) (Lim et al., 2015), (j-i) (Fan et al., 2018; Zhou et al., 2019), (j-c) (Moglia et al., 2011; Paterson et al., 2018; Zhou et al., 2019), (j-n) (Fan et al., 2018), (k-h) (Aldemir Dikici et al., 2019b), (k-f) (Cameron, 2005; Pulko et al., 2010), (k-n) (Carnachan et al., 2006; Aldemir Dikici et al., 2019b), (l-c) (Moglia et al., 2011), (l-f) (Wang et al., 2020), (m-h) (Aldemir Dikici et al., 2019b), (m-n) (Carnachan et al., 2006; Lim et al., 2015), (m-c) (Carnachan et al., 2006; Caldwell et al., 2012; Paterson et al., 2018), (m-d) (Carnachan et al., 2006), (m-f) (Huš et al., 2015). 

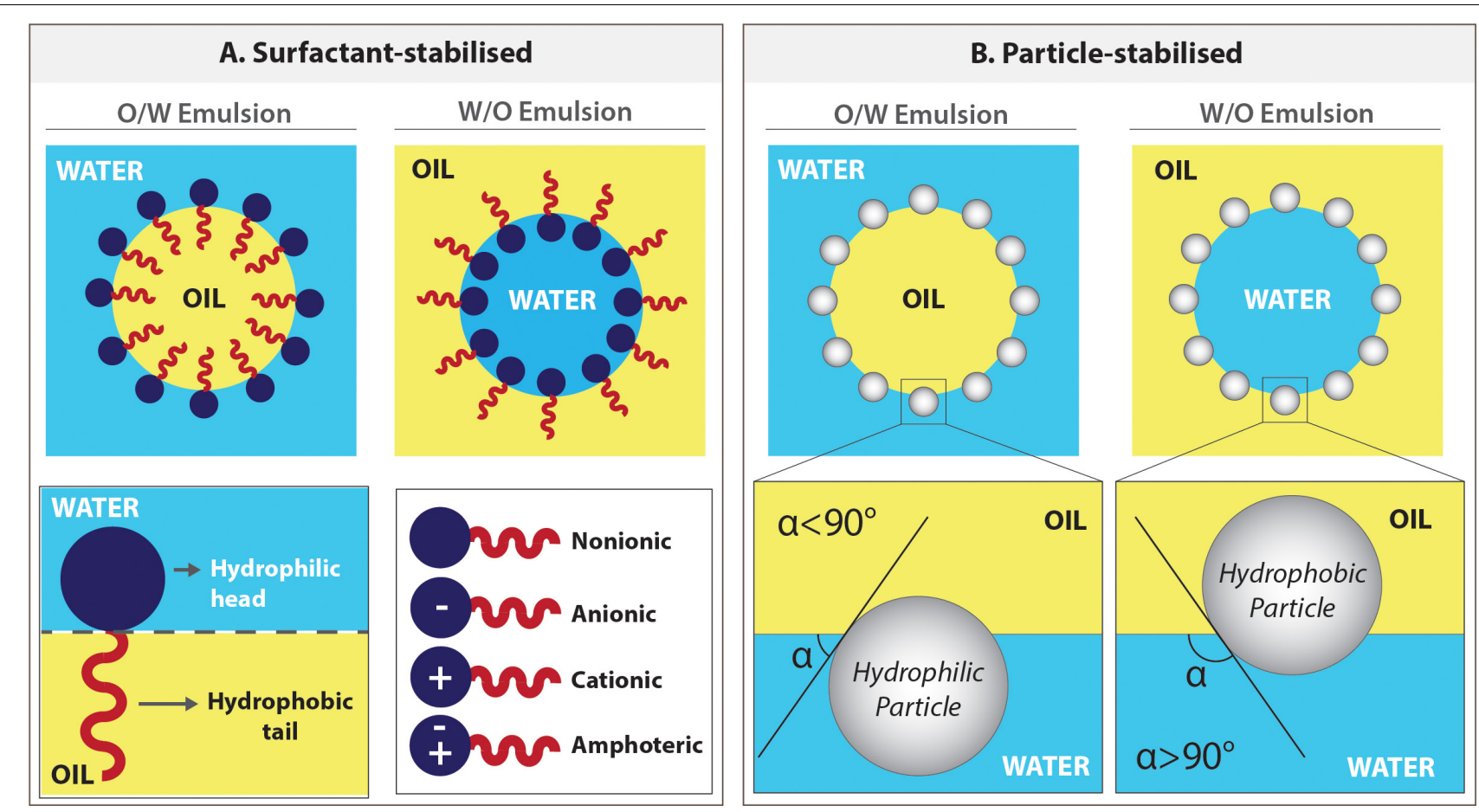

FIGURE 8 | Emulsions can be stabilised either by surfactants or particles. (A) The positioning of the surfactant molecules in o/w and w/o emulsions and types of surfactants. (B) The positioning of the particles on the water-oil interface of either in o/w or w/o emulsions depending on the degree of wettability of the particles by these phases.

phase of the w/o emulsions to increase stability (Kunieda et al., 1989; Rajagopalan et al., 1994). Opawale et al. showed that $\mathrm{NaCl}$ affects the surfactant adsorption and the emulsions interfacial elasticity, which play a crucial role in emulsion stability (Powell et al., 2017). However, the intensity of the impact depends on the type of surfactant used (Opawale and Burgess, 1998). $\mathrm{CaCl}_{2}$ was reported to increase emulsion stability by preventing Oswald ripening (Moglia et al., 2011). Similarly, potassium sulphate $\left(\mathrm{K}_{2} \mathrm{SO}_{4}\right)$ was also reported to increase the rigidity of the interface between the two phases (Lumelsky et al., 2008, 2009; Lumelsky and Silverstein, 2009).

Opposed to abovementioned applications that attempt to increase the stability of the emulsions, there are some approaches to reduce emulsion stability on purpose to enable an increase of the pore size of the PolyHIPE. Magnesium sulphate $\left(\mathrm{MgSO}_{4}\right)$ has been reported to reduce the surfactant adsorption and increases the droplet size within the emulsion (Kent and Saunders, 2001). Also, chemicals that are partially soluble in both phases of the emulsion such as poly(ethylene glycol) (PEG) (Carnachan et al., 2006) and THF (Hayman et al., 2004, 2005; Cameron, 2005; Carnachan et al., 2006) reduce emulsion stability and are included in the internal phase of the w/o emulsions to increase pore size.

\section{Stabilisers}

The coexistence of two immiscible liquids in the emulsion composition causes high surface tension at the interfaces of these liquids. The droplets of the inner phase coalescence gradually to reduce the surface area, and this process ends up inevitably as phase separation. According to surface tension theory, stabilising agents reduce the interfacial tension by stabilising the oil-water interface (Khan et al., 2011; Kale and Deore, 2016).

\section{Surfactant stabilisation}

The surfactant is an amphiphilic compound; that its head is water-soluble, and the tail is oil-soluble (Figure 8). Surfactants create a continuous film around the inner phase, act as a barrier between two phases which reduces the interfacial tension, and stabilises the emulsion. There are various types of surfactants available, and they are classified as non-ionic, anionic, cationic, and amphoteric, depending on the charge of the hydrophilic head (Figure 8A). The surfactant choice (Busby et al., 2002; Moglia et al., 2011) and concentration (Aldemir Dikici et al., 2019b) play an important role in emulsion stability and PolyHIPE morphology.

When there is no surfactant used in the water and oil system, the type of emulsion depends on the volume of the phase. The higher volume phase will mostly be the continuous phase. In the presence of surfactants, according to the Bancroft Rule (Bancroft, 1913), the phase that the surfactant is predominantly dissolved in forms the continuous phase. Specifically, while oil-soluble surfactants tend to form w/o emulsions, water-soluble surfactants are suitable for o/w emulsions (Finkle et al., 1923).

Although the selection of the best working surfactant has been empirical, the quantitative classification of the surfactants, the hydrophile-lipophile balance (HLB) classification described 
by Griffing, gives an insight for the initial surfactant choice (Griffin, 1946, 1954). The HLB value varies between 0 to 20, and the value is in direct correlation with the hydrophilicity of the surfactant (Myers, 2005). While surfactants with low HLB values are good for w/o emulsions, surfactants with high HLB values are more suitable for o/w emulsions (Myers, 2005).

The HLB value of a surfactant is not always a sole determining factor for emulsion stability, which depends on various parameters such as the selection of the monomer and solvent, emulsification temperature, and absence/presence of the electrolyte (Myers, 2005). Indeed, many researchers reported that just HLB is not enough on its own to select a suitable surfactant for emulsion systems (Moglia et al., 2011).

W/o emulsions are mostly stabilised using oil-soluble nonionic surfactants (Silverstein, 2014b). Span 80, Hypermer 246 and polyglycerol polyricinoleate (PGPR) are the most widely used surfactants for w/o HIPEs (Table 1). However, Zhang et al. replaced the non-ionic surfactant with cationic surfactant for divinylbenzene (DVB)-styrene HIPEs and reported the formation of PolyHIPEs with higher pore volumes than the ones prepared using non-ionic surfactants (Zhang and Chen, 2007). The concentration of the surfactants used in the preparation of HIPEs is generally in the range of $1-30 \%(\mathrm{w} / \mathrm{w})$ (of the monomer). A higher surfactant concentration results in smaller average pore size and more uniform pore size distribution (Moglia et al., 2011).

Surfactants are commonly intended not to react with the monomer, and they are removed from the PolyHIPE composition following polymerisation. However, the use of reactive block copolymer surfactants in HIPE composition is also reported (Zhang and Silverstein, 2018). As they covalently attach to the PolyHIPE surface, surfactant removal is not needed.

\section{Pickering particle stabilisation}

The emulsion also can be stabilised using solid particles (micro or nanoparticles), and these surfactant-free emulsions are defined as Pickering emulsions (Gurevitch and Silverstein, 2010; Yang et al., 2017). As in surfactant stabilised emulsions, the pore size of the particle stabilised emulsions can be adjusted by changing the particle concentration (Zhou et al., 2012a).

The principle behind the stabilisation mechanism of Pickering emulsions is based on the wettability of the particles by oil and the water phases (preferential wetting theory) (Chang, 2016). These particles position on the interface and need to be absorbed by both phases to some extent. The particles are more adsorbed in the phase that they are wetted more, and this defines their

TABLE 1 | Commonly used surfactants in HIPEs of various polymer systems.

\begin{tabular}{|c|c|c|c|c|}
\hline Emulsion type & Emulsifier & HLB/type & Polymer & References \\
\hline \multirow[t]{11}{*}{ w/o } & $\begin{array}{l}\text { Polyglycerol polyricinoleate } \\
\text { (PGPR) }\end{array}$ & $\begin{array}{l}\sim 3 \text { (Surh et al., 2007) } \\
\text { Nonionic }\end{array}$ & $\begin{array}{l}\text { 1,6-Diisocyanatohexane and } \\
\text { Polycaprolactone triol }\end{array}$ & David and Silverstein, 2009 \\
\hline & & & Propylene fumarate dimethacrylate & $\begin{array}{l}\text { Moglia et al., 2011, 2014c; Robinson } \\
\text { et al., } 2014\end{array}$ \\
\hline & $\begin{array}{l}\text { Sorbitan monooleate (Span } \\
\text { 80) }\end{array}$ & $\begin{array}{l}4.3 \text { (Kassem et al., 2019) } \\
\text { Nonionic }\end{array}$ & Propylene fumarate (diacrylate) & Christenson et al., 2007 \\
\hline & & & Styrene/divinylbenzene & Akay et al., 2004; Hayman et al., 2005 \\
\hline & & & $\begin{array}{l}\text { 2-Ethylhexyl acrylate (EHA) and } \\
\text { isobornyl acrylate (IBOA) }\end{array}$ & Pierre et al., 2006 \\
\hline & Hypermer 246 & $\begin{array}{l}\text { 5-6 (Audouin and Heise, 2014) } \\
\text { Nonionic }\end{array}$ & $\begin{array}{l}\text { 2-Ethylhexyl acrylate (EHA) and } \\
\text { isobornyl acrylate (IBOA) }\end{array}$ & $\begin{array}{l}\text { Johnson et al., 2013; Malayeri et al., } \\
\text { 2016; Owen et al., 2016; Wang et al., } \\
2016\end{array}$ \\
\hline & & & Thiolene & $\begin{array}{l}\text { Lovelady et al., 2011; Richardson et al., } \\
2019\end{array}$ \\
\hline & & & Polycaprolactone tetramethacrylate & Aldemir Dikici et al., 2019a,b \\
\hline & Brij-58 & $\begin{array}{l}15.7 \text { (Thakare et al., 2017) } \\
\text { Nonionic }\end{array}$ & Polycaprolactone & Samanta et al., 2016a \\
\hline & Pluronic L121 & $\begin{array}{l}1 \text { (Amiiji, 2004) } \\
\text { Nonionic }\end{array}$ & $\begin{array}{l}\text { Tetrakis-3-mercaptopropionate and } \\
\text { divinyladipate }\end{array}$ & Naranda et al., 2016 \\
\hline & $\begin{array}{l}\text { Cetyltrimethylammonium } \\
\text { bromide (CTAB) }\end{array}$ & $\begin{array}{l}10 \text { (Prakash, 2010) } \\
\text { Cationic }\end{array}$ & Styrene/divinylbenzene & Zhang and Chen, 2007 \\
\hline \multirow[t]{7}{*}{$\mathrm{O} / \mathrm{W}$} & Triton X-405 & $\begin{array}{l}17.9 \text { (Slinde and Flatmark, 1976) } \\
\text { Nonionic }\end{array}$ & Alginate methacrylate & Barbetta et al., 2009; Zhou et al., 2013 \\
\hline & & & $\begin{array}{l}\text { Dextran } \\
\text { Dextran-b-PolyNIPAAm } \\
\text { (Poly(N-isopropylacrylamide)) }\end{array}$ & Zhou et al., 2012b \\
\hline & & & Gelatin methacrylate & Barbetta et al., 2005a,b \\
\hline & & & Pullulan methacrylate & Barbetta et al., 2005a \\
\hline & & & Dextran methacrylate & Barbetta et al., 2005a \\
\hline & & & Alginate & Barbetta et al., 2009 \\
\hline & & & Acrylic acid & Krajnc et al., 2005 \\
\hline
\end{tabular}


positioning in the interface (Figure 8B). While water wetted particles forms o/w emulsions, oil-wetted particles can stabilise w/o emulsions (Schulman and Leja, 1954; Binks and Lumsdon, 1999; Pal, 2018). The particles that are not wetted by one of these phases disperse in the phase they are wetted and fail to stabilise the emulsion.

Hydroxyapatite (HA) is one of the most widely used particles for stabilisation of Pickering HIPEs. Interestingly it is reported to be used both o/w (Zhou et al., 2012a) and w/o (Hu et al., 2014a,b, 2015) HIPEs. Hu et al. (2019) used nano-HA to stabilise PCL HIPEs and in their follow-up study, Yang et al. claimed that emulsions stabilised using silica nanoparticles have a higher viscosity than the emulsions stabilised by HA particles (Yang et al., 2017). Starch nanoparticles (Kavousi and Nikfarjam, 2019) and gelatin nanoparticles (Tan et al., 2017) are the other alternative particles used for the stabilisation of the Pickering $\mathrm{o} / \mathrm{w}$ and w/o emulsions, respectively.

\section{Initiators}

Initiators are chemical compounds that react with the monomers. They form intermediate compounds that can be linked with other monomers and propagate to form the polymer chains. Initiators can be included either into the inner or continuous phase of the emulsions, and the locus of initiation has been shown to have a significant effect on porous structures (Gurevitch and Silverstein, 2010).

Ammonium persulphate (APS) (Moglia et al., 2011) and potassium persulphate (KPS) (Lumelsky et al., 2008, 2009; Tunc et al., 2012) are water-soluble oxidising agents that are used as redox initiators in radical crosslinking of the macromer chains. They have been reported to be introduced into the water phase of the styrene (Bokhari et al., 2005; Audouin et al., 2012), dextran, (Zhou et al., 2012a) or polypropylene fumarate (PPF) (Christenson et al., 2007; Moglia et al., 2011) HIPEs with the concentration of $1-5 \% \mathrm{w} / \mathrm{v}$ of the aqueous phase.

Benzoyl peroxide (BPO) is an oil-soluble redox initiator also used for polymerisation of PPF HIPEs. Robinson et al. (2014) showed that initiator selection has a great impact on PolyHIPE morphology. While PPF PolyHIPEs prepared using APS as an initiator resulted in closed cellular structure, BPO included PolyHIPEs exhibited open cellular structure. Also, the concentration of the redox initiator has shown to have an impact on the curing time of HIPEs and on the mechanical properties of PolyHIPEs (Moglia et al., 2014c). 2,2'-Azobisisobutyronitrile (AIBN) is another oil-soluble initiator. It has been reported to be introduced into the continuous phase of styrene (Hayward et al., 2013a) and the internal phase of gelatin HIPEs (Barbetta et al., 2005b) for thermal polymerisation.

Photoinitiators are the molecules that create reactive species when exposed to light, and they are included in the composition of the HIPEs that will be polymerised via photo-initiation. In the photoinitiator selection process, the critical parameter is that the absorption band of the photoinitiator should overlap with the emission spectrum of the light source (Eibel et al., 2018). 2,4,6-Trimethylbenzoyl phosphine oxide/2-hydroxy-2-methyl propiophenone blend (Johnson et al., 2015; Sherborne et al., 2018; Aldemir Dikici et al., 2019a,b) and phenyl bis(2,4,6-trimethyl benzoyl) - phosphine oxide (BAPO) (Sears et al., 2016) are widely used photoinitiators in photo-polymerisation of HIPEs. Photoinitiators are mostly used in the HIPE composition at a concentration range of $0.2-10 \%(\mathrm{w} / \mathrm{w})$ of the polymer. The concentration of the photoinitiator that is included in the composition of the photocurable resins is reported to have an effect on the rheological properties of the monomer and its gelation time (Mishbak et al., 2019). Interestingly, there are few studies that investigate the photoinitiator type and concentration on the characteristics of PolyHIPEs (Harikrishna et al., 2014).

\section{Crosslinker (Crosslinking Agent)}

Crosslinkers are the precursors with at least two reactive ends to connect primary polymer chains by forming intermolecular linkages (Figure 9A). Using an external crosslinking agent increases the degree of crosslinking of the polymer phase, and it improves the stiffness of the materials (Tunc et al., 2012). The most known crosslinker is DVB, used in the composition of styrene HIPEs (Akay et al., 2004; Sevšek et al., 2014; Woodward et al., 2017; Figures 9B,C). Christenson et al. (2007) used propylene fumarate diacrylate (PFDA) as a crosslinker for PPF HIPEs and showed that crosslinker concentration has an impact on the emulsion stability of HIPEs and on the morphology of PolyHIPEs. Nalawade et al. verified this finding on hydrogelbased HIPEs (Nalawade et al., 2016). Trimethylolpropane triacrylate (TMPTA) is also widely used crosslinker for EHA and isobornyl acrylate (IBOA) PolyHIPEs (Malayeri et al., 2016; Owen et al., 2016).

\section{Temperature}

The most dramatic effect of the temperature is on the viscosity of the oil phase which also affects the viscosity and the stability of the emulsion. The viscosity of the polymer and the temperature are inversely related to each other as shown in Eq. 4 where $n$ is the viscosity of the polymer, $T$ is the temperature, $A$ and $B$ are material constants;

$$
n=A e^{\frac{B}{T}}
$$

Also, according to Stoke's equation (Eq. 5), the viscosity of the polymer and the velocity of the droplet $(v)$ are inversely proportional (Murakami et al., 2014);

$$
v=D^{2} \Delta \rho g / 18 n
$$

$D$ is the droplet diameter under gravitational force, $\Delta \rho$ is the density difference between water and oil phase, $n$ is the viscosity of the oil phase, and $g$ is the gravitational force. Consequently, the increasing temperature reduces the oil phase viscosity, and this increases the speed of droplets of the inner phase and creates a bigger pore size (Bokhari et al., 2007b; Sušec et al., 2015; Paterson et al., 2018). Further increase in the temperature can lead to emulsion separation due to the increased mobility of the droplets (Carnachan et al., 2006; Caldwell et al., 2012). Although some studies increase the temperature in a controlled manner to increase the pore size, moderate temperatures are more favourable as they create comparatively more stable emulsions.

To investigate the effect of higher temperature on PolyHIPEs, researchers use different setups. Caldwell et al. showed that 


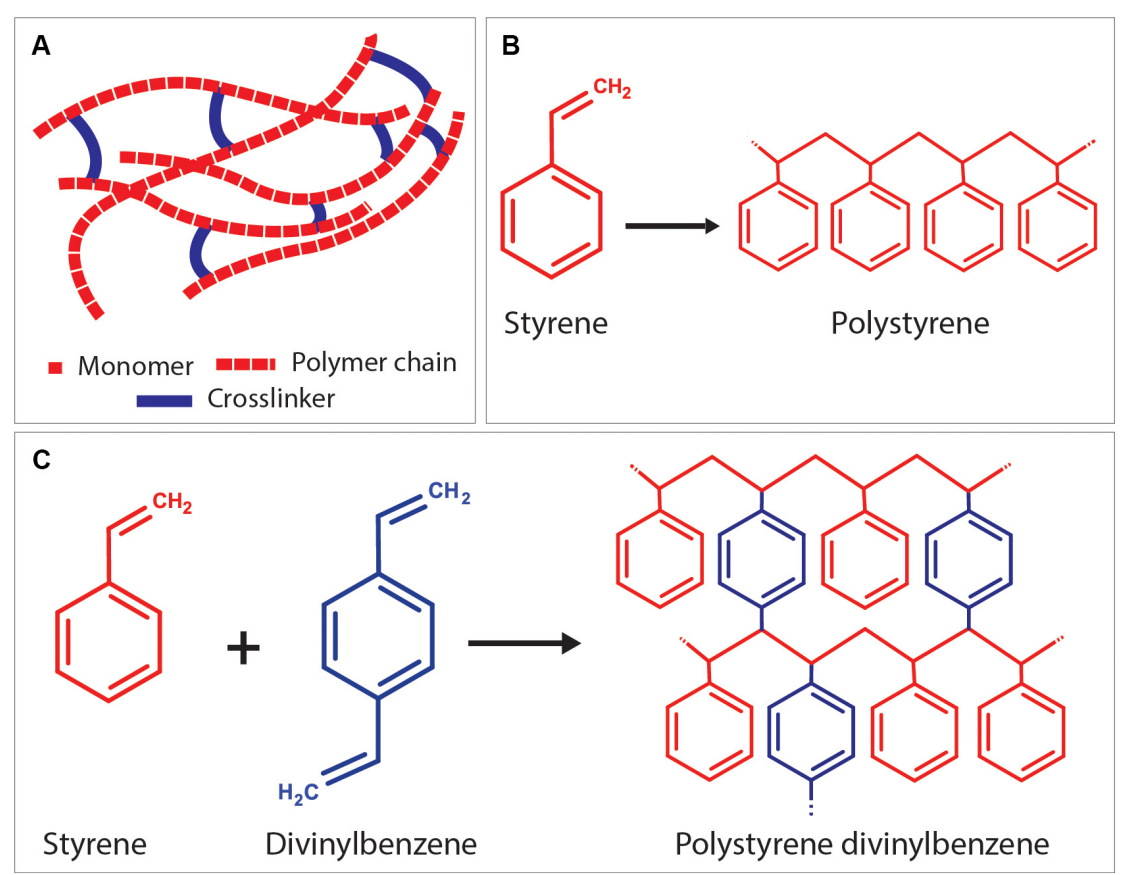

FIGURE 9 | (A) Positioning of the crosslinker between linear polymer chains. As an example; (B) formation of polystyrene chain from styrene monomers, and (C) crosslinking of polystyrene chains using the crosslinker, divinylbenzene.

increasing the temperature of the inner phase from 23 to $80^{\circ} \mathrm{C}$ increased the pore sizes up to twofold (Caldwell et al., 2012). Akay et al. (2004) heated the whole mixing system using a stainless steel vessel with a heating jacket.

\section{Efficiency of Mixing}

In the conventional emulsification route, the internal phase is introduced into the continuous phase dropwise while the system is mixed continuously. There are various mixing methods reported; such as over-head stirrer (Lovelady et al., 2011; Caldwell et al., 2012; Johnson et al., 2015), magnetic stirrer (Aldemir Dikici et al., 2019a,b), mechanical shaking (Yang et al., 2017), speed mixer (Moglia et al., 2011, 2014c; Robinson et al., 2014), vortex (Richez et al., 2005), homogeniser (Hu et al., 2014b), and shaking by hand ( $\mathrm{Hu}$ et al., 2015). The type of mixing is reported to have an effect on the maximum internal phase volume that could be incorporated into the emulsion (Richez et al., 2005). The effect of stirring speed on the characteristics of HIPEs has been reported by many groups (Moglia et al., 2011; Sušec et al., 2015; Paterson et al., 2018). Higher mixing speeds commonly result in smaller pore sizes.

Bokhari et al. (2007b) revealed that the way of adding inner phase into the continuous phase (syringe pump or dropping funnel) also influences the emulsion stability, the pore size distribution of the droplets, and the reproducibility. Another emulsification route; the multiple emulsion method, combines and mixes all the components from the oil and water phase together. But as the emulsion prepared using this method forms gradually, the system needs to be stirred until the HIPE forms (Richez et al., 2005).
Apart from the parameters mentioned above, it is also important to note that, every parameter that affects the energy input for the droplet breakup; such as mixing time, the batch volume of the emulsion, materials and the diameter of the emulsification container, and the magnetic stirrer/paddle size (where relevant) directly affects the mixing efficiency of the emulsion and will have an impact on the final morphology. Keeping these parameters constant between batches helps the consistency and reproducibility of the PolyHIPEs.

\section{HIPEs to PolyHIPEs}

\section{Emulsion Solidification Approaches}

\section{Free-radical polymerisation}

PolyHIPEs based on many popular polymers, such as; acrylates, methacrylates, and styrenes are synthesised using free-radical polymerisation (FRP) (Zhang et al., 2019). The type of the initiator (section "Initiators") used in the emulsion composition determines one of the following initiation routes of FRP; (i) thermal-initiated polymerisation, (ii) photo-initiated polymerisation, and (iii) redox-initiated polymerisation.

The earliest examples of the PolyHIPEs (during the 1980s) were based on thermal polymerisation (Donald and Zia, 1982; Jones et al., 1986). In this process, emulsion mixture that contains thermal initiator is exposed to heat in an oven or in a heat bath for 6-48 h for the polymerisation. The temperature is often kept quite high $\left[60-70^{\circ} \mathrm{C}\right.$ (Busby et al., 2002; Bokhari et al., 2005, 2007b; Christenson et al., 2007; Lumelsky et al., 2008)] to decompose the initiator into radicals thermally. Exceptionally, polypropylene fumarate dimethacrylate (PFDMA) HIPEs can be 
polymerised at $37^{\circ} \mathrm{C}$ (Moglia et al., 2011; Robinson et al., 2014). Also, by the use of a catalyst, the polymerisation temperatures can be reduced (Zhang T. et al., 2016).

In photo-initiated polymerisation, emulsions are prepared using photosensitive materials as a continuous phase and photoinitiators are exposed to light to be able to generate free-radicals and initiate the polymerisation. This method has many advantages over thermal-induced polymerisation; polymerisation takes places at room temperature (RT) just in seconds to minutes depending on the sample size. Photopolymerisation is an efficient polymerisation route, especially in relatively small samples, as ultraviolet (UV) penetration depth can be limited in a larger volume of emulsions. Photo-initiated polymerisation of the emulsions, specifically HIPEs, were described in patents in 1986 (Tanny et al., 1986) and 1999 (Thunhorst et al., 2003), respectively. A more detailed experimental procedure of photo-initiated polymerisation of HIPEs was reported by Pierre et al. (2006). However, lately, a number of studies about the development of PolyHIPEs based on photocurable materials such as thiolene (Johnson et al., 2015), meth(acrylates) of PCL (Aldemir Dikici et al., 2019a,b) or gelatin (Barbetta et al., 2006) have increased the potential applications. Redox-initiated polymerisation, which uses reducing and oxidising agents, is also another FRP route used in the polymerisation of HIPEs (Moglia et al., 2014c).

\section{Step-growth (condensation) polymerisation}

Integration of step-growth polymerisation into emulsion templating process has been successfully implemented in polyurethane PolyHIPEs (David and Silverstein, 2009). It is synthesised using diisocyanate and PCL triol, and the reaction of a diisocyanate with water produced urea groups and carbon dioxide $\left(\mathrm{CO}_{2}\right)$. The bubbles of generated $\mathrm{CO}_{2}$ created additional porosity into PolyHIPE structure.

\section{Ring-opening polymerisation}

Development of PolyHIPEs by ring-opening polymerisation (ROP) of cyclic monomers is a relatively new route of polymerisation HIPEs. $\varepsilon$-caprolactone and L-lactide are the most widely used monomers in this approach (Pérez-García et al., 2016; Sharma et al., 2016; García-Landeros et al., 2019; Utroša et al., 2019; Yadav et al., 2019). One of the most important advantages of this technique is the elimination of diluting solvents from the emulsion composition due to the low viscosity of the cyclic monomers. Catalyst concentration is the deterministic factor of the rate and the degree of polymerisation. The polymerisation temperatures and the polymerisation durations vary between 37 and $120^{\circ} \mathrm{C}$ and $6 \mathrm{~h}$ to overnight, respectively.

\section{Solvent evaporation}

Although the term PolyHIPE refers to polymerised emulsions, recently polylactic acid (PLA), PCL, polylactic-co-glycolic acid (PLGA) PolyHIPEs solidified without polymerisation have been reported (Hu et al., 2014a,b, 2015, 2017; Samanta et al., 2016a; Yang et al., 2017). This process is based on dissolving the non-functional, linear, high molecular weight polymer in an appropriate diluting solvent, followed by emulsification, and finally solidification of HIPEs via solvent evaporation. As high molecular weight polymers are commercially available, this process does not require polymer synthesis or functionalisation steps. PolyHIPEs can be fabricated either with moulding or $3 \mathrm{D}$ printing. The main disadvantages of this technique are the long solidification process (24-48 h) (Yang et al., 2017), and the requirement of development of emulsions with high stability that would keep the shape until solidification.

\section{Crosslinking}

Crosslinking of PolyHIPEs as a solidification approach can be either ionic, thermal or enzymatic. Alginate PolyHIPEs has been synthesised using calcium ions (Barbetta et al., 2009; Zhou et al., 2013). This reversible gelation can be de-crosslinked using sodium citrate. Solidification of gelatin HIPEs using enzymatic crosslinking also has been reported (Barbetta et al., 2006). In another study, gelatin PolyHIPEs has been obtained by physical thermal-crosslinking at $4^{\circ} \mathrm{C}$ (Oh et al., 2015).

\section{Fabrication Routes \\ Casting (moulding)}

The earliest examples of PolyHIPE scaffolds were fabricated using the casting technique (Figure 10Aa). This technique is the easiest way of manufacturing PolyHIPE scaffolds with almost no additional technical equipment requirement. Silicone (Naranda et al., 2016; Aldemir Dikici et al., 2019a,b; Dikici et al., 2020a), polyvinyl chloride (Busby et al., 2002), polytetrafluoroethylene (Hayman et al., 2004, 2005; Lee et al., 2017), glass (Audouin et al., 2012), polypropylene (Moglia et al., 2014b), polycarbonate centrifuge tubes (Carnachan et al., 2006; Hayward et al., 2013b), and aluminium (Moglia et al., 2011) are some of the materials reported to be used to create moulds for the fabrication of PolyHIPE scaffolds. Recently, we have shown that mould material has a significant impact on the morphology of the contact surface of PolyHIPEs which have fully or partially closed cellular morphology (Aldemir Dikici et al., 2019a). Similar to our finding, the influence of the mould material on PolyHIPE morphology and HIPE stability has also been reported previously by Cameron (2005).

In order to avoid the closed-pores on the surface of the PolyHIPEs, the moulded PolyHIPE blocks are typically sectioned using various methods and benefit from the open porous crosssectional surface. Vibratomes (Hayward et al., 2013a; Aldemir Dikici et al., 2019a) and microtomes (Bokhari et al., 2007b) allow precise micro-scale thick scaffolds to be obtained. Additionally, tabletop precision saws (Robinson et al., 2014, 2016; Whitely et al., 2017), and scalpels/razor blades (Caldwell et al., 2012; Aldemir Dikici et al., 2019a,b) have been used cut monoliths to millimetre scale sections.

Casting enables the manufacturing of scaffolds in a wide range of shapes and sizes, depending on the mould design (Paljevac et al., 2018; Diez-Ahedo et al., 2020; Dikici et al., 2020a; Owen et al., 2020). Recently, Dikici et al. (2020a) reported the fabrication of the PolyHIPEs in tubular form by designing a reusable tubular silicone mould system that, HIPE can be injected into, polymerised, and recovered easily (Figure 10Ab). Also, 


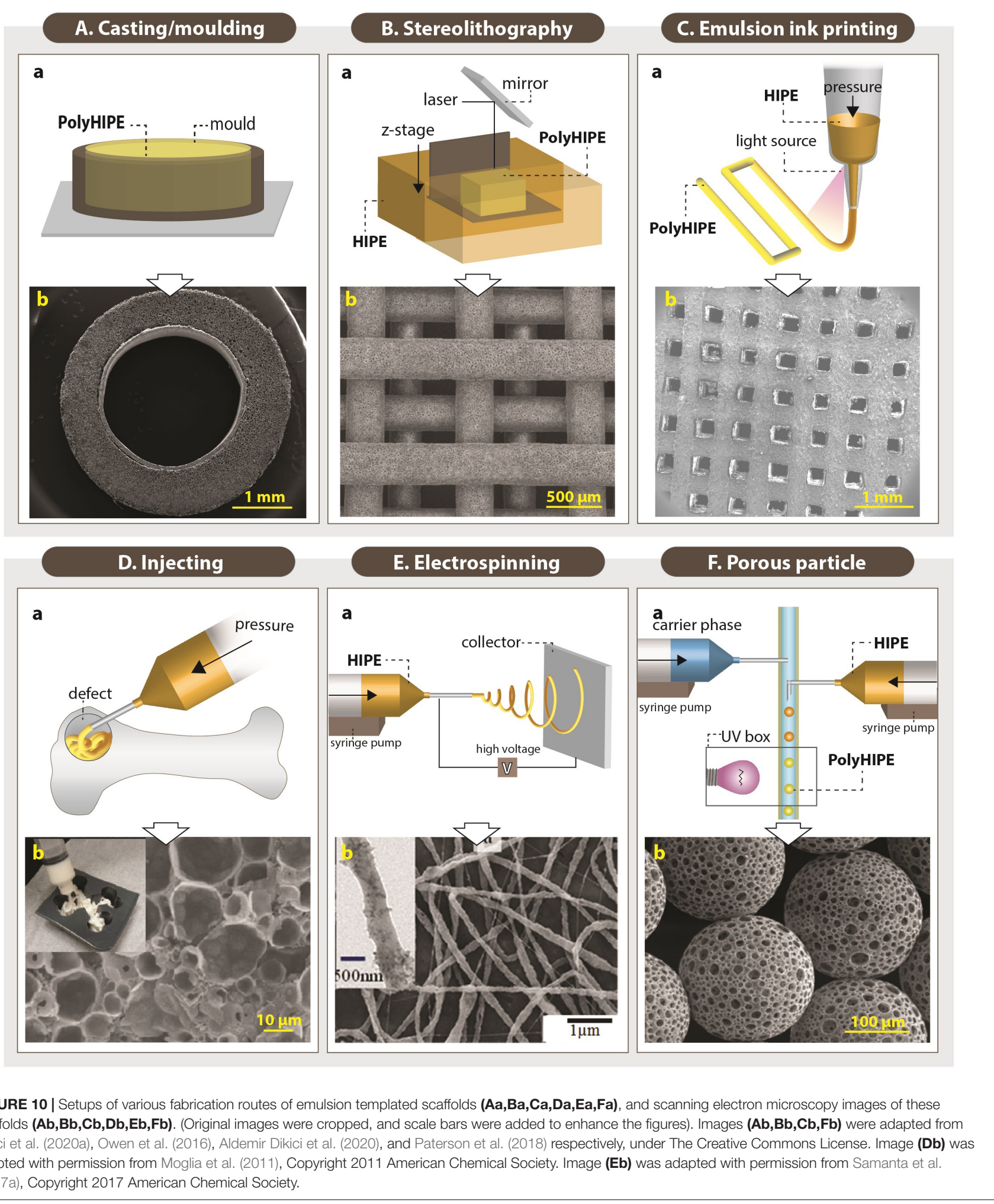

sacrificial polymer beads made of PDMS (Paljevac et al., 2018) or alginate (Owen et al., 2020) have been incorporated into emulsion composition prior to polymerisation in a mould to simply introduce multiscale porosity to PolyHIPEs.

\section{Stereolithography}

Fabrication of TE scaffolds using AM techniques gained huge attention in the last decades due to various advantages of the AM such as enabling the manufacture of complex 
shapes using a broad range of materials, high reproducibility and providing control on the exterior architecture of the scaffolds. However, manufacturing of pores less than $20 \mu \mathrm{m}$ using the current $\mathrm{AM}$ techniques remains a challenge (Pei et al., 2017). Alternatively, combining emulsion templating with AM techniques such as stereolithography or emulsion ink printing enables the fabrication of well-defined multiscale porous complex scaffolds.

Stereolithography is a laser-based fabrication method that selectively polymerises photo-sensitive liquid resin layer-bylayer. It provides higher accuracy compared to other AM technologies (Kawata et al., 2001; Johnson et al., 2013; Yang et al., 2020). The emulsions with low viscosity are preferable to be able to provide enough spreading on the $\mathrm{z}$-stage while the building chamber is moving in the $z$-axis (Figure 10Ba).

Johnson et al. (2013) reported the 3D defined complex structures of PolyHIPEs made of EHA:IBOA using microstereolithography up to $30 \mu \mathrm{m}$ accuracy. Exactly on the same date, Sušec et al. (2013) reported the development of stable photocurable thiolene HIPEs that can be used to produce PolyHIPEs using stereolithography. Fabrication of EHA:IBOA PolyHIPEs via stereolithography in wood-pile structure has been reported many times for various TE applications (Figure 10Bb; Malayeri et al., 2016; Owen et al., 2016; Wang et al., 2016). However, manufacturing of EHA:IBOA PolyHIPEs using stereolithography cause the formation of surface skin that is characterised with the closed pore at the surface. Sherborne et al. (2018) showed that the use of UV absorbers could reduce skin formation without causing any toxic effect on cells.

\section{Emulsion ink printing}

Emulsion ink printing is another convenient AM route to combine with emulsion templating for the fabrication of multiscale porous scaffolds. This method is based on the preparation of emulsion inks, filling the printing head reservoir with a required amount of the emulsion, and printing the emulsion in the designed 3D shape (Figure 10C). Nozzle size, pressure and printing speed are some of the parameters that have an impact on the final structures. There are two approaches used in this manufacturing technique; (i) simultaneous printing and solidification of the HIPEs and (ii) printing HIPEs and subsequent solidification. Only for the first approach, emulsions prepared from photocurable materials are needed. Otherwise, emulsion printing is not limited to use of the photocurable resins as in stereolithography.

The shear-thinning nature and the high viscosity of HIPEs make them good candidates to be used as inks for the $3 \mathrm{D}$ printing. It is essential to highlight the fact that emulsion viscosity is inversely proportional to the size distribution of the water droplets (Ilia Anisa and Nour, 2010). Thus, the viscosity of the emulsion should be high enough for successful printing of the emulsion inks and low enough for enabling the manufacturing of the scaffolds with a pore size range that allows cell infiltration. Recently, a few publications have reported the use of emulsion ink printing for the fabrication of bone TE scaffolds (Sears et al., 2016; Yang et al., 2017; Aldemir Dikici et al., 2020). Unlike stereolithography, emulsion ink printing enables fabrication of heterogeneous structures made of different inks by using different printing heads (Hu et al., 2019).

\section{Injecting}

Although AM techniques are first to come to the mind to fabricate defect matching scaffolds, their use requires highly accurate imaging techniques to be able to create 3D custom-made models (Moglia et al., 2014b). Alternatively, injectable materials that harden in situ can fill irregular shapes by minimal invasive delivery (Figure 10D), and they can also be used as a carrier for cells and other biological molecules (Temenoff and Mikos, 2000; Chang et al., 2017; Guyot and Lerouge, 2018).

The main prerequisites for the development of injectable emulsions are the elimination of the toxic solvents and enabling polymerisation at physiological temperatures. Thus, there is a limited number of materials that can be used to develop injectable HIPEs.

PPF HIPEs, discussed in detail in section "Monomers/Macromers," have a suitable viscosity for injection from a syringe, and they can solidify at body temperature in $15 \mathrm{~min}$. They have been shown to be stable for storage up to 6 months and to integrate into the host tissue successfully (Moglia et al., 2014c; Robinson et al., 2014). Moglia et al. also developed PCL-diisocyanate (PCL-DI) and PCL-triisocyanate (PCL-TI) based injectable PolyMIPEs without the use of any organic solvents, but curing time at $37^{\circ} \mathrm{C}$ has been reported as $48 \mathrm{~h}$ which limits their clinical applicability (Moglia et al., 2014b). Zhou et al. (2013) reported injectable alginate PolyHIPEs (not HIPEs). Following the preparation of $\mathrm{o} / \mathrm{w}$ HIPEs with methacrylate functionalised alginate, they were thermally set. It was shown that PolyHIPEs could be extruded from a needle by retaining its morphology and further crosslinked using calcium ions. Similarly, Oh et al. (2015) developed injectable poly( $N$-isopropylacrylamide) (PNIPAM) grafted gelatin PolyHIPEs.

\section{Electrospinning}

Electrospinning is a versatile route for the fabrication of the fibres with varying diameters from nanometres to micrometres scale using a wide range of materials (Aldemir Dikici et al., 2019a; Dikici et al., 2019, 2020a,b; Mangir et al., 2019a; Figure 10E). There are many examples of electrospinning of emulsions in the literature (Mangir et al., 2016; Pal et al., 2017; Samanta et al., 2017b), but a few studies reported the electrospinning of HIPEs. Samanta et al. (2016a) reported the fabrication of the PCL electrospun fibres from HIPE. Briefly, PCL (dissolved in toluene) and polyvinyl alcohol (PVA) (dissolved in water) were used for continuous and internal phases, respectively. They showed that increasing the continuous/internal phase ratio reduces the fibre diameter. The same group also reported the electrospinning of solvent-free Pickering PCL HIPEs (Samanta et al., 2016b).

\section{Porous particle manufacturing}

Microporous PolyHIPE particles can be applied to the defect site by injecting and used as substrates for controlled drug delivery (Moglia et al., 2014a; Whitely et al., 2019). They can be created using multiphasic emulsion systems that are mostly water-inoil-in-water (w/o/w) emulsions. The easiest fabrication route 


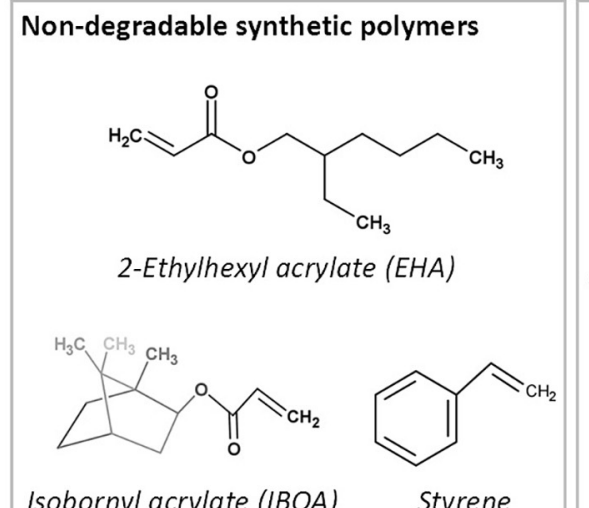

Isobornyl acrylate (IBOA)

Styrene
Degradable synthetic polymers<smiles>CCOCCCCCC(C)=O</smiles><smiles>CC(O)C(C)OC(=O)/C=C/C(=O)OC(C)(C)C(C)O</smiles>

Polycaprolactone (PCL)<smiles>CC(C)C(=O)OCCO</smiles>

Polylactic acid (PLA)
Polypropylene fumarate

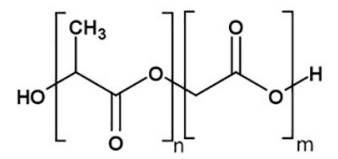

Poly Lactic-co-Glycolic Acid (PLGA)
Functional groups<smiles>C=CC(=O)OC</smiles>

Acrylate<smiles>C=C(C)C(=O)OC</smiles>

Methacrylate<smiles>[R]S</smiles>

Thiol

FIGURE 11 | Commonly used synthetic polymers to prepare emulsion templated matrices.

of porous particles is dropwise addition of w/o emulsion into the water while the system is stirred [controlled stirred-tank reactor (CSTR)]. Although CSTR is practical and does not need a complicated setup, it only enables fabrication of polydisperse particles, and it does not provide an accurate control on particle size. Recently, microfluidic systems gained attention for the fabrication of porous particles due to providing high control over particle size. The process is briefly based on injecting w/o emulsion and water phase into the tubing system using syringe pumps (Figure 10F; Gokmen and Du Prez, 2012). Bead size can be controlled by changing the nozzle size, flow rates of the water phase and emulsion phase. Paterson et al. reported that microfluidics enable the manufacturing of the beads with narrower size distribution compared to particles fabricated using CSTR (Paterson et al., 2018).

\section{Monomers/Macromers \\ Hydrophobic Polymers for the Fabrication of w/o PolyHIPEs}

\section{Non-degradable polymers}

The earliest studies on the development of emulsion templated substrates used styrene as a monomer (Guenther, 1959; Barby and Haq, 1985; Lee et al., 1992a,b; Akay et al., 2000). In 1992, commercial styrene PolyHIPE microcarriers (provided by the company, Microporous Materials) were tested with suspensiongrowing cell lines for the production of a therapeutic protein, and they were found advantageous as being sterilisable, cheap, and suitable for surface functionalisation (Lee et al., 1992a,b). In 1993, human endothelial cells were cultured on the same microcarriers for a similar purpose, and they reported that PolyHIPEs did not support cell growth (Schrimpf and Friedl, 1993). Akay et al. (2000) have a patent on styrene/DVB PolyHIPEs as a cell growth media in 1998. Since then, styrene/DVB is one of the highest reported PolyHIPE materials in the literature.

The blend of acrylate based-monomers; EHA:IBOA is another commonly reported non-degradable material that is mostly solidified using photo-initiated polymerisation (Pierre et al., 2006; Malayeri et al., 2016; Paterson et al., 2018). Owen et al. showed that PolyHIPEs prepared by changing the ratios of EHA or IBOA yield in varying mechanical properties (up to a 60 -fold change) (Owen et al., 2015, 2016).

\section{Degradable polymers}

PCL. As TE scaffolds are desired to be made of biodegradable materials, the development of biodegradable PolyHIPEs is important to satisfy the need of implantable TE constructs (Figure 11). PCL is the earliest biodegradable polymer that has been included in PolyHIPE composition. However, the development of HIPEs made of PCL has been problematic over the years due to the high viscosity of the polymer, which limits the mixing of two phases during emulsification (Busby et al., 2001; Lumelsky et al., 2008, 2009; Lumelsky and Silverstein, 2009).

The earliest reported PolyHIPE made from PCL was created by copolymerisation of PCL diacrylate with non-degradable monomers (Busby et al., 2001). Various diluting solvents were included in HIPE composition to reduce the viscosity of PCL (Busby et al., 2001; David and Silverstein, 2009; Changotade et al., 2015). Johnson et al. reported the incorporation of $76 \%$ PCL triacrylate into HIPE composition when DCE used as a porogenic solvent (Johnson et al., 2015). Recently, we have reported the manufacturing route of PolyHIPEs fully made of photocurable PCL tetra-methacrylate diluted by a solvent blend of chloroform and toluene (Aldemir Dikici et al., 2019b). Also, recently, the development of high molecular weight non-reactive PCL PolyHIPEs has been reported by solvent evaporation (Hu et al., 2015, 2017; Samanta et al., 2016a; Yang et al., 2017).

PLA and PLGA. PLA and its copolymer PLGA are widely used biomaterials for fabrication of TE scaffolds. Busby et al. (2002) reported the development of thermal polymerised PLA diacrylate PolyHIPEs (PLA content up to $40 \%$ ) by diluting the oil phase with methyl methacrylate (MMA). Also, synthesis of PolyHIPEs based on PCL and PLA blends, without the use of any diluents, via ring opening polymerisation also has been reported (Pérez-García et al., 2016). Recently, Hu et al. reported the development of composite HA/PLA (Hu et al., 2014b) and 
HA/PLGA (Hu et al., 2014a) scaffolds by Pickering emulsion templating and solvent evaporation.

$P P F$. PPF, an unsaturated linear polyester, can be easily cured through double-bound on the backbone of the fumarate using various crosslinking agents ( $\mathrm{He}$ et al., 2001). It is commonly suggested to be cured by in situ crosslinking in the defect site (Suggs et al., 1999). Its degradation products are nontoxic monomers (He et al., 2001; Lee et al., 2006). Due to its aforementioned advantages, it has been used in various biomedical applications, including TE scaffolds and orthopaedic implants (Kasper et al., 2009). Fumarate based PolyHIPEs [PPF (Christenson et al., 2007), PFDA (Christenson et al., 2007) and PFDMA (Moglia et al., 2011)], are groups of the well-established biodegradable PolyHIPE compositions.

Christenson et al. (2007) developed PPF PolyHIPEs that can be cured at $60^{\circ} \mathrm{C}$ in $48 \mathrm{~h}$ in the presence of PFDA as a crosslinker. They showed the tunability of the material by changing PPF, PFDA and toluene concentrations. Later on, Moglia et al. (2011) reported the development of injectable solvent-free PFDMA PolyHIPE that can be cured at $37^{\circ} \mathrm{C}$. However, the structures obtained exhibited closed cellular morphology. Robinson et al. (2014) hypothesised that including an oil-soluble initiator into PFDMA PolyHIPE might induce organic phase initiation and this results in open porous monoliths. Indeed, they have used both an oil-soluble initiator; BPO and a water-soluble initiator, APS, and PolyHIPEs with BPO showed open-porosity. However, the curing time of the HIPEs was still long (overnight) for the ultimate aim of in situ crosslinking (Robinson et al., 2014). Moglia et al. used the redox initiated polymerisation rather than thermal initiation in order to reduce the curing time. They created two PolyHIPE compositions; one with BPO as an initiator and other with trimethylaniline (TMA) as reducing agent and used a syringe with the double barrel for the injection of the emulsion and enabled polymerisation of HIPEs just in $15 \mathrm{~min}$ (Moglia et al., 2014c).

Thiol (ene/yne). Thiol(ene/yne) chemistry [also classified as click chemistry (Hoyle and Bowman, 2010)] is the reaction between a thiol and an alk(ene/yne) to thioether. This high yield reaction has recently gained attraction in various applications, including the development of thiol(ene/yne) PolyHIPEs (Lovelady et al., 2011; Caldwell et al., 2012; Johnson et al., 2015).

Lovelady et al. (2011) reported the development of thiol(ene/yne) PolyHIPEs. In the follow-up study, Caldwell et al. developed TMPTA and dipentaerythritol penta/hexa-acrylate (DPEHA)-based thiolene PolyHIPEs and showed the dependency of mechanical properties to monomer selection (Caldwell et al., 2012). Johnson et al. (2015) reported the development of photocurable PCL triacrylate thiolene PolyHIPEs with up to 95\% interconnected porosity. The degradation products have been shown to be non-toxic on fibroblasts up to a concentration of $0.1 \mathrm{mg} / \mathrm{mL}$. Whitely et al. also developed thiolene PolyHIPEs made of tetra-functional thiol, pentaerythritol tetrakis-3mercaptoproprionate, and PFDMA (Whitely et al., 2017), and they showed the hydrolytic and accelerated degradation profiles of these scaffolds.

\section{Hydrophilic Polymers for the Fabrication of o/w PolyHIPEs}

In 1997, Naotaka Kitagawa described the development of hydrophilic PolyHIPEs (Kitagawa, 2001). Since then, a number of naturally derived polymers have been used to fabricate PolyHIPEs from $\mathrm{o} / \mathrm{w}$ emulsions. These matrices have the advantages of being hydrophilic, biocompatible and biodegradable, often similar to extracellular matrix (ECM) components to be used as materials for the fabrication of TE scaffolds. However, they have the disadvantages of having a high degree of batch-to-batch variability and comparably lower mechanical strength than synthetic counterparts (Cheung et al., 2007; Shoichet, 2010).

Gelatin is one of the most commonly used natural biopolymers for the fabrication of TE scaffolds. As it is derived from collagen of skin, bone or tendon of animals, it is highly abundant and cost-effective (Hoque et al., 2015). In 2005, Barbetta et al. successfully developed gelatin-methacrylate PolyHIPEs with up to 95\% internal phase using FRP (Barbetta et al., 2005b). Following this, they also reported the development polysaccharides; dextran and pullulan methacrylate PolyHIPEs (Barbetta et al., 2005a). They also developed gelatin PolyHIPEs that are solidified via enzymatic crosslinking (Barbetta et al., 2006). Although PolyHIPEs obtained via FRP of gelatin exhibited better-defined morphology, enzymatically crosslinked PolyHIPEs were found less toxic on hepatocytes and showed an improved expression of adhesion proteins (Barbetta et al., 2006). Oh et al. (2015) developed gelatin PolyHIPEs by grafting gelatin with poly( $N$-isopropylacrylamide) (PNIPAM). Due to the amphiphilic nature of gelatin-graft-PNIPAM as a continuous phase, they managed to incorporate an internal phase of up to $90 \%$ without the use of any surfactants. Recently Yuan et al. (2019) reported the fabrication of gelatin PolyHIPEs with 92\% porosity by two-step crosslinking and freeze-drying. Alginate, a polysaccharide derived from seaweed, is another biomaterial that can be used to fabricate PolyHIPE scaffolds (Barbetta et al., 2009; Zhou et al., 2013). Krajnc et al. (2005) also reported the development of o/w HIPEs from a synthetic hydrophilic monomer, acrylic acid.

\section{Post-processes Improving the Biomimetic Behaviour of the PolyHIPE Scaffolds}

The suitability of the morphology of PolyHIPE matrices to be used as TE scaffolds has been well-accepted. However, as PolyHIPEs are most commonly created using w/o emulsions, they are highly hydrophobic, and lack of functionality which limits their interaction with biological tissues (Richardson et al., 2019). Thus, starting from the early 2000s, researchers started to explore the ways of enhancing the biological activities of the PolyHIPE scaffolds using various methods such as chemical functionalisation (Aldemir Dikici et al., 2019a), incorporation of the hydrophilic particles such as HA (Akay et al., 2004; Wang et al., 2016), incorporation of a single biologically active agent (Ratcliffe et al., 2019; Richardson et al., 2019), or decoration PolyHIPEs with 
cell-derived in vitro generated ECM (Aldemir Dikici et al., 2020; Table 2).

\section{Chemical functionalisation}

The surface of the scaffolds can be modified to create functional groups that act as hooks for biomolecules and cells. Amines, hydroxyl, carbonyl, carboxyl, epoxy groups, and thiols are the functional groups generally used to improve cell-material interaction or enabling the incorporation of other biomacromolecules into the scaffolds (Richbourg et al., 2019). A wide range of techniques can be used for chemical functionalisation of PolyHIPEs (Kircher et al., 2013a). There are two main approaches for chemical functionalisation of PolyHIPEs; (i) incorporating co-monomers with desired functionality into HIPE composition and (ii) post-functionalisation of PolyHIPEs. Although the first approach seems convenient as the functionality can be improved using a one-step route, incorporating hydrophilic monomers may cause destabilisation of the emulsion, results in bigger pores, and less well-defined morphology (Kircher et al., 2013b). The second

TABLE 2 | Various functionalisation strategies for PolyHIPE scaffolds from the literature.

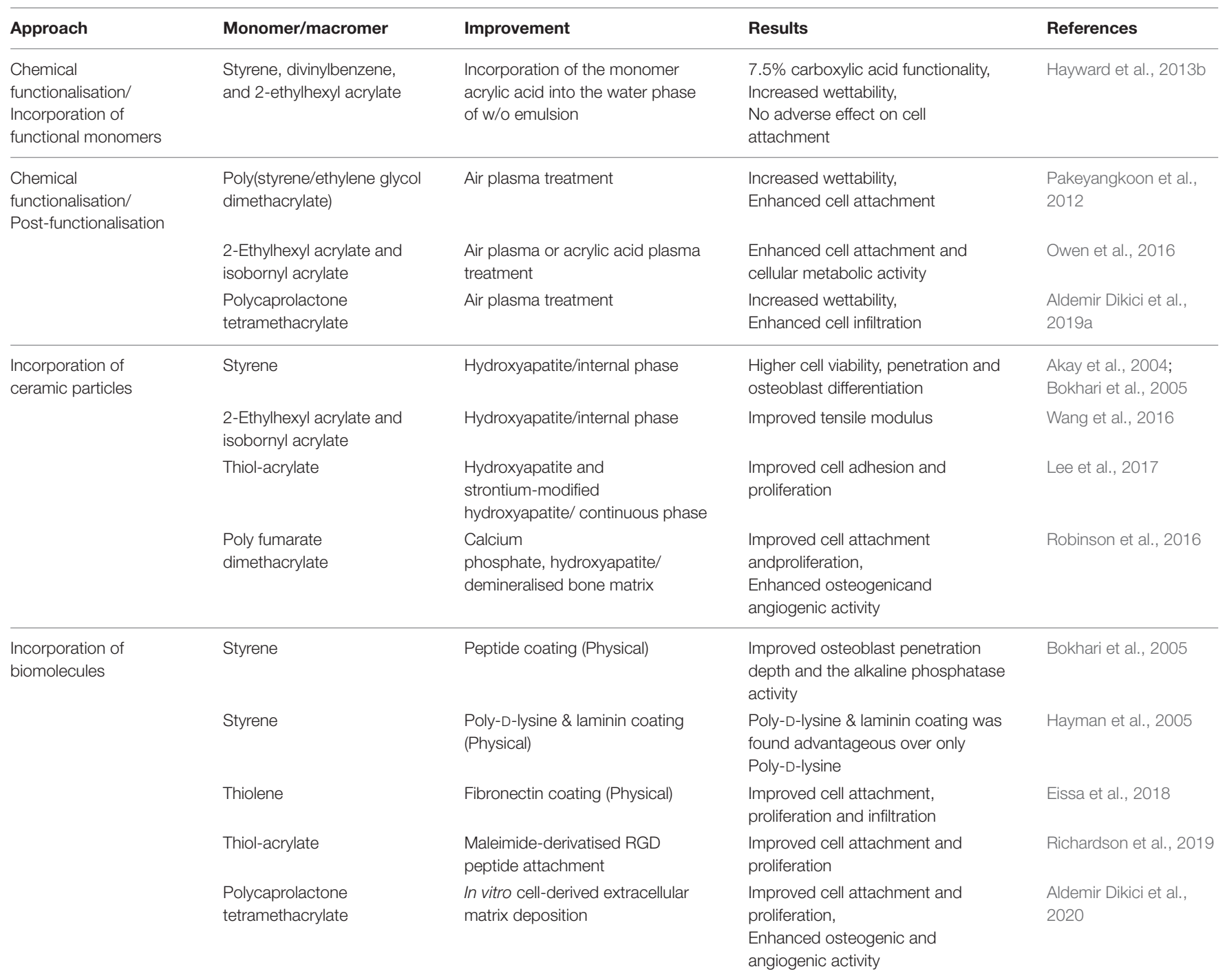

Chemical

functionalisation/

Incorporation of

functional monomers +

Incorporation of

biomolecules
Thiol-acrylate

Functionalisation with sulfo-SANPAH + Covalent

fibronectin attachment
Improved cell attachment and infiltration
Richardson et al., 2019
Pakeyangkoon et al.

Owen et al., 2016

Aldemir Dikici et al. Akay et al., 2004 Bokhari et al., 2005

Wang et al., 2016

Lee et al., 2017

Robinson et al., 2016

$-$

.


approach enables the introduction of functional groups without changing the morphology of the PolyHIPEs.

Hayward et al. incorporated acrylic acid into the water phase of the styrene/DVB/EHA PolyHIPE, and they verified the success of the carboxylic acid functionalisation by X-ray photoelectron spectroscopy, wettability analysis, and toluidin blue staining (Hayward et al., 2013b).

Post-polymerisation of thiol-acrylate PolyHIPEs has also been reported. During the polymerisation of thiol-acrylate, there are two competing addition reactions that occur; the first one is between thiols and acrylates, and the second one is between acrylates and acrylates. With a stoichiometric thiol to acrylate ratio, the occurrence of the second reaction will result in the presence of unreacted residual thiols. These can be used for further functionalisation using various reactions, such as thiolene click chemistry (Langford et al., 2014) or Michael addition reaction (Ratcliffe et al., 2019).

Plasma treatment is one of the most common and effective ways of post-functionalisation to promote hydrophilicity of the polymer surfaces by adding polar groups to the surface of the material without altering the bulk properties (Jokinen et al., 2012; Abedalwafa et al., 2013; Valence et al., 2013; Shafei et al., 2017; Ivanova et al., 2018). Owen et al. showed that both air and acrylic acid plasma treatment improved the attachment and proliferation of mesenchymal progenitors on acrylate-based PolyHIPEs, whereas untreated scaffolds did not support cell attachment (Owen et al., 2015, 2016). Pakeyangkoon et al. reported that water contact angle on poly(styrene/ethylene glycol dimethacrylate) PolyHIPE dramatically dropped and attachment of fibroblast-like cells on PolyHIPEs improved after air plasma treatment of the scaffolds (Pakeyangkoon et al., 2012). Recently, we reported that air plasma treatment improved the wettability of highly hydrophobic polymer, PCL PolyHIPEs, and it enhanced infiltration of bone cells through PolyHIPE scaffolds (Aldemir Dikici et al., 2019a).

\section{Incorporation of ceramic particles}

Incorporating $\mathrm{HA}$, a bioceramic that is present in native bone with a percentage of $70 \%$, within a scaffold is a common approach to improve the biocompatibility, osteoconductivity, and osteoinductivity of polymer-based bone TE scaffolds. Although emulsions are metastable systems that are readily destabilised by incorporation of additional particles, many researchers have managed to incorporate nano/micro HA particles into the various PolyHIPE compositions to improve the biological or mechanical properties of PolyHIPEs rather than using HA as Pickering particle.

HA is commonly included in HIPE composition before emulsification. It can be added either into the oil phase or into the water phase. Akay and Bokhari et al. incorporated commercially available HA into the water phase of the w/o PolyHIPEs to be able to locate the HA particles only on the surface of the pores. They showed that $0.5 \%$ HA (of the aqueous phase) incorporated DVB/styrene PolyHIPE increased the viability of cells, cell penetration into the scaffolds, and osteoblast differentiation in vitro (Akay et al., 2004; Bokhari et al., 2005). Wang et al. (2016) incorporated 4-32\% HA that was synthesised in house into the water phase of the EHA:IBOA
PolyHIPE. No pore size difference was observed between groups except that $32 \%$ HA incorporated HIPEs showed reduced stability and increased pore size. However, the tensile modulus of this group was increased more than twofold in comparison to the control group, probably due to having bigger pore sizes. Lee et al. (2017) incorporated (5-10\%) HA and strontium-modified HA into a PolyHIPE composition by adding it into the oil phase of the emulsion. HA incorporation increased the pore size distribution with increasing concentration and significantly increased the compressive strength. Although it was incorporated into the oil phase, SEM/Energy Dispersive X-Ray Analysis (EDX) images showed the presence of HA particles on the surface of the scaffolds. Incorporation of HA, particularly strontiummodified HA, increased cell adhesion and proliferation when compared to unmodified PolyHIPE. Similarly, Robinson et al. incorporated $2 \mathrm{wt} \%$ calcium phosphate nanoparticles, $5 \mathrm{wt} \% \mathrm{HA}$ nanoparticles, and $15 \mathrm{wt} \%$ demineralised bone matrix (DBM) particles into injectable PFDMA HIPEs (Robinson et al., 2016). Particles affected neither the emulsion stability nor the pore size of the PolyHIPEs. Similar to the results of Lee et al., although the particles were added into the oil phase of the emulsion, transmission electron microscopy (TEM) images showed the localisation of the particles on the surface unless they aggregated.

\section{Incorporation of biomolecules}

Incorporation of the biomolecules into the composition of PolyHIPE scaffolds requires moderate operation conditions in terms of temperature and solvents. Biomolecules such as peptides and ECM proteins can be either covalently attached to the surfaces or physically absorbed/coated to the PolyHIPEs.

Robinson et al. applied biologically inspired self-assembling peptide hydrogel into HA-doped styrene PolyHIPEs via cell seeding suspension. Osteoblast penetration depth and the alkaline phosphatase (ALP) activity have been shown to be increased in comparison with the control (Bokhari et al., 2005). Hayman et al. used Poly-D-lysine and laminin coating on DVB/styrene PolyHIPEs and showed the advantages of PolyD-lysine and laminin coating over only Poly-D-lysine coating in terms of increasing the mean neurite length (Hayman et al., 2004, 2005). Eissa et al. (2018) reported that fibronectin coating of thiolene PolyHIPEs significantly increased the attachment, proliferation and infiltration of primary human endometrial epithelial and stromal cells when compared to the uncoated PolyHIPEs.

Richardson et al. functionalised thiol-acrylate PolyHIPE scaffolds with covalent attachment of fibronectin using a two-step procedure. First, they functionalised PolyHIPEs with $\quad N$-sulfosuccinimidyl-6-(4'-azido-2' ${ }^{\prime}$-nitrophenylamino hexanoate (sulfo-SANPAH)), which is a photo-linker compound that enables conjugation of biomolecules to the surfaces, and then they further functionalised the surface by covalent attachment of fibronectin to sulfo-SANPAH molecule. An improved cell attachment and infiltration of human endometrial stromal cells have been found when compared to unmodified, just sulfoSANPAH functionalised, and fibronectin-absorbed (physically) PolyHIPEs (Richardson et al., 2019).

Ratcliffe et al. functionalised thiol-acrylate PolyHIPE using maleimide-derivatised cyclo-arginine-glycine-aspartate (RGD) 
peptide by benefiting from the reaction between the unreacted thiols in PolyHIPE and the maleimide. While non-functionalised scaffolds did not support attachment and proliferation of human embryonic stem cells, PolyHIPEs functionalised with RGD showed significantly higher proliferation and infiltration rate (Ratcliffe et al., 2019).

Hayward et al. incorporated pentafluorophenyl acrylate (PFPA) into the oil phase of the styrene HIPE to be able to conduct a coupling reaction between ester groups of PFPA and galactose afterward, as hepatocytes are known to have specific receptors that bind to galactose. Hepatocytes have been shown to proliferate on the functionalised scaffold, and they showed significantly higher activity on galactose functionalised PolyHIPEs in terms of albumin synthesis compared to cells cultured on unmodified PolyHIPEs (Hayward et al., 2013a).

In our recent study, we decorated 3D printed PCL PolyHIPE scaffolds with in vitro cell generated bone ECM rather than a single biologically active agent (Aldemir Dikici et al., 2020). This collagen and mineral-rich ECM coating was shown to improve attachment and proliferation of human mesenchymal progenitor cells (hES-MPs). Both angiogenic and osteogenic activities of biohybrid scaffolds were found to be significantly higher than the activities of the non-coated PolyHIPEs (Aldemir Dikici et al., 2020).

\section{Washing}

Following the fabrication of the emulsion templated scaffolds, typically a series of washing steps need to be applied to remove uncured material and residual surfactant. Insufficient washing of scaffolds may cause a toxic effect on cells. Also, they may give false colour changes on colourimetric cell viability assays such as MTT (3-[4, 5-dimethylthiazol-2-yl]-2, 5 diphenyl tetrazolium bromide) and resazurin reduction. The washing process can be conducted by either series of manual soakings in selected solvents or using Soxhlet extractor.

The solubilities of the materials that need to be removed should be considered for the selection of the washing solvent. Acetone is one of the commonly used solvents for washing of PolyHIPEs due to the high solubility of a wide range of polymers in acetone (Caldwell et al., 2012; Hayward et al., 2013a; Richardson et al., 2019). In our recent studies, we have used methanol instead of acetone due to it being less toxic and less destructive to crosslinked monoliths (Aldemir Dikici et al., 2019a,b). There are also studies reported using different solvents such as isopropanol (Bokhari et al., 2005) or combinations of multiple solvents (Krajnc et al., 2005; Zhou et al., 2013).

A limited number of studies have reported the effect of the washing method, duration and the choice of solvent on the features of PolyHIPE. Pakeyangkoon et al. showed that duration of solvent extraction has an impact on the surface area and mechanical properties of the PolyHIPEs (Pakeyangkoon et al., 2008). While an extraction time of between $6 \mathrm{~h}$ and $12 \mathrm{~h}$ improves the surface area and mechanical properties compared to non-extracted samples, mechanical properties become poorer than control when the extraction time is longer than $12 \mathrm{~h}$.

\section{Sterilisation}

TE scaffolds should be free of contamination by living organisms such as bacteria and viruses for in vitro and in vivo tests and also for implantation to the human body. There are various methods used for this purpose, such as treatments with heat (Fleith et al., 2005; Yoganarasimha et al., 2014), gamma irradiation (Fleith et al., 2005), UV (Andrews et al., 2007), plasma (Poncin-Epaillard and Legeay, 2003; Griffin et al., 2018), ethylene oxide (Andrews et al., 2007; Yoganarasimha et al., 2014), ethanol (Griffin et al., 2018), and peracetic acid (Yoganarasimha et al., 2014). As the efficiency of the methods in terms of the degree of removal/inactivation of microorganism varies, it might be appropriate to clarify the difference between the terms of disinfection and sterilisation. While disinfection reduces the number of organisms present, this method cannot provide removal of all microorganisms, including spores. However, sterilisation indicates the removal of all kind of microorganisms including spores (Lerouge and Simmons, 2012). Most common sterilisation techniques in the clinics are ethylene oxide, gamma irradiation, and heat treatment. However, some of these methods have been found to cause compositional changes in the biomaterials (Fleith et al., 2005; Rogers, 2012; Dai et al., 2016).

Ethanol and UV treatment are commonly used for inactivation of the microorganisms on biomaterials for in vitro applications. However, ethanol treatment cannot inactivate bacteria spores, non-enveloped viruses, and prions. UV treatment works by damaging the DNA of microorganisms, and the major drawback of this technique is the limited penetration depth of UV. In addition, it was also found to be insufficient for inactivation of mycobacteria, bacteria spores, non-enveloped viruses, and prions. Thus, ethanol and UV treatments are categorised as medium level inactivation methods (Dai et al., 2016).

The sterilisation/disinfection method of the scaffolds should be selected by considering the material properties, application type, and experiment duration. Inactivation of microorganism on PolyHIPE scaffolds was commonly reported by using ethanol (Hayman et al., 2005; Caldwell et al., 2012; Moglia et al., 2014c; Eissa et al., 2018). There are also several studies that reported the use of UV irradiation (Moglia et al., 2011; Oh et al., 2015), gamma-irradiation (Yang et al., 2017), electron-beam irradiation (Hu et al., 2019), and autoclave (Naranda et al., 2016; Paljevac et al., 2018). Future studies investigating the effect of sterilisation methods on physical, chemical, and mechanical properties of emulsion templated scaffolds are needed to establish a greater degree of understanding of this matter.

\section{PolyHIPEs IN TE APPLICATIONS}

\section{In vitro Models}

In 2018, 3.53 million procedures involving living animals were conducted in the United Kingdom, and 56\% of these procedures were for basic research purposes (Home Office, 2018). Although animal models are the gold standard due to their better ability to mimic complex human physiology, the 3R approach; replacing, reducing and refining of animal-based tests, should also be 
considered where possible (Peric et al., 2015). As an alternative to these in vivo platforms, the use of in vitro models has gained attention in various research areas such as; testing new drugs, studying diseases and monitoring of the natural behaviour of the cells at different scales (Owen and Reilly, 2018). In vitro models aim to mimic the natural environment of the cells isolated from the body in architectural, mechanical and biological aspects to be able to encourage cells to behave the similar way as they would behave in their own niche in vivo.

Cells populated in 2D tissue culture plates (TCPs) are known not to be a good representative of the in vivo environment of the cells. Cells grown in $2 \mathrm{D}$ have shown to have flattened morphology opposed to their stretched 3D morphology in vivo, and they have been reported to have less similar gene expression profiles to that observed in vivo (Abbott, 2003).

Non-degradable or slow-degrading 3D emulsion templated substrates are attractive in vitro test platforms due to their tunability in the physical and mechanical properties for different applications, ease of fabrication, reproducibility, and stability for long term experiments (Eissa et al., 2018).

Styrene PolyHIPEs have been used as an in vitro platform by many researchers. Hayman et al. proposed the differentiation behaviour of human pluripotent stem cell-derived neurons to be studied in vitro on styrene PolyHIPEs (Hayman et al., 2004, 2005). Bokhari et al. showed that styrene PolyHIPEs showed better results over TCP in terms of cell viability, ALP activity, and osteocalcin secretion of MG63 osteoblast-like cells, and better represents an in vivo environment (Bokhari et al., 2007b). The same group also cultured hepatic carcinoma cells on polystyrene PolyHIPE and proposed this system to be used as in vitro platform to study toxicity and screening of drugs (Bokhari et al., 2007a). Similarly, Sun et al. (2019) used styrene PolyHIPEs as a 3D tissue model to study the cytotoxicity of the cigarette smoke. Polystyrene PolyHIPE is also commercially available $\left(\right.$ Alvetex $\left.^{\circledR}\right)$. Costello et al. developed a multi-layered skin equivalent on these scaffolds and suggested its use for disease modelling and testing of cosmetics' active compounds (Costello et al., 1993).

Non-degradable EHA and IBOA PolyHIPEs were also shown to support bone cell proliferation (Malayeri et al., 2016; Sherborne et al., 2018) and osteosarcoma growth (Malayeri et al., 2016), and they were suggested as an in vitro platform to study tumour tissue (Malayeri et al., 2016). Eissa et al. proposed DPEHA and trimethylolpropane tris(3mercaptopropionate) (trithiol) PolyHIPEs as an in vitro model that could mimic native human endometrial architecture and function (Eissa et al., 2018).

Severn et al. (2019) revealed that functionalised thiolene PolyHIPEs are promising platforms to mimic the bone marrow niche. Recently, Dikici et al. developed a 3D dynamic in vitro model using tubular PCL PolyHIPEs combined with electrospun PCL tubes that can be used for the testing of angiogenic agents (Figure 12D; Dikici et al., 2020a). In the developed dynamic system, PCL PolyHIPE was found to be a suitable environment for comparison of the infiltration capacity of endothelial cells in response to different pro-angiogenic factors.

\section{PolyHIPEs as TE Scaffolds}

Tissues in the body are subjected to various mechanical forces including compression, tension, torsion, and bending, and have some mechanical features such as; Young's modulus, toughness, elasticity, tensile, and compressive strength. These mechanical features vary depending on tissue type and function. Mechanical properties of the scaffolds are required to match with the mechanical properties of the host tissue to avoid over/under mechanical loading and undesirable, heterogeneous stress distribution. The required Young's modulus of scaffolds are reported to be in the range of 10-1,500 $\mathrm{MPa}$ and $0.4-350 \mathrm{MPa}$ for hard and soft tissues, respectively (Hollister, 2005). Also, cells can sense and respond to the mechanical forces in their microenvironments (mechanosensitivity). Thus, the elasticity of the surface that cells are attached to is also known to affect cell behaviour, such as differentiation to specific phenotypes (Bershadsky et al., 2003; Engler et al., 2006).

\section{PolyHIPEs for Hard TE}

In hard TE, it is highly desirable to fabricate porous scaffolds with adequate strength and Young's Modulus. Thus, PolyHIPE scaffolds made from synthetic polymers are preferable over naturally sourced polymers for hard TE applications due to their comparatively higher mechanical strength.

Akay et al. (2004) showed the biocompatibility of HA incorporated DVB-styrene scaffolds up to 35 days using primary rat osteoblasts. They penetrated up to $1.4 \mathrm{~mm}$, differentiated and formed mineralised matrix (Akay et al., 2004).

We have recently investigated the potential use of PCL PolyHIPE scaffolds for guided bone regeneration (Figure 12A; Aldemir Dikici et al., 2019a). We showed that murine longbone osteocytes (MLO-A5s) attached, proliferated and infiltrated throughout the interconnects of the PCL PolyHIPE scaffolds. Suitability of the pores for blood vessel ingrowth was also shown using chick chorioallantoic membrane (CAM) assay (Figures 13L-O; Aldemir Dikici et al., 2019a, 2020).

Moglia et al. developed injectable PFDMA PolyHIPEs with an average compressive modulus and strength of 33 and $5 \mathrm{MPa}$ and showed up to $95 \%$ initial cytocompatibility of fibroblasts after 24 h (Moglia et al., 2011). Whitely et al. (2018) have developed an in situ cell seeding approach for 3D printed PFDMA HIPEs to be used as bone regeneration strategy. They successfully showed the homogeneous seeding of human mesenchymal stem cells (hMSCs) all over the scaffold. HMSCs on scaffolds were mineralised and showed higher ALP activity compared to hMSCs on TCP.

Langford et al. (2015) reported the fabrication of bilayer thiol-acrylate PolyHIPEs made of two different HIPE compositions. They obtained PolyHIPE structures with different morphologies and suggested their use as scaffolds for the tissues that require layered designs such as ligaments, tendons, and bone attachments (Figure 12B).

Naranda et al. (2016) developed thiolene PolyHIPEs for cartilage regeneration and showed that PolyHIPE scaffolds fully degraded via accelerated degradation and lost $55 \%$ of their weight in PBS in 4 weeks. The Young's modulus of the scaffolds was 

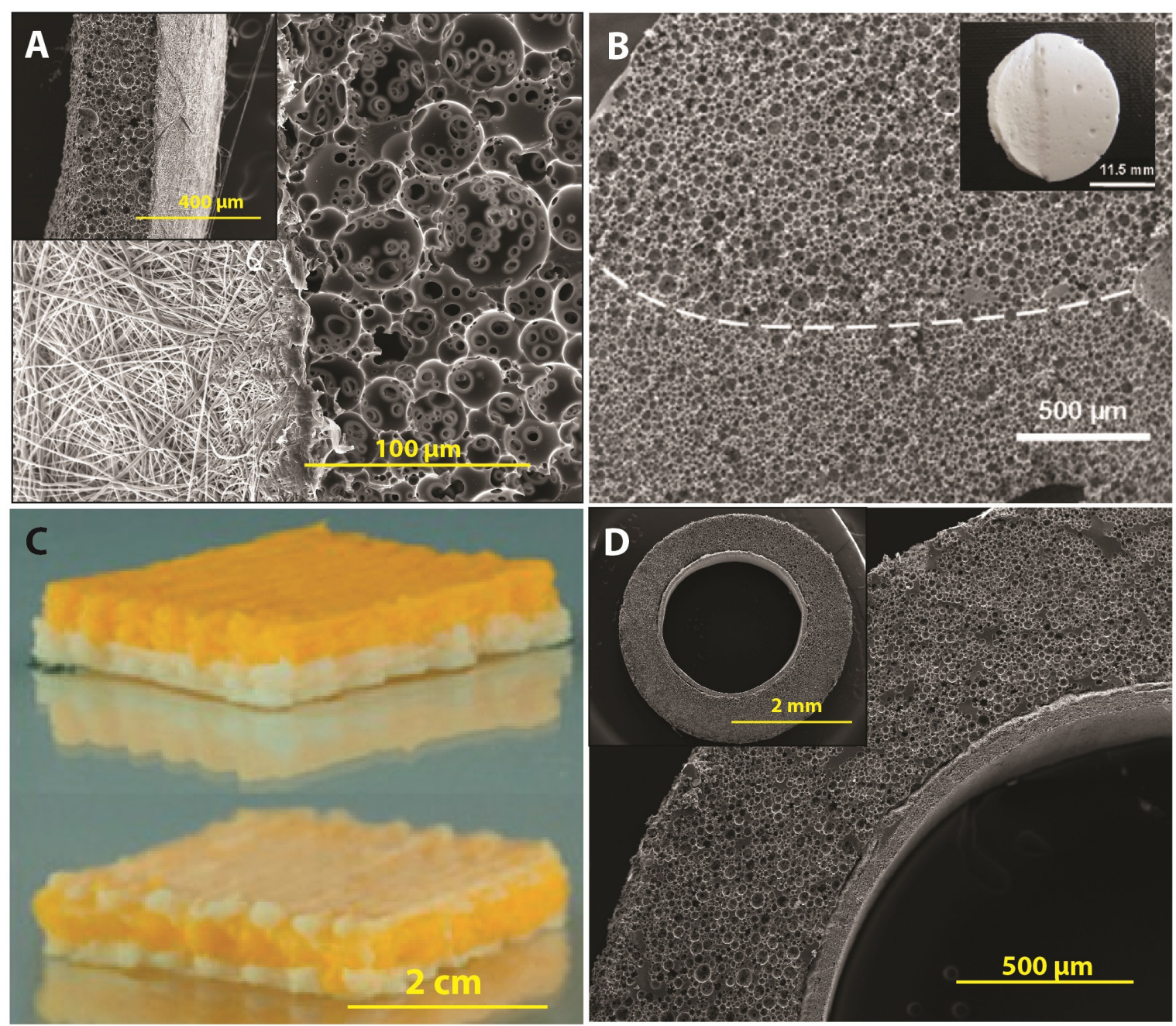

FIGURE 12 | Hybrid PolyHIPE scaffolds with multiple layers: (A) emulsion templating combined with electrospinning for development of a membrane for guided bone regeneration, (B) PolyHIPEs with two different morphologies, (C) 3D printing of drug-loaded and drug-free HIPEs selectively, and (D) emulsion templating combined with electrospinning in a tubular form for the development of in vitro angiogenesis model. Images (A,D) were reproduced with permission from Ref. Aldemir Dikici et al. (2019a) and Dikici et al. (2020a), respectively, under The Creative Commons License. Image (B) was adapted with permission from Langford et al. (2015), Copyright 2015 John Wiley and Sons. Image (C) was adapted with permission from Yang et al. (2017), Copyright 2017 American Chemical Society.

measured as $0.15 \mathrm{MPa}$ as prepared and $0.18 \mathrm{MPa}$ after 20day culture of primary human chondrocytes on the scaffolds. Collagen type-II deposition and gene upregulation were shown using immunostaining and PCR, respectively.

\section{PolyHIPEs for Soft TE}

The two main components of soft tissues, such as skin, nerve, fascia, and blood vessels, are elastin and collagen, which both of them have very high water content (De Santis et al., 2004). Thus, hydrogels are preferable candidates to be used as scaffold materials for soft TE (Landers et al., 2002).

Barbetta et al. reported that dextran PolyHIPEs supports penetration and colonisation of the neurons into the inner cavities of the scaffold (Barbetta et al., 2005a). Murphy et al. showed that TMPTA, 1,6-hexanediol diacrylate (HDDA) and PEGDA thiolene PolyHIPEs support proliferation, differentiation and infiltration of induced pluripotent stem cell (iPSC)-derived human neural progenitor cells (hNPCs) (Murphy et al., 2017). Especially the PEGDA PolyHIPE was found to be a favourable substrate for hNPCs culture due to the similarity of its mechanical properties to the native human brain. Recently, the same group further explored the ability of laminin-coated PEGDA PolyHIPE for the culture of humaninduced pluripotent stem cell- and embryonic stem cell-derived neural precursor cells (hPSC-NPCs) in 45-day culture period (Murphy et al., 2020).

Luo et al. developed surfactant-free and solvent-free PolyHIPEs and showed the proliferation of fibroblasts and cardiac muscle cells on PVA PolyHIPE hydrogels (Luo et al., 2015b). Recently, we showed cell viability and attachment of human dermal fibroblasts (HDFs) on PCL PolyHIPEs in comparison with commercially available styrene PolyHIPE 

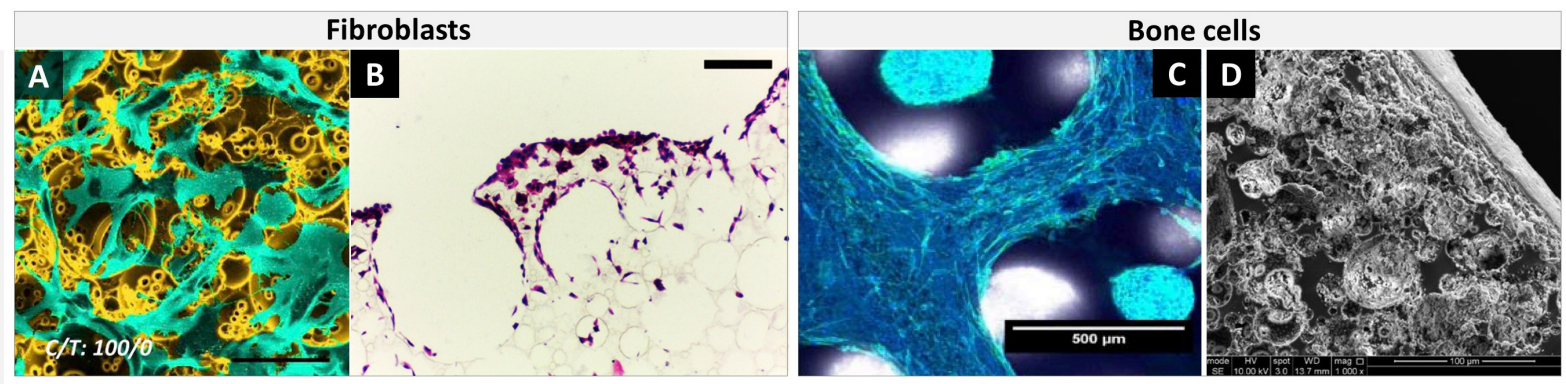

Mesenchymal stem cells

Mesenchymal progenitors

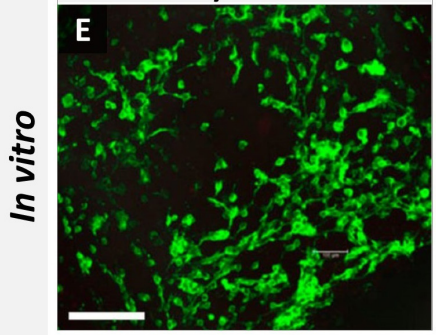

Neuronal cells

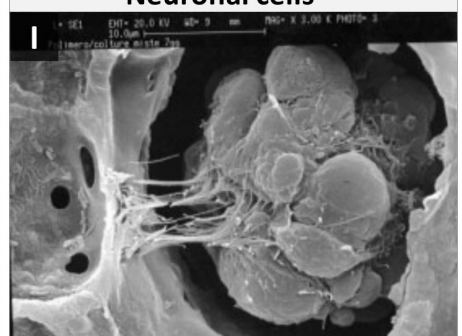

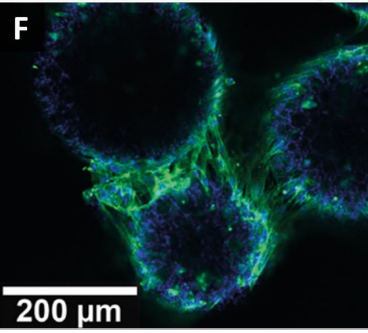

Cardiac muscle cells

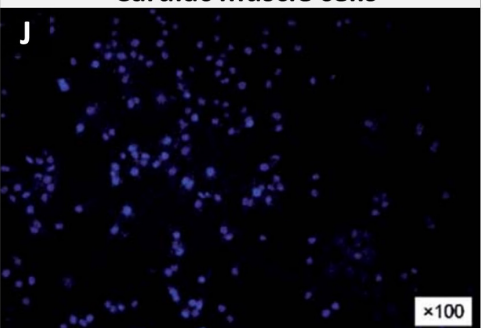

Endothelial cells

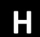

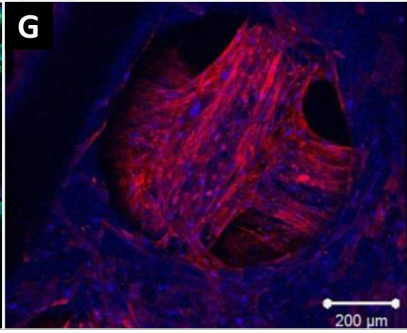

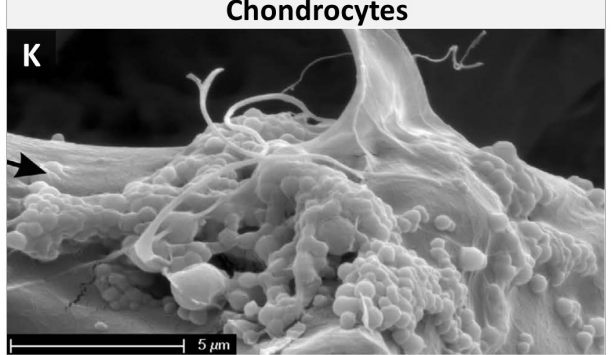

Chick chorioallantoic membrane assay
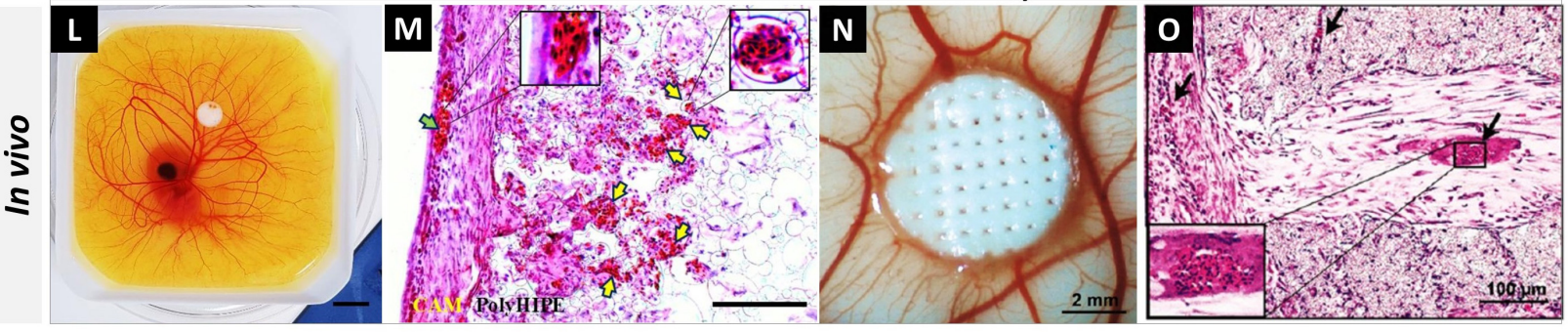

FIGURE 13 | Tissue engineering applications of emulsion templated scaffolds. (A) False coloured scanning electron microscopy (SEM) image of human dermal fibroblasts on PCL PolyHIPE (Aldemir Dikici et al., 2019b) (scale bar: $250 \mu \mathrm{m}$ ), (B) H\&E image of L929 fibroblasts on thiolene PolyHIPE (Johnson et al., 2015) (scale bar: $200 \mu \mathrm{m}$ ), (C) confocal microscopy image of MG63 bone cells on EHA:IBOA PolyHIPE (DAPI and Phalloidin-FITC) (Malayeri et al., 2016$)$ (scale bar: 500 $\mu$ m), (D) SEM image of murine long-bone osteocytes (MLO-A5s) on PCL PolyHIPE (Aldemir Dikici et al., 2019a) (scale bar: 100 $\mu$ m), (E) confocal microscopy image of mouse bone mesenchymal stem cells (mBMSCs) on PCL PolyHIPE (Calcein-AM staned) (Yang et al., 2017) (scale bar: 200 $\mu$ m), (F) confocal microscopy image of human embryonic stem cell-derived mesenchymal progenitor cells (hES-MPs) on EHA:IBOA PolyHIPE (DAPI and Phalloidin-FITC) (Paterson et al., 2018) (scale bar: $200 \mu \mathrm{m}$ ), (G) confocal microscopy image of hES-MPs on EHA PolyHIPE (DAPI and Phalloidin-TRITC) (Owen et al., 2016) (scale bar: 200 $\mu \mathrm{m}),(\mathbf{H})$ fluorescent microscopy image of human aortic endothelial cells (HAECs) on PCL PolyHIPE (Phalloidin-TRITC) (Dikici et al., $2020 a)$ (scale bar: 200 $\mu$ m), (I) SEM image of mix nerve cells (extracted from mice retina) on dextran PolyHIPE (Barbetta et al., 2005a) (scale bar: $10 \mu \mathrm{m}$ ), (J) fluorescent microscopy image of cardiac muscle cells (H9c2s) on polyacrylamide PolyHIPE (DAPI) (Luo et al., 2015a), (K) SEM image of human articular chondrocytes on polyester PolyHIPE (Naranda et al., 2016) (scale bar: $5 \mu \mathrm{m}$ ), (L) PCL PolyHIPE on chick chorioallantoic membrane (CAM) (Aldemir Dikici et al., 2019a) (scale bar: 10 mm), (M) H\&E image of PCL PolyHIPE on CAM at day 14 (green arrow indicates the blood vessel on the CAM itself; yellow arrows indicate the blood vessels in PCL PolyHIPE (Aldemir Dikici et al., 2019a) (scale bar: $100 \mu \mathrm{m}$ ), (N) in vitro bone ECM decorated 3D printed PCL PolyHIPE on CAM (Aldemir Dikici et al., 2020) (scale bar: 2 mm), (O) H\&E image of in vitro bone ECM decorated 3D printed PCL PolyHIPE on CAM at day 14 (black arrows indicate the blood vessels) (Aldemir Dikici et al., 2020) (scale bar: 100 $\mu \mathrm{m}$ ). Images were reproduced with permission from the indicated references. Images (A,C,D,F,G,H,K) were adapted from Aldemir Dikici et al. (2019b), Malayeri et al. (2016), Aldemir Dikici et al. (2019a), Paterson et al. (2018), Owen et al. (2016), Dikici et al. (2020a), and Naranda et al. (2016), respectively, Images (L,M) were adapted from Aldemir Dikici et al. (2019a), images (N,O) were adapted from Aldemir Dikici et al. (2020), under The Creative Commons License. The image (B) was adapted with permission from Johnson et al. (2015), Copyright 2015 Royal Society of Chemistry. Image (E) was adapted with permission from Yang et al. (2017), Copyright 2017 American Chemical Society. The image (I) was adapted with permission from Barbetta et al. (2005a), Copyright 2005 John Wiley and Sons. Image (J) was adapted with permission from Luo et al. (2015a), Copyright 2015 Royal Society of Chemistry. 
scaffold (Aldemir Dikici et al., 2019b). SEM images of the HDFs suggested that the pore size of the PolyHIPEs have a profound effect on the orientation of the cells.

Moglia et al. developed injectable PCL PolyMIPEs with 20-200 $\mathrm{KPa}$ and 4-60 $\mathrm{KPa}$ compressive moduli and strengths, respectively. They suggested their use for soft tissue regeneration and showed the initial cytocompatibility of PolyHIPEs with the activity of hMSC higher than $95 \%$ after $72 \mathrm{~h}$ (Moglia et al., 2014b).

\section{Drug-Releasing PolyHIPEs}

Controlled release of drugs and bioactive molecules is desired for accelerating tissue regeneration, controlling biological responses or inhibiting pathology. PolyHIPEs are good candidates to elute drugs in a controlled manner as the surface area of these matrices can be precisely engineered. However, there is only a limited number of studies reported the PolyHIPE matrices as drug delivery tools.

Yang et al. (2017) incorporated enrofloxacin (ENR) solution (in DCM), a veterinary wide-spectrum antibiotic, into the oil phase of the PCL HIPEs. They also showed the possibility of fabricating scaffolds using two different inks (drug-loaded and non-loaded) for the selective construction of drug-loaded parts (Figure 12C). Drug-loaded PolyHIPEs showed a rapid release profile with 80 and $98 \%$ release in 2.5 and $10 \mathrm{~h}$, respectively. $\mathrm{Hu}$ et al. dissolved ibuprofen, an anti-inflammatory drug, in the oil phase of PCL HIPE to create ibuprofen releasing PolyHIPE scaffolds ( $\mathrm{Hu}$ et al., 2019). Burst release of the drug (75-90\% for various compositions) was observed within the first $8 \mathrm{~h}$. The release profile has been shown to be controllable by changing the concentration of the PCL. More research on the development of ibuprofen-loaded PCL ( $\mathrm{Hu}$ et al., 2016), PLGA (Hu et al., 2014a), and PLA (Hu et al., 2014b, 2016) Poly(HIPEs/MIPEs) has been reported by the same group. They also incorporated bovine serum albumin (BSA) into the water phase of the HA stabilised Pickering emulsions and showed that the release profile of BSA could be controlled by changing HA concentration in the composition (Hu et al., 2016).

All of these studies suggested promising results for the use of PolyHIPEs in drug delivery applications. The common characteristics of all the studies mentioned above were the inclusion of the drugs in the emulsion composition before emulsification, and the use of toxic solvents in the emulsion composition to dissolve the polymers. Although scaffolds were left under vacuum to remove the solvent after solidification, they did not include any washing step for the removal of any leftover uncured materials or solvent as this step may also cause washout of the high amount of drugs from the scaffolds.

Moglia et al. developed bone morphogenetic protein 2 (BMP-2) releasing solvent-free ethylene glycol dimethacrylate PolyHIPE microspheres using w/o/w double emulsion system (Moglia et al., 2014a). They reported that while the encapsulation efficiency of their system was up to $73 \%$, but this efficiency reduced to as low as $15 \%$ in the processes which require purification. In the follow-up study from the same group, they have shown the sustained release of BMP-2 in at least 14 days, and the retention of bioactivity was confirmed by osteogenic differentiation of osteoblasts cultured on these microspheres (Whitely et al., 2019).

\section{WHERE ARE WE CURRENTLY?}

To date, PolyHIPEs based on a wide variety of synthetic and natural materials have been developed, characterised, and tested in vitro. It is beyond doubt that we have gained a greater understanding of this formulation technique over the last decade. In addition to producing favourable 3D porosity, the development of surface functionalisation methods have further improved cell-material interaction of the emulsion templated matrices and increased the potential of PolyHIPEs to be used in the medical industry.

This extensively tunable fabrication technique has been used for the manufacturing of TE scaffolds for various soft and hard tissues so far. The emulsion templated scaffolds have been demonstrated to support the in vitro growth of various cell types (Figures 13A-K); fibroblasts Johnson et al., 2015; Aldemir Dikici et al., 2019b), bone cells (Sherborne et al., 2018; Aldemir Dikici et al., 2019a, 2020), mesenchymal stem cells (Moglia et al., 2014b), mesenchymal progenitors (Owen et al., 2016; Aldemir Dikici et al., 2020), endothelial cells (Dikici et al., 2020a), neuronal cells (Barbetta et al., 2005a; Murphy et al., 2017, 2020), cardiac muscle cells (Luo et al., 2015a), and chondrocytes (Naranda et al., 2016). Although aforementioned in vitro results are promising, in vivo evaluation of the PolyHIPEs remains limited to the chick chorioallantoic membrane (CAM) assay which is a rapid and inexpensive in vivo platform to investigate initial tissue response to biomaterials and angiogenic agents (Dikici et al., 2019, 2020b; Mangir et al., 2019b). We previously reported testing of in vivo biocompatibility and angiogenic potential of PCL PolyHIPEs using an ex-ovo CAM assay (Figures 13L-O; Aldemir Dikici et al., 2019a, 2020).

Bringing medical devices to market is challenging in many countries due to the strict regulations on the commercialisation process (Bertram et al., 2012). For commercialisation and clinical use of PolyHIPE matrices, there are still many issues that need to be investigated, such as; the long-term behaviour of PolyHIPEs in vivo and their clinical validation, the evaluation of the integration of them with host tissue, how their mechanical properties are changing by time, sterilisation routes, and shelf life of these matrices (Plagnol et al., 2009).

One of the most important changes in the Medical Device Regulations (MDR) that come into force on May 2020 is that the human originated cells and tissues or their derivatives (in the same way as those of animal originated) will also be considered as a high-risk medical device (Class III) (Medical Device Regulation [MDR], 2020). Due to these regulatory restrictions, human or animal-sourced medical devices and implants will likely to have more restrictive approval processes and a more challenging pathway for clinical approval (Maak and Wylie, 2016; Hammerl et al., 2019; Haugen et al., 2019). Thus, synthetic source PolyHIPE matrices, in particular, are promising alternative substrates to be used for the fabrication of medical devices. 


\section{CONCLUSION AND PROSPECTIVE OUTLOOK}

Emulsion templating is a favourable scaffold fabrication technique with various advantages, such as enabling high porosity, providing high interconnectivity, having high tunability of the architecture, mechanical properties and functionality, being suitable to be fabricated in various forms using a wide range of materials. Important to note is that emulsion templating can be used as a reliable fabrication method, but the production is dependent on a large number of process variables, and the fabrication setup is extremely sensitive to changes in the composition and condition of the process. Thus, to be able to have control over the morphology and the mechanical properties of the scaffolds, it is important to know the effect of individual parameters on the PolyHIPE properties. We devised this review as an update on the state-of-the-art of emulsion templating in $\mathrm{TE}$ and as a guide text for the use of emulsion templating as a TE scaffold fabrication route by summarising the key points that should be considered during the fabrication process of PolyHIPEs.

The main challenge of emulsion templating is to remove the toxic organic solvents used in emulsion composition and other impurities such as unreacted monomers and residual surfactant. Thus, especially solvent-free and surfactant-free HIPE compositions are considered as promising and cost-effective as they eliminate the solvent and impurity removal steps.

For improved scaffold-biological tissue interaction, more studies focusing on the development of $\mathrm{o} / \mathrm{w}$ PolyHIPEs with

\section{REFERENCES}

Abbott, A. (2003). Biology's new dimension. Nature 424, 870-872. doi: 10.1038/ $424870 \mathrm{a}$

Abedalwafa, M., Wang, F., Wang, L., and Li, C. (2013). Biodegradable poly-epsiloncaprolactone (PCL) for tissue engineering applications: a review. Rev. Adv. Mater. Sci. 34, 123-140.

Akay, G., Birch, M. A., and Bokhari, M. A. (2004). Microcellular PolyHIPE polymer supports osteoblast growth and bone formation in Vitro. Biomaterials 25, 3991-4000. doi: 10.1016/j.biomaterials.2003.10.086

Akay, G., Downes, S., and Price, V. J. (2000). Microcellular polymer as cell growth media and novel polymers. U.S. Patent No 20080281003A1. Washington, DC: U.S. Patent and Trademark Office.

Aldemir Dikici, B., Dikici, S., Karaman, O., and Oflaz, H. (2017). The effect of zinc oxide doping on mechanical and biological properties of 3D printed calcium sulfate based scaffolds. Biocybern. Biomed. Eng. 37, 733-741. doi: 10.1016/j.bbe. 2017.08.007

Aldemir Dikici, B., Dikici, S., Reilly, G. C., MacNeil, S., and Claeyssens, F. (2019a). A novel bilayer polycaprolactone membrane for guided bone regeneration: combining electrospinning and emulsion templating. Materials 12:2643. doi: $10.3390 / \mathrm{ma} 12162643$

Aldemir Dikici, B., Sherborne, C., Reilly, G. C., and Claeyssens, F. (2019b). Emulsion templated scaffolds manufactured from photocurable polycaprolactone. Polymer 175, 243-254. doi: 10.1016/j.polymer.2019.05.023

Aldemir Dikici, B., Reilly, G. C., and Claeyssens, F. (2020). Boosting the osteogenic and angiogenic performance of multiscale porous polycaprolactone scaffolds by in Vitro generated extracellular matrix decoration. ACS Appl. Mater. Interfaces 12, 12510-12524. doi: 10.1021/acsami.9b23100

Amiji, M. M. (2004). Polymeric Gene Delivery: Principles and Applications. doi: $10.1201 / 9780203500477$ enhanced mechanical properties and development functionalised w/o PolyHIPEs is needed. We are confident that emulsion templating will become an increasingly popular scaffold manufacturing technique in the next decade by considering the increasing number of publications on emulsions templating in TE. Also, future studies that concentrate on the investigation of long term behaviour of PolyHIPE matrices in vivo would aid to establish a greater degree of understanding on the potential of emulsion templated matrices to be used in the clinic.

\section{AUTHOR CONTRIBUTIONS}

BA performed the review and wrote the manuscript. FC provided feedback and edited the manuscript. Both authors contributed to the article and approved the submitted version.

\section{ACKNOWLEDGMENTS}

The authors gratefully acknowledge the Republic of Turkey The Ministry of National Education for funding BA. The authors gratefully acknowledge Prof. Gwendolen Reilly and Serkan Dikici for providing feedback on the manuscript and designing 3D models used in Figures 2E-G, respectively. The authors also acknowledge the Engineering and Physical Sciences Research Council (Grant No. EP/I007695/1) and the Medical Research Council (Grant No. MR/L012669/1).

Andrews, K. D., Hunt, J. A., and Black, R. A. (2007). effects of sterilisation method on surface topography and In-Vitro cell behaviour of electrostatically spun scaffolds. Biomaterials 28, 1014-1026. doi: 10.1016/j.biomaterials.2006. 10.014

Audouin, F., Fox, M., Larragy, R., Clarke, P., Huang, J., O’Connor, B., et al. (2012). Polypeptide-grafted macroporous PolyHIPE by surface-initiated N-Carboxyanhydride (NCA) polymerization as a platform for bioconjugation. Macromolecules 45, 6127-6135. doi: 10.1021/ma3010263

Audouin, F., and Heise, A. (2014). Synthesis of polymer-silica hybrid PolyHIPEs by double in Situ polymerization of concentrated water in oil emulsion. Polymer 55, 403-409. doi: 10.1016/j.polymer.2013.09.002

Bak, T. Y., Kook, M. S., Jung, S. C., and Kim, B. H. (2014). Biological effect of gas plasma treatment on $\mathrm{CO} 2$ gas foaming/salt leaching fabricated porous polycaprolactone scaffolds in bone tissue engineering. J. Nanomater. 2014, 1-6. doi: $10.1155 / 2014 / 657542$

Bancroft, W. D. (1913). The theory of emulsification, V. J. Phys. Chem. 17, 501-519. doi: 10.1021/j150141a002

Barbara, I., Dourges, M. A., and Deleuze, H. (2017). Preparation of porous polyurethanes by emulsion-templated step growth polymerization. Polymer 132, 243-251. doi: 10.1016/j.polymer.2017.11.018

Barbetta, A., Barigelli, E., and Dentini, M. (2009). Porous alginate hydrogels: synthetic methods for tailoring the porous texture. Biomacromolecules 10 , 2328-2337. doi: 10.1021/bm900517q

Barbetta, A., and Cameron, N. R. (2004). Morphology and surface area of emulsion-derived (PolyHIPE) solid foams prepared with oil-phase soluble porogenic solvents: span 80 as surfactant. Macromolecules 37, 3188-3201. doi: 10.1021/ma0359436

Barbetta, A., Dentini, M., De Vecchis, M. S., Filippini, P., Formisano, G., and Caiazza, S. (2005a). Scaffolds based on biopolymeric foams. Adv. Funct. Mater. 15, 118-124. doi: 10.1002/adfm.200400072 
Barbetta, A., Dentini, M., Zannoni, E. M., and De Stefano, M. E. (2005b). Tailoring the Porosity and Morphology of Gelatin-Methacrylate PolyHIPE scaffolds for tissue engineering applications. Langmuir 21, 12333-12341. doi: 10.1021/ la0520233

Barbetta, A., Massimi, M., Devirgiliis, L. C., and Dentini, M. (2006). Enzymatic cross-linking versus radical polymerization in the preparation of gelatin PolyHIPEs and their performance as scaffolds in the culture of hepatocytes. Biomacromolecules 7, 3059-3068. doi: 10.1021/bm0605331

Barby, D., and Haq, Z. (1985). Low density porous cross-linked polymeric materials and their preparation and use as carriers for included liquids.

Barnes, H. A. (1994). Rheology of emulsions - a review. Colloids Surf. A Physicochem. Eng. Aspects 91, 89-95. doi: 10.1016/0927-7757(93)02719-U

Bartl, V. H., and Von Bonin, W. (1962). Über die polymerisation in Umgekehrter emulsion. Die Makromol. Chemie 57, 74-95. doi: 10.1002/macp. 1962.020570105

Bartl, V. H., and von Bonin, W. (1963). Über Die Polymerisation in Umgekehrter Emulsion. II. Die Makromol. Chem. 66, 151-156. doi: 10.1002/macp.1963. 020660115

Bershadsky, A. D., Balaban, N. Q., and Geiger, B. (2003). Adhesion-dependent cell mechanosensitivity. Annu. Rev. Cell Dev. Biol. 19, 677-695. doi: 10.1146/ annurev.cellbio.19.111301.153011

Bertram, T. A., Tentoff, E., Johnson, P. C., Tawil, B., Van Dyke, M., and Hellman, K. B. (2012). Hurdles in tissue engineering/regenerative medicine product commercialization: a pilot survey of governmental funding agencies and the financial industry. Tissue Eng. Part A 18, 2187-2194. doi: 10.1089/ten.tea.2012. 0186

Bhagavathi Kandy, S., Simon, G. P., Cheng, W., Zank, J., Joshi, K., Gala, D., et al. (2018). Effect of incorporation of multiwalled carbon nanotubes on the microstructure and flow behavior of highly concentrated emulsions. ACS Omega 3, 13584-13597. doi: 10.1021/acsomega.8b00579

Binks, B. P., and Lumsdon, S. O. (1999). Stability of oil-in-water emulsions stabilised by silica particles. Phys. Chem. Chem. Phys. 1, 3007-3016. doi: 10. 1039/a902209k

Bokhari, M., Carnachan, R. J., Cameron, N. R., and Przyborski, S. A. (2007a). Culture of HepG2 liver cells on three dimensional polystyrene scaffolds enhances cell structure and function during toxicological challenge. J. Anat. 211, 567-576. doi: 10.1111/j.1469-7580.2007.00778.x

Bokhari, M., Carnachan, R. J., Przyborski, S. A., and Cameron, N. R. (2007b). Emulsion-templated porous polymers as scaffolds for three dimensional cell culture: effect of synthesis parameters on scaffold formation and homogeneity. J. Mater. Chem. 17, 4088-4094. doi: 10.1039/b707499a

Bokhari, M. A., Akay, G., Zhang, S., and Birch, M. A. (2005). The enhancement of osteoblast growth and differentiation in Vitro on a peptide hydrogel PolyHIPE polymer hybrid material. Biomaterials 26, 5198-5208. doi: 10.1016/j. biomaterials.2005.01.040

Borwankar, R. P., and Case, S. E. (1997). Rheology of Emulsions, Foams and Gels. Curr. Opin. Colloid Interface Sci. 2, 584-589. doi: 10.1016/s1359-0294(97) 80049-0

Bose, S., Roy, M., and Bandyopadhyay, A. (2012). Recent advances in bone tissue engineering scaffolds. Trends Biotechnol. 30, 546-554. doi: 10.1016/j.tibtech. 2012.07.005

Brown, I. J., and Sotiropoulos, S. (2001). Electrodeposition of Ni from a high internal phase emulsion (HIPE) template. Electrochim. Acta 46, 2711-2720. doi: 10.1016/S0013-4686(01)00481-9

Busby, W., Cameron, N. R., and Jahoda, C. A. B. (2001). Emulsionderived foams (PolyHIPEs) containing poly( $\varepsilon$-Caprolactone) as matrixes for tissue engineering. Biomacromolecules 2, 154-164. doi: 10.1021/bm00 00889

Busby, W., Cameron, N. R., and Jahoda, C. A. B. (2002). Tissue engineering matrixes by emulsion templating. Polym. Int. 51, 871-881. doi: 10.1002/ pi.934

Caldwell, S., Johnson, D. W., Didsbury, M. P., Murray, B. A., Wu, J. J., Przyborski, S. A., et al. (2012). Degradable emulsion-templated scaffolds for tissue engineering from Thiol-Ene photopolymerisation. Soft Matter 8, 1034410351. doi: $10.1039 / \mathrm{c} 2 \mathrm{sm} 26250 \mathrm{a}$

Cameron, N. R. (2005). High internal phase emulsion templating as a route to welldefined porous polymers. Polymer 46, 1439-1449. doi: 10.1016/j.polymer.2004. 11.097
Cameron, N. R., and Sherrington, D. C. (1996). High Internal Phase Emulsions (HIPEs) - structure, properties and use in polymer preparation. Adv. Polym. Sci. 126, 162-214. doi: 10.1007/3-540-60484-7_4

Cameron, N. R., Sherrington, D. C., Albiston, L., and Gregory, D. P. (1996). Study of the formation of the open-cellular morphology of poly(styrene/divinylbenzene) PolyHIPE materials by Cryo-SEM. Colloid Polym. Sci. 274, 592-595. doi: 10.1007/BF00655236

Carnachan, R. J., Bokhari, M., Przyborski, S. A., and Cameron, N. R. (2006). Tailoring the morphology of emulsion-templated porous polymers. Soft Matter 2, 608-616. doi: 10.1039/b603211g

Ceglia, G., Mahéo, L., Viot, P., Bernard, D., Chirazi, A., Ly, I., et al. (2012). Formulation and mechanical properties of emulsion-based model polymer foams. Eur. Phys. J. E Soft Matter 35:9708. doi: 10.1140/epje/i2012-12031-0

Chang, B., Ahuja, N., Ma, C., and Liu, X. (2017). Injectable scaffolds: preparation and application in dental and craniofacial regeneration. Mater. Sci. Eng. R Rep. 111, 1-26. doi: 10.1016/j.mser.2016.11.001

Chang, Q. (2016). "Emulsion, foam, and gel," in Colloid and Interface Chemistry for Water Quality Control, ed. S. Tian (Cambridge, MA: Academic Press). doi: 10.1016/b978-0-12-809315-3.00011-6

Changotade, S., Radu Bostan, G., Consalus, A., Poirier, F., Peltzer, J., Lataillade, J. J., et al. (2015). Preliminary in Vitro assessment of stem cell compatibility with cross-linked poly $(\varepsilon$-Caprolactone Urethane) scaffolds designed through high internal phase emulsions. Stem Cells Int. 2015:283796. doi: 10.1155/2015/ 283796

Chen, J. H., Le, T. T. M., and Hsu, K. C. (2018). Application of PolyHIPE membrane with tricaprylmethylammonium chloride for $\mathrm{Cr}(\mathrm{VI})$ ion separation: parameters and mechanism of transport relating to the pore structure. Membranes 8:11. doi: 10.3390/membranes8010011

Cheung, H. Y., Lau, K. T., Lu, T. P., and Hui, D. (2007). A critical review on polymer-based bio-engineered materials for scaffold development. Compos. Part B Eng. 38, 291-300. doi: 10.1016/j.compositesb.2006.06.014

Christenson, E. M., Soofi, W., Holm, J. L., Cameron, N. R., and Mikos, A. G. (2007). Biodegradable fumarate-based PolyHIPEs as tissue engineering scaffolds. Biomacromolecules 8, 3806-3814. doi: 10.1021/bm7007235

Costello, L., Fullard, N., Roger, M., Bradbury, S., Dicolandrea, T., Isfort, R., et al. (1993). Engineering a multilayered skin equivalent: the importance of endogenous extracellular matrix maturation to provide robustness and reproducibility. Methods Mol. Biol. 1993, 107-122. doi: 10.1007/978-1-49399473-1_9

Dai, Z., Ronholm, J., Tian, Y., Sethi, B., and Cao, X. (2016). Sterilization techniques for biodegradable scaffolds in tissue engineering applications. J. Tissue Eng. 7:2041731416648810. doi: 10.1177/2041731416648810

Das, A. K., Mukesh, D., Swayambunathan, V., Kotkar, D. D., and Ghosh, P. K. (1992). Concentrated emulsions. 3. Studies on the influence of continuousphase viscosity, volume fraction, droplet size, and temperature on emulsion viscosity. Langmuir 8, 2427-2436. doi: 10.1021/la00046a015

David, D., and Silverstein, M. S. (2009). Porous polyurethanes synthesized within high internal phase emulsions. J. Polym. Sci. Part A Polym. Chem. 47, 58065814. doi: $10.1002 /$ pola. 23624

De Santis, R., Sarracino, F., Mollica, F., Netti, P. A., Ambrosio, L., and Nicolais, L. (2004). Continuous fibre reinforced polymers as connective tissue replacement. Compos. Sci. Technol. 64, 861-871. doi: 10.1016/j.compscitech.2003.09.008

Diez-Ahedo, R., Mendibil, X., Márquez-Posadas, M. C., Quintana, I., González, F., Rodríguez, F. J., et al. (2020). UV-casting on methacrylated PCL for the production of a peripheral nerve implant containing an array of porous aligned microchannels. Polymers 12:971. doi: 10.3390/polym12040971

Dikici, S., Aldemir Dikici, B., Bhaloo, S. I., Balcells, M., Edelman, E. R., MacNeil, S., et al. (2020a). Assessment of the angiogenic potential of 2-Deoxy-D-Ribose using a novel in Vitro 3D dynamic model in comparison with established in Vitro assays. Front. Bioeng. Biotechnol. 7:451. doi: 10.3389/fbioe.2019.00451

Dikici, S., Claeyssens, F., and MacNeil, S. (2020b). Bioengineering vascular networks to study angiogenesis and vascularization of physiologically relevant tissue models in Vitro. ACS Biomater. Sci. Eng. 6, 3513-3528. doi: 10.1021/ acsbiomaterials.0c00191

Dikici, S., Claeyssens, F., and MacNeil, S. (2020c). Pre-seeding of simple electrospun scaffolds with a combination of endothelial cells and fibroblasts strongly promotes angiogenesis. Tissue Eng. Regen. Med doi: 10.1007/s13770020-00263-7 [Epub ahead of print]. 
Dikici, S., Mangır, N., Claeyssens, F., Yar, M., and MacNeil, S. (2019). Exploration of 2-Deoxy-D-Ribose and $17 \beta$-Estradiol as alternatives to exogenous VEGF to promote angiogenesis in tissue-engineered constructs. Regen. Med. 14, 179-197. doi: 10.2217/rme-2018-0068

Donald, B., and Zia, H. (1982). Low density porous cross-linked polymeric materials and their preparation. U.S. Patent No 5912276A. Washington, DC: U.S. Patent and Trademark Office.

Dzobo, K., Thomford, N. E., Senthebane, D. A., Shipanga, H., Rowe, A., Dandara, C., et al. (2018). Advances in regenerative medicine and tissue engineering: innovation and transformation of medicine. Stem Cells Int. 2018:2495848. doi: $10.1155 / 2018 / 2495848$

Eibel, A., Fast, D. E., and Gescheidt, G. (2018). Choosing the ideal photoinitiator for free radical photopolymerizations: predictions based on simulations using established data. Polym. Chem. 9, 5107-5115. doi: 10.1039/c8py01195h

Eissa, A. M., Barros, F. S. V., Vrljicak, P., Brosens, J. J., and Cameron, N. R. (2018). Enhanced differentiation potential of primary human endometrial cells cultured on 3D scaffolds. Biomacromolecules 19, 3343-3350. doi: 10.1021/acs. biomac. 8 b00635

Elomaa, L., Teixeira, S., Hakala, R., Korhonen, H., Grijpma, D. W., and Seppälä, J. V. (2011). Preparation of $\operatorname{Poly}(\varepsilon$-Caprolactone)-based tissue engineering scaffolds by stereolithography. Acta Biomater. 7, 3850-3856. doi: 10.1016/j. actbio.2011.06.039

Engler, A. J., Sen, S., Sweeney, H. L., and Discher, D. E. (2006). Matrix elasticity directs stem cell lineage specification. Cell 126, 677-689. doi: 10.1016/j.cell. 2006.06.044

Fan, X., Zhang, S., Zhu, Y., and Chen, J. (2018). Macroporous polymers prepared via frozen UV polymerization of the emulsion-templates stabilized by a low amount of surfactant. RSC Adv. 8, 10141-10147. doi: 10.1039/c8ra01000e

Farah, M. A., Oliveira, R. C., Caldas, J. N., and Rajagopal, K. (2005). Viscosity of water-in-oil emulsions: variation with temperature and water volume fraction. J. Pet. Sci. Eng. 48, 169-184. doi: 10.1016/j.petrol.2005.06.014

Finkle, P., Draper, H. D., and Hildebrand, J. H. (1923). The theory of emulsification. J. Am. Chem. Soc. 45, 2780-2788. doi: 10.1021/ja01665a002

Fleith, S., Ponche, A., Bareille, R., Amédée, J., and Nardin, M. (2005). Effect of several sterilisation techniques on homogeneous self assembled monolayers. Colloids Surf. B Biointerfaces 44, 15-24. doi: 10.1016/j.colsurfb.2005.05.009

Fletcher, J. C., and Marsh, H. E. Jr. (1977). Oil and fat absorbing polymers. U.S. Patent No 4039489. Washington, DC: U.S. Patent and Trademark Office.

Ford, R. E., and Furmidge, C. G. L. (1967). Physico-chemical studies on agricultural sprays VIII.-Viscosity and spray drop size of water-in-oil emulsions. J. Sci. Food Agric. 18, 419-428. doi: 10.1002/jsfa.2740180910

Fox, C. B., Carter, D., Baldwin, S. L., and Reed, S. G. (2012). "Innovations in emulsion technology," in Emulsion-based Vaccine Adjuvants, eds S. G. Reed, C. B. Fox, and D. Carter (London: Future Medicine Ltd). doi: 10.2217/EBO. 11.334

García-Landeros, S. A., Cervantes-Díaz, J. M., Gutiérrez-Becerra, A., PelayoVázquez, J. B., Landazuri-Gomez, G., Herrera-Ordonez, J., et al. (2019). Oil-ineutectic mixture HIPEs co-stabilized with surfactant and nanohydroxyapatite: ring-opening polymerization for nanocomposite scaffold synthesis. Chem. Commun. 55, 12292-12295. doi: 10.1039/c9cc06292k

Gholami, M. S., Doutres, O., and Atalla, N. (2017). Effect of microstructure closedpore content on the mechanical properties of flexible polyurethane foam. Int. J. Solids Struct. 112, 97-105. doi: 10.1016/j.ijsolstr.2017.02.016

Gokmen, M. T., and Du Prez, F. E. (2012). Porous polymer particles - a comprehensive guide to synthesis, characterization, functionalization and applications. Prog. Polym. Sci. 37, 365-405. doi: 10.1016/j.progpolymsci.2011. 07.006

Goodarzi, F., and Zendehboudi, S. (2019). A comprehensive review on emulsions and emulsion stability in chemical and energy industries. Can. J. Chem. Eng 97, 281-309. doi: 10.1002/cjce. 23336

Grace, R. (1992). "Commercial emulsion breaking," in Emulsions Fundamentals and Applications in Petroleum Industry, ed. L. L. Schramm (Washington, DC: American Chemical Society), 313-338. doi: 10.1021/ba-1992-0231.ch009

Griffin, M., Naderi, N., Kalaskar, D. M., Malins, E., Becer, R., Thornton, C. A., et al. (2018). Evaluation of sterilisation techniques for regenerative medicine scaffolds fabricated with polyurethane nonbiodegradable and bioabsorbable nanocomposite materials. Int. J. Biomater. 2018:6565783. doi: 10.1155/2018/ 6565783
Griffin, W. C. (1946). Classification of surface-active agents by "HLB.”. J. Soc. Cosmet. Chem. 1, 311-326.

Griffin, W. C. (1954). Calculation of HLB values of non-ionic surfactants. J. Soc. Cosmet. Chem. 5, 249-256.

Guenther, W. (1959). Process for the production of porous plastics and products comprising polymerizing a monomer in a water-in-oil emulsion. U.S. Patent No 3256219A. Washington, DC: U.S. Patent and Trademark Office.

Guenther, W. (1971). Method of producing porous polymerizates from water-inoil emulsions. U.S. Patent No 3734867A. Washington, DC: U.S. Patent and Trademark Office.

Gurevitch, I., and Silverstein, M. S. (2010). Polymerized pickering HIPEs: effects of synthesis parameters on porous structure. J. Polym. Sci. Part A Polym. Chem. 48, 1516-1525. doi: 10.1002/pola.23911

Guyot, C., and Lerouge, S. (2018). Can we achieve the perfect injectable scaffold for cell therapy? Future Sci. OA 4:FSO284. doi: 10.4155/fsoa-2017-0153

Hales, T. C. (2005). A proof of the kepler conjecture. Ann. Math. 162, 1065-1185. doi: 10.4007/annals.2005.162.1065

Hammerl, A., Diaz Cano, C. E., De-Juan-Pardo, E. M., van Griensven, M., and Poh, P. S. P. (2019). A growth factor-free co-culture system of osteoblasts and peripheral blood mononuclear cells for the evaluation of the osteogenesis potential of melt-electrowritten polycaprolactone scaffolds. Int. J. Mol. Sci. 20:1068. doi: 10.3390/ijms20051068

Harikrishna, R., Shaikh, A. W., Ponrathnam, S., Rajan, C. R., and Bhongale, S. (2014). Photopolymerization of high internal phase emulsions based on 2Ethylhexyl (Meth)acrylates and ethylene glycol dimethacrylate. Des. Monomers Polym. 17, 1-6. doi: 10.1080/15685551.2013.771312

Haugen, H. J., Lyngstadaas, S. P., Rossi, F., and Perale, G. (2019). Bone grafts: which is the ideal biomaterial? J. Clin. Periodontol. 46, 92-102. doi: 10.1111/jcpe. 13058

Hayman, M. W., Smith, K. H., Cameron, N. R., and Przyborski, S. A. (2004). Enhanced neurite outgrowth by human neurons grown on solid threedimensional scaffolds. Biochem. Biophys. Res. Commun. 314, 483-488. doi: 10. 1016/j.bbrc.2003.12.135

Hayman, M. W., Smith, K. H., Cameron, N. R., and Przyborski, S. A. (2005). Growth of human stem cell-derived neurons on solid three-dimensional polymers. J. Biochem. Biophys. Methods 62, 231-240. doi: 10.1016/j.jbbm.2004. 12.001

Hayward, A. S., Eissa, A. M., Maltman, D. J., Sano, N., Przyborski, S. A., and Cameron, N. R. (2013a). Galactose-functionalized PolyHIPE scaffolds for use in routine three dimensional culture of mammalian hepatocytes. Biomacromolecules 14, 4271-4277. doi: 10.1021/bm401145x

Hayward, A. S., Sano, N., Przyborski, S. A., and Cameron, N. R. (2013b). Acrylicacid-functionalized polyhipe scaffolds for use in 3D cell culture. Macromol. Rapid Commun. 34, 1844-1849. doi: 10.1002/marc.201300709

He, S., Timmer, M. D., Yaszemski, M. J., Yasko, A. W., Engel, P. S., and Mikos, A. G. (2001). Synthesis of biodegradable poly(propylene fumarate) networks with poly(propylene fumarate)-diacrylate macromers as crosslinking agents and characterization of their degradation products. Polymer 42, 1251-1260. doi: 10.1016/S0032-3861(00)00479-1

Hollister, S. J. (2005). Porous scaffold design for tissue engineering. Nat. Mater. 4, 518-524. doi: 10.1038/nmat 1421

Home Office (2018). Annual Statistics of Scientific Procedures on Living Animals: Great Britain 2018.. Available online at: https://assets.publishing.service. gov.uk/government/uploads/system/uploads/attachment_data/file/835935/ annual-statistics-scientific-procedures-living-animals-2018.pdf (accessed July 17, 2020).

Hoque, M., Nuge, T., Yeow, T., Nordin, N., and Prasad, R. (2015). Gelatin based scaffolds for tissue engineering-a review. Polym. Res. J. 9:15.

Hoyle, C., and Bowman, C. N. (2010). Thiol-ene click chemistry. Angew. Chem. Int. Ed. 49, 1540-1573.

Hu, Y., Gao, H., Du, Z., Liu, Y., Yang, Y., and Wang, C. (2015). Pickering high internal phase emulsion-based hydroxyapatite-poly( $\varepsilon$-caprolactone) nanocomposite scaffolds. J. Mater. Chem. B 3, 3848-3857. doi: 10.1039/ c5tb00093a

Hu, Y., Gu, X., Yang, Y., Huang, J., Hu, M., Chen, W., et al. (2014a). Facile fabrication of poly(L-lactic acid)-grafted hydroxyapatite/poly(lacticco-glycolic acid) scaffolds by Pickering high internal phase emulsion templates. ACS Appl. Mater. Interfaces 6, 17166-17175. doi: 10.1021/am5 04877h 
Hu, Y., Zou, S., Chen, W., Tong, Z., and Wang, C. (2014b). Mineralization and drug release of hydroxyapatite/poly(L-lactic acid) nanocomposite scaffolds prepared by Pickering emulsion templating. Colloids Surf. B Biointerfaces 122, 559-565. doi: 10.1016/j.colsurfb.2014.07.032

Hu, Y., Han, W., Chen, Y., Zou, R., Ouyang, Y., Zhou, W., et al. (2017). One-pot fabrication of poly( $\varepsilon$-caprolactone)-incorporated bovine serum albumin/calcium alginate/hydroxyapatite nanocomposite scaffolds by high internal phase emulsion templates. Macromol. Mater. Eng. 302:1600367. doi: 10.1002/mame.201600367

Hu, Y., Ma, S., Yang, Z., Zhou, W., Du, Z., Huang, J., et al. (2016). Facile fabrication of poly(L-lactic acid) microsphere-incorporated calcium alginate/hydroxyapatite porous scaffolds based on Pickering emulsion templates. Colloids Surf. B Biointerfaces 140, 382-391. doi: 10.1016/j.colsurfb.2016.01.005

Hu, Y., Wang, J., Li, X., Hu, X., Zhou, W., Dong, X., et al. (2019). Facile preparation of bioactive nanoparticle/poly( $\varepsilon$-caprolactone) hierarchical porous scaffolds via 3D printing of high internal phase Pickering emulsions. J. Colloid Interface Sci. 545, 104-115. doi: 10.1016/j.jcis.2019.03.024

Huš, S., Kolar, M., and Krajnc, P. (2015). Tailoring morphological features of crosslinked emulsion-templated poly(glycidyl methacrylate). Des. Monomers Polym. 18, 698-703. doi: 10.1080/15685551.2015.1070503

Huš, S., and Krajnc, P. (2014). PolyHIPEs from methyl methacrylate: hierarchically structured microcellular polymers with exceptional mechanical properties. Polymer 55, 4420-4424. doi: 10.1016/j.polymer.2014.07.007

Ilia Anisa, A. N., and Nour, A. H. (2010). Affect of viscosity and droplet diameter on water-in-oil (w/o) emulsions: an experimental study. World Acad. Sci. Eng. Technol. 62, 691-694.

Ivanova, A. A., Syromotina, D. S., Shkarina, S. N., Shkarin, R., Cecilia, A., Weinhardt, V., et al. (2018). Effect of low-temperature plasma treatment of electrospun polycaprolactone fibrous scaffolds on calcium carbonate mineralisation. RSC Adv. 8, 39106-39114. doi: 10.1039/c8ra07386d

Jiang, B., Wang, Z., and Zhao, N. (2007). Effect of pore size and relative density on the mechanical properties of open cell aluminum foams. Scr. Mater. 56, 169-172. doi: 10.1016/j.scriptamat.2006.08.070

Jin, F. L., Zhao, M., Park, M., and Park, S. J. (2019). Recent trends of foaming in polymer processing: a review. Polymers 11:953. doi: 10.3390/polym11060953

Johnson, D. W., Langford, C. R., Didsbury, M. P., Lipp, B., Przyborski, S. A., and Cameron, N. R. (2015). Fully biodegradable and biocompatible emulsion templated polymer scaffolds by thiol-acrylate polymerization of polycaprolactone macromonomers. Polym. Chem. 6, 7256-7263. doi: 10.1039/ c5py00721f

Johnson, D. W., Sherborne, C., Didsbury, M. P., Pateman, C., Cameron, N. R., and Claeyssens, F. (2013). Macrostructuring of emulsion-templated porous polymers by 3D laser patterning. Adv. Mater. 25, 3178-3181. doi: 10.1002/adma. 201300552

Jokinen, V., Suvanto, P., and Franssila, S. (2012). Oxygen and nitrogen plasma hydrophilization and hydrophobic recovery of polymers. Biomicrofluidics 6 , 16501-16501-10. doi: 10.1063/1.3673251

Jones, K., Lothian, B. R., Martin, A., Taylor, G., and Haq, Z. (1986). Porous polymers. U.S. Patent No 4,612,334, 1986. Washington, DC: U.S. Patent and Trademark Office.

Kale, S. N., and Deore, S. L. (2016). Emulsion micro emulsion and nano emulsion: a review. Syst. Rev. Pharm. 8, 39-47. doi: 10.5530/srp.2017.1.8

Karageorgiou, V., and Kaplan, D. (2005). Porosity of 3D biomaterial scaffolds and osteogenesis. Biomaterials 26, 5474-5491. doi: 10.1016/j.biomaterials.2005.02. 002

Kasper, F. K., Tanahashi, K., Fisher, J. P., and Mikos, A. G. (2009). Synthesis of poly(propylene fumarate). Nat. Protoc. 4, 518-525. doi: 10.1038/nprot.2009.24

Kassem, M. G. A., Ahmed, A. M. M., Abdel-Rahman, H. H., and Moustafa, A. H. E. (2019). Use of span 80 and tween 80 for blending gasoline and alcohol in spark ignition engines. Energy Rep. 5, 221-230. doi: 10.1016/j.egyr.2019. 01.009

Kavousi, F., and Nikfarjam, N. (2019). Highly interconnected macroporous structures made from starch nanoparticle-stabilized medium internal phase emulsion polymerization for use in cell culture. Polymer 180:121744. doi: 10. 1016/j.polymer.2019.121744

Kawata, S., Sun, H. B., Tanaka, T., and Takada, K. (2001). Finer features for functional microdevices. Nature 412, 697-698. doi: 10.1038/35089130
Kent, P., and Saunders, B. R. (2001). The role of added electrolyte in the stabilization of inverse emulsions. J. Colloid Interface Sci. 242, 437-442. doi: 10.1006/jcis.2001.7792

Khan, B. A., Akhtar, N., Khan, H. M. S., Waseem, K., Mahmood, T., Rasul, A., et al. (2011). Basics of pharmaceutical emulsions: a review. Afr. J. Pharm. Pharmacol. 5, 2715-2725. doi: 10.5897/AJPP11.698

Kircher, L., Theato, P., and Cameron, N. R. (2013a). "Functionalization of porous polymers from high-internal-phase emulsions and their applications," in Functional Polymers by Post-Polymerization Modification: Concepts, Guidelines, and Applications, eds P. Theato, and H.-A. Klok (Weinheim: Wiley-VCH), 333-352. doi: 10.1002/9783527655427.ch13

Kircher, L., Theato, P., and Cameron, N. R. (2013b). Reactive thiol-ene emulsiontemplated porous polymers incorporating pentafluorophenyl acrylate. Polymer 54, 1755-1761. doi: 10.1016/j.polymer.2013.01.024

Kitagawa, N. (2001). Hydrophilic Polymeric Material and Method of Preparation. Available online at: https://patentscope.wipo.int/search/en/detail.jsf?docId= WO1999000187 (accessed July 17, 2020).

Kovačič, S., Žagar, E., and Slugovc, C. (2019). Strength versus toughness of emulsion templated poly(dicyclopentadiene) foams. Polymer 169, 58-65. doi: 10.1016/j.polymer.2019.02.045

Krajnc, P., Štefanec, D., and Pulko, I. (2005). Acrylic acid "reversed” polyHIPEs. Macromol. Rapid Commun. 26, 1289-1293. doi: 10.1002/marc.200500353

Kravchenko, O. G., Gedler, G., Kravchenko, S. G., Feke, D. L., and ManasZloczower, I. (2018). Modeling compressive behavior of open-cell polymerized high internal phase emulsions: effects of density and morphology. Soft Matter 14, 1637-1646. doi: 10.1039/c7sm02043k

Kuhlmann, U. (2000). Encyclopedia of food sciences and nutrition. J. Mol. Biol. 301, 1163-1178. doi: 10.1017/CBO9781107415324.004

Kunieda, H., Yano, N., and Solans, C. (1989). The stability of gel-emulsions in a water/nonionic surfactant/oil system. Colloids Surf. 36, 313-322. doi: 10.1016/ 0166-6622(89)80246-X

Landers, R., Pfister, A., Hübner, U., John, H., Schmelzeisen, R., and Mülhaupt, R. (2002). Fabrication of soft tissue engineering scaffolds by means of rapid prototyping techniques. J. Mater. Sci. 37, 3107-3116. doi: 10.1023/A: 1016189724389

Langer, R., and Vacanti, J. P. (1993). Tissue engineering. Science 260, 920-926. doi: $10.1126 /$ science. 8493529

Langford, C. R., Johnson, D. W., and Cameron, N. R. (2014). Chemical functionalization of emulsion-templated porous polymers by thiol-ene "click" chemistry. Polym. Chem. 5, 6200-6206. doi: 10.1039/c4py00713a

Langford, C. R., Johnson, D. W., and Cameron, N. R. (2015). Preparation of hybrid thiol-acrylate emulsion-templated porous polymers by interfacial copolymerization of high internal phase emulsions. Macromol. Rapid Commun. 36, 834-839. doi: $10.1002 /$ marc.201400733

Lee, A., Langford, C. R., Rodriguez-Lorenzo, L. M., Thissen, H., and Cameron, N. R. (2017). Bioceramic nanocomposite thiol-acrylate polyHIPE scaffolds for enhanced osteoblastic cell culture in 3D. Biomater. Sci. 5, 2035-2047. doi: 10. 1039/c7bm00292k

Lee, D. W., Gregory, D., Piret, J. M., Kilburn, D. G., and Haddow, D. J. (1992a). "High density Bhk culture using porous microcarriers," in Animal Cell Technology, eds R. E. Spier, J. B. Griffiths, and C. MacDonald (Amsterdam: Elsevier), 480-487. doi: 10.1016/b978-0-7506-0421-5.50109-4

Lee, D. W., Piret, J. M., Gregory, D., Haddow, D. J., and Kilburn, D. G. (1992b). Polystyrene macroporous bead support for mammalian cell culture. Ann. N. Y. Acad. Sci. 665, 137-145. doi: 10.1111/j.1749-6632.1992.tb42581.x

Lee, K. W., Wang, S., Lu, L., Jabbari, E., Currier, B. L., and Yaszemski, M. J. (2006). Fabrication and characterization of poly(propylene fumarate) scaffolds with controlled pore structures using 3-dimensional printing and injection molding. Tissue Eng. 12, 2801-2811. doi: 10.1089/ten.2006.12.2801

Lerouge, S., and Simmons, A. (2012). Sterilisation of Biomaterials and Medical Devices. (Oxford: Elsevier). doi: 10.1533/9780857096265

Li, K., Gao, X. L., and Subhash, G. (2006). Effects of cell shape and strut crosssectional area variations on the elastic properties of three-dimensional open-cell foams. J. Mech. Phys. Solids. 54, 783-806. doi: 10.1016/j.jmps.2005.10.007

Lim, J. S., Wong, S. F., Law, M. C., Samyudia, Y., and Dol, S. S. (2015). A review on the effects of emulsions on flow behaviours and common factors affecting the stability of emulsions. J. Appl. Sci. 15, 167-172. doi: 10.3923/jas.2015. 167.172 
Lin-Gibson, S., Cooper, J. A., Landis, F. A., and Cicerone, M. T. (2007). Systematic investigation of porogen size and content on scaffold morphometric parameters and properties. Biomacromolecules 8 , 1511-1518. doi: 10.1021/bm061139q

Lissant, K. J. (1966). The geometry of high-internal-phase-ratio emulsions. J. Colloid Interface Sci. 22, 462-468. doi: 10.1016/0021-9797(66)90091-9

Loh, Q. L., and Choong, C. (2013). Three-dimensional scaffolds for tissue engineering applications: role of porosity and pore size. Tissue Eng. Part B Rev. 19, 485-502. doi: 10.1089/ten.teb.2012.0437

Lovelady, E., Kimmins, S. D., Wu, J., and Cameron, N. R. (2011). Preparation of emulsion-templated porous polymers using Thiol-Ene and Thiol-Yne chemistry. Polym. Chem. 2, 559-562. doi: 10.1039/c0py00374c

Lumelsky, Y., Lalush-Michael, I., Levenberg, S., and Silverstein, M. S. (2009). A degradable, porous, emulsion-templated polyacrylate. J. Polym. Sci. Part A Polym. Chem. 47, 7043-7053. doi: 10.1002/pola.23744

Lumelsky, Y., and Silverstein, M. S. (2009). Biodegradable porous polymers through emulsion templating. Macromolecules 42, 1627-1633. doi: 10.1021/ ma802461m

Lumelsky, Y., Zoldan, J., Levenberg, S., Silverstein, M. S., and December, R. V. (2008). Porous polycaprolactone - polystyrene semi-interpenetrating polymer networks synthesized within high internal phase emulsions. Macromolecules 41 , 1469-1474. doi: 10.1021/ma7027177

Luo, W., Xu, R., Liu, Y., Hussain, I., Lu, Q., and Tan, B. (2015a). Emulsiontemplated poly(acrylamide)s by using polyvinyl alcohol (PVA) stabilized CO2in-water emulsions and their applications in tissue engineering scaffolds. RSC Adv. 5, 92017-92024. doi: 10.1039/c5ra14345d

Luo, W., Zhang, S., Li, P., Xu, R., Zhang, Y., Liang, L., et al. (2015b). Surfactantfree CO2-in-water emulsion-templated poly (vinyl alcohol) (PVA) hydrogels. Polymer 61, 183-191. doi: 10.1016/j.polymer.2015.02.002

Maak, T. G., and Wylie, J. D. (2016). Medical device regulation: a comparison of the united states and the European Union. J. Am. Acad. Orthop. Surg. 24, 537-543.

Malayeri, A., Sherborne, C., Paterson, T., Mittar, S., Asencio, I. O., Hatton, P. V., et al. (2016). Osteosarcoma growth on trabecular bone mimicking structures manufactured via laser direct write. Int. J. Bioprint. 2, 176-186. doi: 10.18063/ IJB.2016.02.005

Mangir, N., Aldemir Dikici, B., Chapple, C. R., and MacNeil, S. (2019a). Landmarks in vaginal mesh development: polypropylene mesh for treatment of SUI and POP. Nat. Rev. Urol. 16, 675-689. doi: 10.1038/s41585-019-0230-2

Mangir, N., Bullock, A. J., Roman, S., Osman, N., Chapple, C., and MacNeil, S. (2016). Production of ascorbic acid releasing biomaterials for pelvic floor repair. Acta Biomater. 29, 188-197. doi: 10.1016/j.actbio.2015.10.019

Mangir, N., Dikici, S., Claeyssens, F., and Macneil, S. (2019b). Using ex Ovo chick chorioallantoic membrane (CAM) assay to evaluate the biocompatibility and angiogenic response to biomaterials. ACS Biomater. Sci. Eng. 5, 3190-3200. doi: 10.1021/acsbiomaterials.9b00172

Manley, S. S., Graeber, N., Grof, Z., Menner, A., Hewitt, G. F., Stepanek, F., et al. (2009). New insights into the relationship between internal phase level of emulsion templates and gas-liquid permeability of interconnected macroporous polymers. Soft Matter 5, 4780-4787. doi: 10.1039/b900426b

Medical Device Regulation [MDR] (2020). Available online at: https://eurlex.europa.eu/legal-content/EN/TXT/PDF/?uri=CELEX:32017R0745 (accessed January 31, 2020).

Menner, A., Powell, R., and Bismarck, A. (2006). Open porous polymer foams via inverse emulsion polymerization: should the definition of high internal phase (ratio) emulsions be extended? Macromolecules 39, 2034-2035. doi: 10.1021/ ma052705x

Mert, E. H., Kaya, M. A., and Yildirim, H. (2012). Preparation and characterization of polyester-glycidyl methacrylate PolyHIPE monoliths to use in heavy metal removal. Des. Monomers Polym. 15, 113-126. doi: 10.1163/156855511X615001

Meyer, U. (2009). "The history of tissue engineering and regenerative medicine in perspective," in Fundamentals of Tissue Engineering and Regenerative Medicine, eds U. Meyer, T. Meyer, J. Handschel, and H. P. Wiesmann (Berlin: Springer), 5-12. doi: 10.1007/978-3-540-77755-7_1

Mezhoud, S., Paljevac, M., Koler, A., Le Droumaguet, B., Grande, D., and Krajnc, P. (2018). Novel hypercrosslinking approach toward high surface area functional 2-hydroxyethyl methacrylate-based polyHIPEs. React. Funct. Polym. 132, 5159. doi: 10.1016/j.reactfunctpolym.2018.09.009
Mishbak, H. H., Cooper, G., and Bartolo, P. J. (2019). Development and characterization of a photocurable alginate bioink for three-dimensional bioprinting. Int. J. Bioprint. 5:189. doi: 10.18063/IJB.V5I2.189

Moglia, R., Whitely, M., Brooks, M., Robinson, J., Pishko, M., and CosgriffHernandez, E. (2014a). Solvent-free fabrication of polyHIPE microspheres for controlled release of growth factors. Macromol. Rapid Commun. 35, 1301-1305. doi: 10.1002/marc. 201400145

Moglia, R. S., Holm, J. L., Sears, N. A., Wilson, C. J., Harrison, D. M., and Cosgriff-Hernandez, E. (2011). Injectable polyHIPEs as high-porosity bone grafts. Biomacromolecules 12, 3621-3628. doi: 10.1021/bm2008839

Moglia, R. S., Robinson, J. L., Muschenborn, A. D., Touchet, T. J., Maitland, D. J., and Cosgriff-Hernandez, E. (2014b). Injectable polyMIPE scaffolds for soft tissue regeneration. Polymer 56, 426-434. doi: 10.1016/j.polymer.2013.09.009

Moglia, R. S., Whitely, M., Dhavalikar, P., Robinson, J., Pearce, H., Brooks, M., et al. (2014c). Injectable polymerized high internal phase emulsions with rapid in Situ curing. Biomacromolecules 15, 2870-2878. doi: 10.1021/bm500754r

Murakami, R., Moriyama, H., Noguchi, T., Yamamoto, M., and Binks, B. P. (2014). Effects of the density difference between water and oil on stabilization of powdered oil-in-water emulsions. Langmuir 30, 496-500. doi: 10.1021/ la4042056

Murphy, A. R., Ghobrial, I., Jamshidi, P., Laslett, A., O’Brien, C. M., and Cameron, N. R. (2017). Tailored emulsion-templated porous polymer scaffolds for IPSCderived human neural precursor cell culture. Polym. Chem. 8, 6617-6627. doi: 10.1039/c7py01375b

Murphy, A. R., Haynes, J. M., Laslett, A. L., Cameron, N. R., and O’Brien, C. M. (2020). Three-dimensional differentiation of human pluripotent stem cellderived neural precursor cells using tailored porous polymer scaffolds. Acta Biomater. 101, 102-116. doi: 10.1016/j.actbio.2019.10.017

Myers, D. (2005). Surfactant Science and Technology, Third Edn. (Hoboken, NJ: John Wiley \& Sons, Inc). doi: 10.1002/047174607X

Nalawade, A. C., Ghorpade, R. V., Shadbar, S., Qureshi, M. S., Chavan, N. N., Khan, A. A., et al. (2016). Inverse high internal phase emulsion polymerization (i-HIPE) of GMMA, HEMA and GDMA for the preparation of superporous hydrogels as a tissue engineering scaffold. J. Mater. Chem. B 4, 450-460. doi: $10.1039 / \mathrm{c} 5 \mathrm{tb} 01873 \mathrm{k}$

Naranda, J., Sušec, M., Maver, U., Gradišnik, L., Gorenjak, M., Vukasović, A., et al. (2016). Polyester type polyHIPE scaffolds with an interconnected porous structure for cartilage regeneration. Sci. Rep. 6:28695. doi: 10.1038/srep28695

O’Brien, F. J. (2011). Biomaterials \& scaffolds for tissue engineering. Mater. Today 14, 88-95. doi: 10.1016/S1369-7021(11)70058-X

Oh, B. H. L., Bismarck, A., and Chan-Park, M. B. (2015). Injectable, interconnected, high-porosity macroporous biocompatible gelatin scaffolds made by surfactantfree emulsion templating. Macromol. Rapid Commun. 36, 364-372. doi: 10. 1002/marc. 201400524

Opawale, F. O., and Burgess, D. J. (1998). Influence of interfacial properties of lipophilic surfactants on water- in-oil emulsion stability. J. Colloid Interface Sci. 197, 142-150. doi: 10.1006/jcis.1997.5222

Ovadia, M., and Silverstein, M. S. (2016). High porosity, responsive hydrogel copolymers from emulsion templating. Polym. Int. 65, 280-289. doi: 10.1002/ pi.5052

Owen, R., and Reilly, G. C. (2018). In Vitro models of bone remodelling and associated disorders. Front. Bioeng. Biotechnol. 6:134. doi: 10.3389/fbioe.2018. 00134

Owen, R., Sherborne, C., Evans, R., Reilly, G. C., and Claeyssens, F. (2020). Combined porogen leaching and emulsion templating of bone tissue engineering scaffolds. Int. J. Bioprint. 6, 99-113.

Owen, R., Sherborne, C., Reilly, G. C., and Claeyssens, F. (2015). Data for the analysis of polyHIPE scaffolds with tunable mechanical properties for bone tissue engineering. Data Brief. 5, 616-620. doi: 10.1016/j.dib.2015. 09.051

Owen, R., Sherborne, C., Reilly, G. C., Claeyssens, F., Paterson, T., Green, N. H., et al. (2016). Emulsion templated scaffolds with tunable mechanical properties for bone tissue engineering. J. Mech. Behav. Biomed. Mater. 54, 159-172. doi: 10.1016/j.jmbbm.2015.09.019

Padbury, S. (2019). Reprocell. Available online at: https://news.reprocell.com/ reinnervate-launches-alvetex-a-breakthrough-product-for-enabling-routine3d-cell-culture (accessed December 5, 2019). 
Pakeyangkoon, P., Magaraphan, R., Malakul, P., and Nithitanakul, M. (2008). Effect of soxhlet extraction and surfactant system on morphology and properties of Poly(DVB)PolyHIPE. Macromol. Symp. 264, 149-156. doi: 10.1002/masy. 200850424

Pakeyangkoon, P., Magaraphan, R., Malakul, P., and Nithitanakul, M. (2012). Surface modification of high internal phase emulsion foam as a scaffold for tissue engineering application via atmospheric pressure plasma treatment. $A d v$. Sci. Technol. 77, 172-177. doi: 10.4028/www.scientific.net/ast.77.172

Pal, J., Skrifvars, M., Nandan, B., and Srivastava, R. K. (2017). Electrospun composite matrices from tenside-free poly( $\varepsilon$-caprolactone)-grafted acrylic acid/hydroxyapatite oil-in-water emulsions. J. Mater. Sci. 52, 2254-2262. doi: 10.1007/s10853-016-0518-z

Pal, R. (2018). A simple model for the viscosity of Pickering emulsions. Fluids 3:2. doi: 10.3390/fluids3010002

Pal, R., and Rhodes, E. (1985). A novel viscosity correlation for non-newtonian concentrated emulsions. J. Colloid Interface Sci. 107, 301-307. doi: 10.1016/ 0021-9797(85)90181-X

Paljevac, M., Gradišnik, L., Lipovšek, S., Maver, U., Kotek, J., and Krajnc, P. (2018). Multiple-level porous polymer monoliths with interconnected cellular topology prepared by combining hard sphere and emulsion templating for use in bone tissue engineering. Macromol. Biosci. 18:1700306. doi: 10.1002/mabi.201700306

Paterson, T. E., Gigliobianco, G., Sherborne, C., Green, N. H., Dugan, J. M., MacNeil, S., et al. (2018). Porous microspheres support mesenchymal progenitor cell ingrowth and stimulate angiogenesis. APL Bioeng. 2:026103. doi: $10.1063 / 1.5008556$

Pei, X., Ma, L., Zhang, B., Sun, J., Sun, Y., Fan, Y., et al. (2017). Creating hierarchical porosity hydroxyapatite scaffolds with osteoinduction by three-dimensional printing and microwave sintering. Biofabrication 9:045008. doi: 10.1088/17585090/aa90ed

Pérez-García, M. G., Gutiérrez, M. C., Mota-Morales, J. D., Luna-Bárcenas, G., and Del Monte, F. (2016). Synthesis of biodegradable macroporous poly(L-lactide)/poly( $\varepsilon$-caprolactone) blend using oil-in-eutectic-mixture highinternal-phase emulsions as template. ACS Appl. Mater. Interfaces 8, 1693916949. doi: 10.1021/acsami.6b04830

Peric, M., Dumic-Cule, I., Grcevic, D., Matijasic, M., Verbanac, D., Paul, R., et al. (2015). The rational use of animal models in the evaluation of novel bone regenerative therapies. Bone 73-86. doi: 10.1016/j.bone.2014.07.010

Pickering, S. U. (1907). CXCVI.-Emulsions. J. Chem. Soc. Trans. 91, 2001-2021. doi: 10.1039/CT9079102001

Pierre, S. J., Thies, J. C., Dureault, A., Cameron, N. R., Van Hest, J. C. M., Carette, N., et al. (2006). Covalent enzyme immobilization onto photopolymerized highly porous monoliths. Adv. Mater. 18, 1822-1826. doi: 10.1002/adma. 200600293

Plagnol, A. C., Rowley, E., Martin, P., and Livesey, F. (2009). Industry perceptions of barriers to commercialization of regenerative medicine products in the UK. Regen. Med 4, 549-559. doi: 10.2217/rme.09.21

Poncin-Epaillard, F., and Legeay, G. (2003). Surface engineering of biomaterials with plasma techniques. J. Biomater. Sci. Polym. Ed. 14, 1005-1028. doi: 10. 1163/156856203769231538

Pons, R., Solans, C., Stebé, M. J., Erra, P., and Ravey, J. C. (2007). "Stability and rheological properties of gel emulsions," in Trends in Colloid and Interface Science VI, eds C. Helm, M. Lösche, and H. Möhwald (Nama Khoi: Steinkopff), 110-113. doi: 10.1007/bfb0116290

Powell, K. C., Damitz, R., and Chauhan, A. (2017). Relating emulsion stability to interfacial properties for pharmaceutical emulsions stabilized by Pluronic F68 surfactant. Int. J. Pharm. 521, 8-18. doi: 10.1016/j.ijpharm.2017. 01.058

Prakash, A. S. (2010). Selecting surfactants for the maximum inhibition of the activity of the multi drug resistance efflux pump transporter, P-Glycoprotein: conceptual development. J. Excip. Food Chem. 1, 51-59.

Princen, H. M. (1979). Highly concentrated emulsions. I. Cylindrical systems. J. Colloid Interface Sci. 71, 55-66. doi: 10.1016/0021-9797(79)90221-2

Pulko, I., and Krajnc, P. (2012). High internal phase emulsion templating - a path to hierarchically porous functional polymers. Macromol. Rapid Commun. 33, 1731-1746. doi: 10.1002/marc.201 200393

Pulko, I., Wall, J., Krajnc, P., and Cameron, N. R. (2010). Ultra-high surface area functional porous polymers by emulsion templating and hypercrosslinking: efficient nucleophilic catalyst supports. Chem. A Eur. J. 16, 2350-2354. doi: 10.1002/chem.200903043

Rajagopalan, V., Solans, C., and Kunieda, H. (1994). ESR Study on the Stability of W/O Gel-Emulsions. Colloid Polym. Sci. 272, 1166-1173. doi: 10.1007/ BF00652387

Ratcliffe, J. L., Walker, M., Eissa, A. M., Du, S., Przyborski, S. A., Laslett, A. L., et al. (2019). Optimized peptide functionalization of thiol-acrylate emulsiontemplated porous polymers leads to expansion of human pluripotent stem cells in 3D culture. J. Polym. Sci. Part A Polym. Chem. 57, 1974-1981. doi: $10.1002 /$ pola. 29353

Reignier, J., and Huneault, M. A. (2006). Preparation of interconnected poly(E\{lunate\}-Caprolactone) porous scaffolds by a combination of polymer and salt particulate leaching. Polymer 47, 4703-4717. doi: 10.1016/j.polymer. 2006.04.029

Richardson, S. A., Rawlings, T. M., Muter, J., Walker, M., Brosens, J. J., Cameron, N. R., et al. (2019). Covalent attachment of fibronectin onto emulsiontemplated porous polymer scaffolds enhances human endometrial stromal cell adhesion, infiltration, and function. Macromol. Biosci. 19:1800351. doi: 10.1002/ mabi.201800351

Richbourg, N. R., Peppas, N. A., and Sikavitsas, V. I. (2019). Tuning the biomimetic behavior of scaffolds for regenerative medicine through surface modifications. J. Tissue Eng. Regen. Med. 1275-1293. doi: 10.1002/term.2859

Richez, A., Deleuze, H., Vedrenne, P., and Collier, R. (2005). Preparation of ultralow-density microcellular materials. J. Appl. Polym. Sci. 96, 2053-2063. doi: 10.1002/app. 21668

Robinson, J. L., McEnery, M. A. P., Pearce, H., Whitely, M. E., Munoz-Pinto, D. J., Hahn, M. S., et al. (2016). Osteoinductive PolyHIPE foams as injectable bone grafts. Tissue Eng. Part A 22, 403-414. doi: 10.1089/ten.tea.2015.0370

Robinson, J. L., Moglia, R. S., Stuebben, M. C., Mcenery, M. A. P., and CosgriffHernandez, E. (2014). Achieving interconnected pore architecture in injectable PolyHIPEs for bone tissue engineering. Tissue Eng. Part A 20, 1103-1112. doi: 10.1089/ten.tea.2013.0319

Rogers, W. J. (2012). "Sterilisation techniques for polymers," in Sterilisation of Biomaterials and Medical Devices, eds S. Lerouge and A. Simmons (Amsterdam: Elsevier), 151-211. doi: 10.1016/B978-1-84569-932-1.50007-6

Salerno, A., Oliviero, M., Di Maio, E., Iannace, S., and Netti, P. A. (2009). Design of porous polymeric scaffolds by gas foaming of heterogeneous blends. J. Mater. Sci. Mater. Med. 20, 2043-2051. doi: 10.1007/s10856-009-3767-4

Samanta, A., Nandan, B., and Srivastava, R. K. (2016a). Morphology of electrospun fibers derived from high internal phase emulsions. J. Colloid Interface Sci. 471, 29-36. doi: 10.1016/j.jcis.2016.03.012

Samanta, A., Takkar, S., Kulshreshtha, R., Nandan, B., and Srivastava, R. K. (2016b). Electrospun composite matrices of $\operatorname{Poly}(\varepsilon$-Caprolactone)-montmorillonite made using tenside free pickering emulsions. Mater. Sci. Eng. C 69, 685-691. doi: 10.1016/j.msec.2016.07.046

Samanta, A., Takkar, S., Kulshreshtha, R., Nandan, B., and Srivastava, R. K. (2017a). facile fabrication of composite electrospun nanofibrous matrices of Poly $(\varepsilon-$ Caprolactone)-silica based pickering emulsion. Langmuir 33, 8062-8069. doi: 10.1021/acs.langmuir.7b02119

Samanta, A., Takkar, S., Kulshreshtha, R., Nandan, B., and Srivastava, R. K. (2017b). Hydroxyapatite stabilized pickering emulsions of poly( $\varepsilon$-Caprolactone) and their composite electrospun scaffolds. Colloids Surf. A Physicochem. Eng. Asp. 533, 224-230. doi: 10.1016/j.colsurfa.2017.09.001

Schrimpf, G., and Friedl, P. (1993). Growth of human vascular endothelial cells on various types of microcarriers. Cytotechnology 13, 203-211. doi: 10.1007/ BF00749816

Schulman, J. H., and Leja, J. (1954). Control of contact angles at the oil-water-solid interfaces: emulsions stabilized by solid particles (BaSO4). Trans. Faraday Soc. 50, 598-605. doi: 10.1039/tf9545000598

Sears, N. A., Dhavalikar, P. S., and Cosgriff-Hernandez, E. M. (2016). Emulsion inks for 3D printing of high porosity materials. Macromol. Rapid Commun. 37, 1369-1374. doi: 10.1002/marc.201600236

Severn, C. E., Eissa, A. M., Langford, C. R., Parker, A., Walker, M., Dobbe, J. G. G., et al. (2019). Ex vivo culture of adult CD34+ stem cells using functional highly porous polymer scaffolds to establish biomimicry of the bone marrow niche. Biomaterials 225:119533. doi: 10.1016/j.biomaterials.2019.119533

Sevšek, U., Brus, J., Jeřabek, K., and Krajnc, P. (2014). Post Polymerisation Hypercrosslinking of Styrene/Divinylbenzene Poly(HIPE)s: creating 
Micropores within Macroporous Polymer. Polymer. 55, 410-415. doi: 10.1016/j.polymer.2013.09.026

Shafei, S., Foroughi, J., Chen, Z., Wong, C. S., and Naebe, M. (2017). Short oxygen plasma treatment leading to long-term hydrophilicity of conductive PCL-PPy nanofiber scaffolds. Polymers 9:614. doi: 10.3390/polym9110614

Sharma, E., Samanta, A., Pal, J., Bahga, S. S., Nandan, B., and Srivastava, R. K. (2016). High internal phase emulsion ring-opening polymerization of pentadecanolide: strategy to obtain porous scaffolds in a single step. Macromol. Chem. Phys. 217, 1752-1758. doi: 10.1002/macp.201600117

Sherborne, C., Owen, R., Reilly, G. C., and Claeyssens, F. (2018). Light-based additive manufacturing of PolyHIPEs: controlling the surface porosity for $3 \mathrm{D}$ cell culture applications. Mater. Des. 156, 494-503. doi: 10.1016/j.matdes.2018. 06.061

Shoichet, M. S. (2010). Polymer scaffolds for biomaterials applications. Macromolecules 43, 581-591. doi: 10.1021/ma901530r

Silverstein, M. S. (2014a). Emulsion-templated porous polymers: a retrospective perspective. Polymer 55, 304-320. doi: 10.1016/j.polymer.2013.08.068

Silverstein, M. S. (2014b). PolyHIPEs: recent advances in emulsion-templated porous polymers. Prog. Polym. Sci. 39, 199-234. doi: 10.1016/j.progpolymsci. 2013.07.003

Silverstein, M. S., and Cameron, N. R. (2010). "PolyHIPEs - porous polymers from high internal phase emulsions," in Encyclopedia of Polymer Science and Technology, ed. H. F. Mark (Hoboken, NJ: Wiley), 1-36. doi: 10.1002/ 0471440264.pst571

Silverstein, M. S., Cameron, N. R., and Hillmyer, M. (2011). Porous Polymers. (Hoboken, NJ: Wiley). doi: 10.1002/9780470929445

Silverstein, M. S., Tai, H., Sergienko, A., Lumelsky, Y., and Pavlovsky, S. (2005). PolyHIPE: IPNs, hybrids, nanoscale porosity, silica monoliths and ICP-based sensors. Polymer 6682-6694. doi: 10.1016/j.polymer.2005.05.022

Slinde, E., and Flatmark, T. (1976). Effect of the hydrophile-lipophile balance of non-ionic detergents (Triton X-Series) on the solubilization of biological membranes and their integral b-type cytochromes. Biochim Biophys. Acta 455, 796-805. doi: 10.1016/0005-2736(76)90049-3

Small, P. W., and Sherrington, D. C. (1989). Design and application of a new rigid support for high efficiency continuous-flow peptide synthesis. J. Chem. Soc. Chem. Commun., No. 21, 1589-1591. doi: 10.1039/C39890001589

Suggs, L. J., Shive, M. S., Garcia, C. A., Anderson, J. M., and Mikos, A. G. (1999). In vitro cytotoxicity and in vivo biocompatibility of Poly(Propylene FumarateCo-Ethylene Glycol) Hydrogels. J. Biomed. Mater. Res. 46, 22-32. doi: 10.1002/ (sici) 1097-4636(199907)46:1<22::aid-jbm3>3.0.co;2-r

Sun, P., Yang, S., Sun, X., Wang, Y., Jia, Y., Shang, P., et al. (2019). Preparation of PolyHIPE scaffolds for 3D cell culture and the application in cytotoxicity evaluation of cigarette smoke. Polymers 11:959. doi: 10.3390/polym11060959

Surh, J., Vladisavljević, G. T., Mun, S., and McClements, D. J. (2007). Preparation and Characterization of Water/Oil and Water/Oil/Water Emulsions Containing Biopolymer-Gelled Water Droplets. J. Agric. Food Chem. 55, 175-184. doi: 10.1021/jf061637q

Sušec, M., Ligon, S. C., Stampfl, J., Liska, R., and Krajnc, P. (2013). Hierarchically porous materials from layer-by-layer photopolymerization of high internal phase emulsions. Macromol. Rapid Commun. 34, 938-943. doi: 10.1002/marc. 201300016

Sušec, M., Liska, R., Russmüller, G., Kotek, J., and Krajnc, P. (2015). Microcellular open porous monoliths for cell growth by thiol-ene polymerization of lowtoxicity monomers in high internal phase emulsions. Macromol. Biosci. 15, 253-261. doi: 10.1002/mabi.201400219

Tan, H., Wei, J., Sun, G., Mu, C., Lin, W., and Ngai, T. (2017). Interconnected macroporous 3D scaffolds templated from gelatin nanoparticle-stabilized high internal phase emulsions for biomedical applications. Soft Matter 13, 38713878. doi: 10.1039/c7sm00706j

Tanny, G., Kenigsberg, Y., and Shchori, E. (1986). Microporous Membrane Laminate. Available online at: https://patents.google.com/patent/ EP0216622A2/en?oq=Eur.Patent+0216622+tanny

Temenoff, J. S., and Mikos, A. G. (2000). Injectable biodegradable materials for orthopedic tissue engineering. Biomaterials 21, 2405-2412. doi: 10.1016/S01429612(00)00108-3

Thakare, M., Israel, B., Garner, S., Ahmed, H., Elder, D., and Capomacchia, A. (2017). Nonionic surfactant structure on the drug release, formulation and physical properties of ethylcellulose microspheres. Pharm. Dev. Technol. 22, 418-425. doi: 10.1080/10837450.2016.1221431

Thunhorst, K. L., Gehlsen, M. D., Wright, R. E., Nelson, E. W., Koecher, S. D., and Gold, D. (2003). Foams made by photopolymerization of emulsions. WO Patent No WO 021693.

Tunc, Y., Hasirci, N., and Ulubayram, K. (2012). Synthesis of emulsion-templated acrylic-based porous polymers: from brittle to elastomeric. Soft Mater. 10, 449-461. doi: 10.1080/1539445X.2010.532848

Utroša, P., Onder, O. C., Žagar, E., Kovačič, S., and Pahovnik, D. (2019). Shape memory behavior of emulsion-templated poly( $\varepsilon$-Caprolactone) synthesized by organocatalyzed ring-opening polymerization. Macromolecules 52, 9291-9298. doi: 10.1021 /acs.macromol.9b01780

Vacanti, C. A. (2006). The history of tissue engineering. J. Cell. Mol. Med. 10, 569-576. doi: 10.1111/j.1582-4934.2006.tb00421.x

Valence, S., De, Tille, J. C., Chaabane, C., Gurny, R., Bochaton-Piallat, M. L., et al. (2013). Plasma treatment for improving cell biocompatibility of a biodegradable polymer scaffold for vascular graft applications. Eur. J. Pharm. Biopharm. 85, 78-86. doi: 10.1016/j.ejpb.2013.06.012

Wang, A., Paterson, T., Owen, R., Sherborne, C., Dugan, J., Li, J., et al. (2016). Photocurable high internal phase emulsions (HIPEs) containing hydroxyapatite for additive manufacture of tissue engineering scaffolds with multi-scale porosity. Mater. Sci. Eng. C 67, 51-58. doi: 10.1016/j.msec.2016.04.087

Wang, Y., Wan, X., He, J., Azhar, U., Chen, H., Zhao, J., et al. (2020). A one-step fabrication and modification of HIPE-templated fluoro-porous polymer using PEG-b-PHFBMA macrosurfactant. J. Mater. Sci. 55, 4970-4986. doi: 10.1007/ s10853-019-04296-9

Welch, C. F., Rose, G. D., Malotky, D., and Eckersley, S. T. (2006). Rheology of high internal phase emulsions. Langmuir 22, 1544-1550. doi: 10.1021/la052207h

Whitely, M., Cereceres, S., Dhavalikar, P., Salhadar, K., Wilems, T., Smith, B., et al. (2018). Improved in situ seeding of 3D printed scaffolds using cell-releasing hydrogels. Biomaterials 185, 194-204. doi: 10.1016/j.biomaterials.2018. 09.027

Whitely, M., Rodriguez-Rivera, G., Waldron, C., Mohiuddin, S., Cereceres, S., Sears, N., et al. (2019). Porous PolyHIPE microspheres for protein delivery from an injectable bone graft. Acta Biomater. 93, 169-179. doi: 10.1016/j.actbio.2019. 01.044

Whitely, M. E., Robinson, J. L., Stuebben, M. C., Pearce, H. A., McEnery, M. A. P., and Cosgriff-Hernandez, E. (2017). Prevention of oxygen inhibition of PolyHIPE radical polymerization using a thiol-based cross-linker. ACS Biomater. Sci. Eng. 3, 409-419. doi: 10.1021/acsbiomaterials.6b00663

Williams, D. F. (2008). On the mechanisms of biocompatibility. Biomaterials 29, 2941-2953. doi: 10.1016/j.biomaterials.2008.04.023

Woodward, R. T., Jobbe-Duval, A., Marchesini, S., Anthony, D. B., Petit, C., and Bismarck, A. (2017). Hypercrosslinked PolyHIPEs as precursors to designable, hierarchically porous carbon foams. Polymer 115, 146-153. doi: 10.1016/j. polymer.2017.03.042

Yadav, A., Pal, J., Nandan, B., and Srivastava, R. K. (2019). Macroporous scaffolds of cross-linked Poly( $\varepsilon$-Caprolactone)via high internal phase emulsion templating. Polymer 176, 66-73. doi: 10.1016/j.polymer.2019.05.034

Yang, J., Yang, G., Liu, H., Bai, L., and Zhang, Q. (2010). Novel porous monolithic column using Poly(High Internal Phase Emulsion) methacrylate as materials for immunoglobulin separation performance on HPLC. Chin. J. Chem. 28, 229-234. doi: 10.1002/cjoc.201090058

Yang, T., Hu, Y., Wang, C., and Binks, B. P. (2017). Fabrication of hierarchical macroporous biocompatible scaffolds by combining pickering high internal phase emulsion templates with three-dimensional printing. ACS Appl. Mater. Interfaces 9, 22950-22958. doi: 10.1021/acsami.7b05012

Yang, X., Mohseni, M., Bas, O., Meinert, C., New, E., and Castro, N. J. (2020). Type II photoinitiator and tuneable PEG-based materials library for visible light photolithography. Tissue Eng. Part A 26:292. doi: 10.1089/ten.tea.2019. 0282

Yoganarasimha, S., Trahan, W. R., Best, A. M., Bowlin, G. L., Kitten, T. O., Moon, P. C., et al. (2014). Peracetic acid: a practical agent for sterilizing heat-labile polymeric tissue-engineering scaffolds. Tissue Eng. Part C Methods 20, 714-723. doi: 10.1089/ten.tec.2013.0624

Yuan, L., Li, X., Ge, L., Jia, X., Lei, J., Mu, C., et al. (2019). Emulsion template method for the fabrication of gelatin-based scaffold with a controllable pore 
structure. ACS Appl. Mater. Interfaces 11, 269-277. doi: 10.1021/acsami. $8 \mathrm{~b} 17555$

Zhang, S., and Chen, J. (2007). Synthesis of open porous emulsion-templated monoliths using cetyltrimethylammonium bromide. Polymer 48, 3021-3025. doi: 10.1016/j.polymer.2007.04.009

Zhang, T., Sanguramath, R. A., Israel, S., and Silverstein, M. S. (2019). Emulsion templating: porous polymers and beyond. Macromolecules 52, 5445-5479. doi: 10.1021/acs.macromol.8b02576

Zhang, T., and Silverstein, M. S. (2018). Microphase-separated macroporous polymers from an emulsion-templated reactive triblock copolymer. Macromolecules 51, 3828-3835. doi: 10.1021/acs.macromol.8b00213

Zhang, T., Xu, G., Regev, O., and Blum, F. D. (2016). Low-temperature polymerization of methyl methacrylate emulsion gels through surfactant catalysis. J. Colloid Interface Sci. 461, 128-135. doi: 10.1016/j.jcis.2015.09.003

Zhang, Y., Shen, Y., Chen, Y., Yan, Y., Pan, J., Xiong, Q., et al. (2016). Hierarchically carbonaceous catalyst with brønsted-lewis acid sites prepared through pickering HIPEs templating for biomass energy conversation. Chem. Eng. J. 294, 222-235. doi: 10.1016/j.cej.2016.02.092

Zhou, C., Qiao, M., Zhang, X., Zhu, Y., Zhang, S., and Chen, J. (2019). Production of high internal phase emulsion with a miniature twin screw extruder. ACS Omega 4, 9957-9963. doi: 10.1021/acsomega.9b01156
Zhou, S., Bismarck, A., and Steinke, J. H. G. (2012a). Interconnected macroporous glycidyl methacrylate-grafted dextran hydrogels synthesised from hydroxyapatite nanoparticle stabilised high internal phase emulsion templates. J. Mater. Chem. 22, 18824-18829. doi: 10.1039/c2jm33294a

Zhou, S., Bismarck, A., and Steinke, J. H. G. (2012b). Thermoresponsive macroporous scaffolds prepared by emulsion templating. Macromol. Rapid Commun. 33, 1833-1839. doi: 10.1002/marc.201200336

Zhou, S., Bismarck, A., and Steinke, J. H. G. (2013). Ion-responsive alginate based macroporous injectable hydrogel scaffolds prepared by emulsion templating. J. Mater. Chem. B 1, 4736-4745. doi: 10.1039/c3tb20888e

Conflict of Interest: The authors declare that the research was conducted in the absence of any commercial or financial relationships that could be construed as a potential conflict of interest.

Copyright (c) 2020 Aldemir Dikici and Claeyssens. This is an open-access article distributed under the terms of the Creative Commons Attribution License (CC BY). The use, distribution or reproduction in other forums is permitted, provided the original author(s) and the copyright owner(s) are credited and that the original publication in this journal is cited, in accordance with accepted academic practice. No use, distribution or reproduction is permitted which does not comply with these terms. 